Florida International University FIU Digital Commons

FIU Electronic Theses and Dissertations

University Graduate School

3-21-2018

\title{
Origami Antennas for Novel Reconfigurable Communication Systems
}

Xueli Liu

Florida International University, xliu038@fiu.edu

DOI: $10.25148 /$ etd.FIDC004091

Follow this and additional works at: https://digitalcommons.fiu.edu/etd

Part of the Electrical and Electronics Commons, and the Electromagnetics and Photonics Commons

\section{Recommended Citation}

Liu, Xueli, "Origami Antennas for Novel Reconfigurable Communication Systems" (2018). FIU Electronic Theses and Dissertations. 3644.

https://digitalcommons.fiu.edu/etd/3644

This work is brought to you for free and open access by the University Graduate School at FIU Digital Commons. It has been accepted for inclusion in FIU Electronic Theses and Dissertations by an authorized administrator of FIU Digital Commons. For more information, please contact dcc@fiu.edu. 


\title{
FLORIDA INTERNATIONAL UNIVERSITY
}

Miami, Florida

\section{ORIGAMI ANTENNAS FOR NOVEL RECONFIGURABLE COMMUNICATION SYSTEMS}

\author{
A dissertation submitted in partial fulfillment of \\ the requirements for the degree of \\ DOCTOR OF PHILOSOPHY \\ in \\ ELECTRICAL ENGINEERING \\ by \\ Xueli Liu
}

2018 
To: Dean John L. Volakis

College of Engineering and Computing

This dissertation, written by Xueli Liu, and entitled Origami Antennas for Novel Reconfigurable Communication Systems, having been approved in respect to style and intellectual content, is referred to you for judgment.

We have read this dissertation and recommend that it be approved.

$\begin{array}{r}\text { Nezih Pala } \\ \hline \text { Jean H. Andrian } \\ \hline \text { Berrin Tansel } \\ \hline \text { Stavros V. Georgakopoulos, Major Professor }\end{array}$

Date of Defense: March 21, 2018.

The dissertation of Xueli Liu is approved.

Dean John L. Volakis College of Engineering and Computing

Andres G. Gil

Vice President for Research and Economic Development and Dean of the University Graduate School

Florida International University, 2018 
C Copyright 2017 by Xueli Liu

All rights reserved. 


\section{DEDICATION}

I dedicate this dissertation to my family, especially my dear husband. Without their

love, understanding and support, the completion of this work would never have been achievable. 


\section{ACKNOWLEDGMENTS}

I would like to express my sincerest gratitude to my major professor, Dr. Stavros V. Georgakopoulos, for his great mentoring and relentless support through my Ph.D. program at FIU. He provided the most excellent research environment with the latest research software and top advanced equipment. His hard-working, gentle and earnest way of life and research sets up a role model for me, and I sincerely thank him for his constructive academic advices, graceful patience and understanding during these five important years of my life. He has truly given me the confidence and knowledge base to excel in the next stage of my career. I also appreciate Dr. Nezih Pala, Dr. Jean H. Andrian, Dr. Berrin Tansel, and Dr. Kang Yen for serving on my dissertation defense committee and for their illuminating comments.

I am sincerely thankful for my husband who encouraged me throughout the research. Thanks for his and my parents' inspiration, love, understanding, encouragement and advices. I also thank all the members of FIU Electrical and Computing Engineering Department and special thanks to Dr. Hao Hu, Dr. Shun Yao, Kun Bao, Daerhan Liu, John Gibson, Karina Quintana, Elad Siman Tov, Pablo Gonzalez, Yonathan Bonan, Dr. Yipeng Qu, Ms. Xiang Li, and Mr. Oscar Silveira for their help and friendship.

Finally, I would like to greatly thank the Graduate School of FIU for awarding me the Dissertation Year Fellowship, which supported me in the last year of my Ph.D. research. I would also like to recognize the supported by the National Science Foundation and Northrop Grumman for their support of this work. 
ABSTRACT OF THE DISSERTATION

ORIGAMI ANTENNAS FOR NOVEL RECONFIGURABLE COMMUNICATION

SYSTEMS

by

Xueli Liu

Florida International University, 2017

Miami, Florida

Professor Stavros. V. Georgakopoulos, Major Professor

Antennas play a crucial role in communication systems since they are the transmitting/receiving elements that transition information from guided transmission to open-space propagation. Antennas are used in many different applications such as aerospace communications, mobile phones, TVs and radios. Since the dimensions of antennas are usually physically proportional to the wavelength at their operating frequencies, it is important to develop large antennas and arrays that can be stowed compactly and easily deployed. Also, it is important to minimize the number of antennas on a platform by developing multifunctional antennas.

The first aim of this research is to develop new deployable, collapsible, light-weight and robust reconfigurable antennas based on origami principles. All designs will be validated through simulations and measurements. Paper as well as other substrates, such as, Kapton and fabric, will be used to develop our origami antennas. The second aim of this research is to derive integrated analytical and simulation models for designing optimal origami antennas for various applications, such as, satellite or ground communications. 
This dissertation presents research on origami antennas for novel reconfigurable communication systems. New designs of reconfigurable monofilar, bifilar and quadrifilar antennas based on origami cylinders are developed and validated. Novel fabrication methods of origami antennas are presented with detailed geometrical analysis. Furthermore, multi-radii origami antennas are proposed, analyzed, fabricated and validated and they exhibit improved circular polarization performance and wide bandwidths. An actuation mechanism is designed for these antennas. For the first time, a low-cost and lightweight reconfigurable origami antenna with a reflector is developed here. In addition, an array is developed using this antenna as its element. Finally, a kresling conical spiral antenna and a spherical helical antenna are designed with mode reconfigurabilities. 


\section{TABLE OF CONTENTS}

CHAPTER

PAGE

Contents

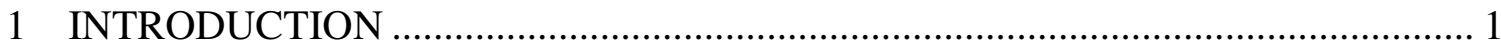

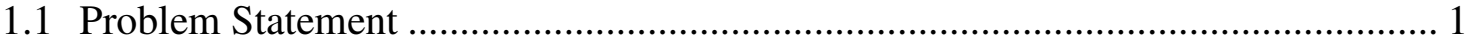

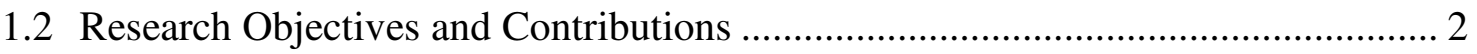

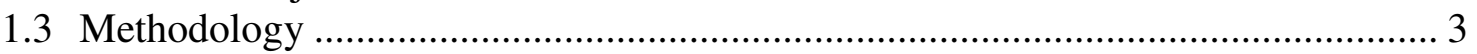

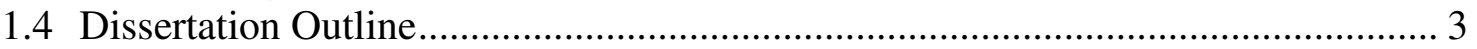

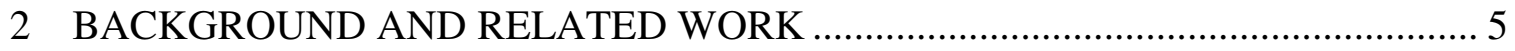

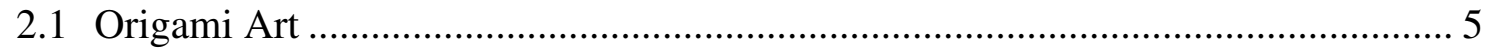

2.2 Reconfigurable Antennas ............................................................................. 5

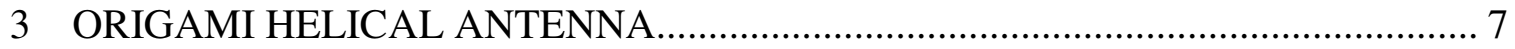

3.1 Standard Axial Mode Helical Monofilar Antenna ………………........................... 7

3.2 Analysis of Origami Helical Model ................................................................. 8

3.3 Comparison of Standard Helical Antennas with Equivalent Origami Helical

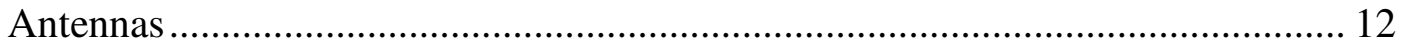

3.4 Reconfigurable Helical Antenna Based on Origami Neoprene with High

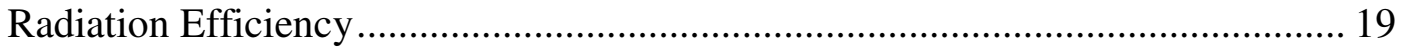

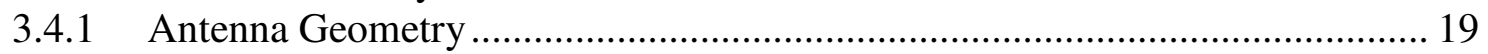

3.4.2 Prototype of the Helical Antenna...................................................................... 21

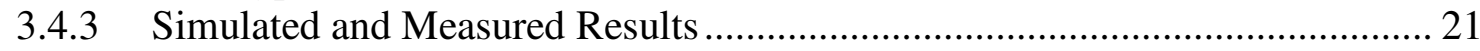

3.5 Reconfigurable Origami Bifilar Helical Antenna ………………......................... 24

3.6 Frequency Reconfigurable QHA Based on Kapton Origami Helical Tube for

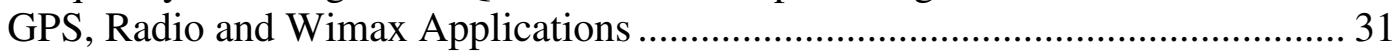

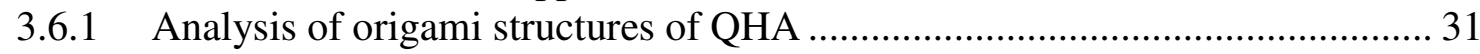

3.6.2 Helical and Bellow origami tube QHAs ............................................................ 33

3.6.3 Prototypes and Results of Helical Tube Based QHA ………………………..... 36

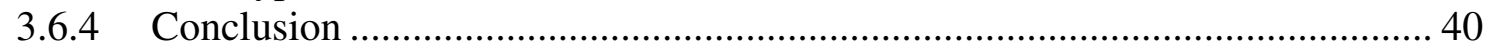

4 A RECONFIGURABLE PACKABLE AND MULTIBAND ORIGAMI MULTIRADII HELICAL ANTENNA ………………………....................................... 41

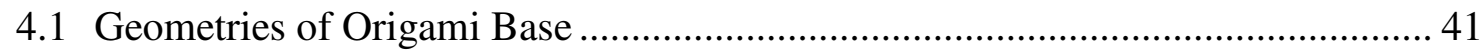

4.2 Geometries of Antenna Model ......................................................................... 44

4.3 Comparison of Origami Multi-Radii Monofilar with Standard and Origami

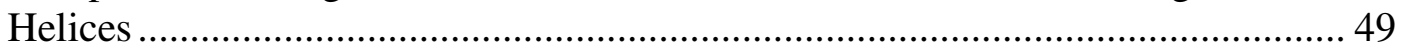

4.3.1 Comparison of Origami Multi-Radii Monofilar with Standard Helix .............. 49

4.3.2 Performance Comparison of Reconfigurable Origami Multi-Radii Monofilar with Previous Origami Monofilar ................................................. 53

4.4 Parametric Analysis of the Origami Multi-radii Helical Antenna .......................... 58

4.4.1 Determining Parameter $a_{1}$ of the Top Helix................................................... 58

4.4.2 Determining the Number of Turns of the Large Helix ..................................... 60 
4.4.3 Determining the Number of Turns of the Small Helix ....................................... 60

4.4.4 Spacing between Adjacent Turns of Bottom Helix .......................................... 61

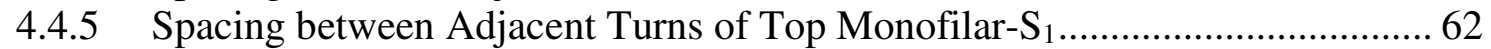

4.5 Fabrication of Antenna and Actuation Mechanism............................................... 64

4.5.1 Fabrication of the Origami Multi-Radii Helix .................................................. 64

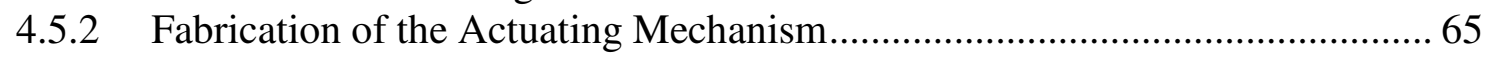

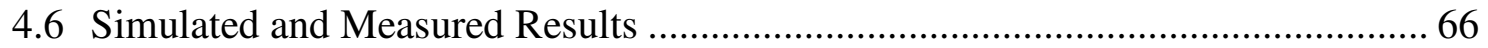

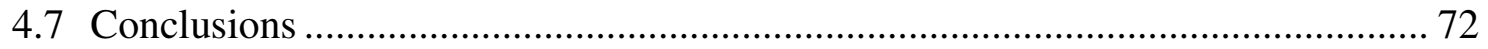

5 REFLECTOR RECONFIGURABLE ORIGAMI QUADRIFILAR AND MONOFILAR HELICAL ANTENNA FOR SATELLITE

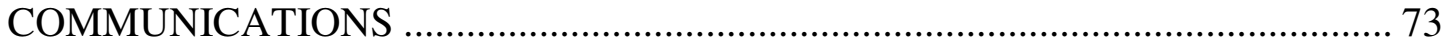

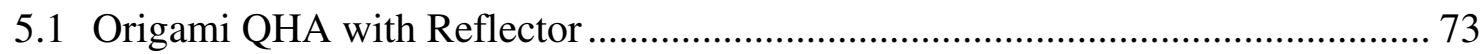

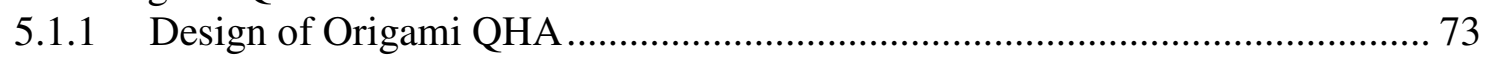

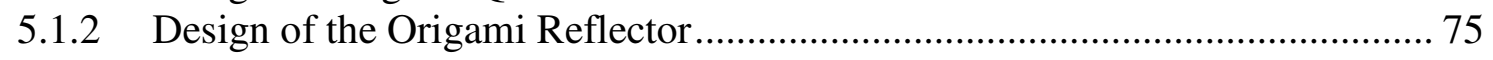

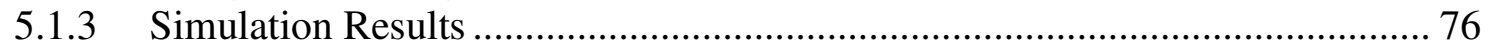

5.1.4 10:1 Scale Model of Origami QHA ……………........................................ 79

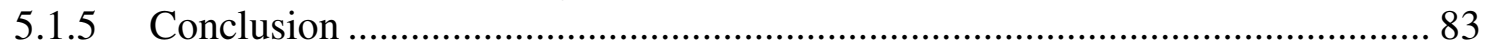

5.2 Tri-band Reconfigurable Origami Helical Array ………......................................... 84

5.2.1 Geometry of Single Helical Antenna Element................................................... 84

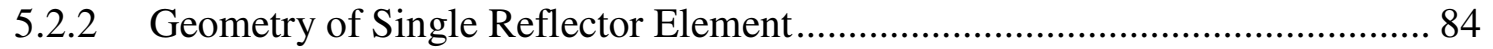

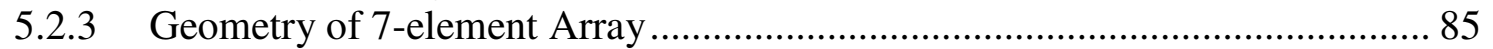

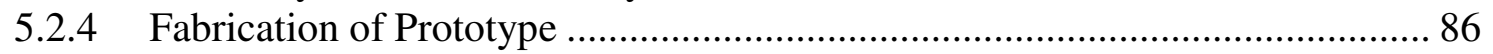

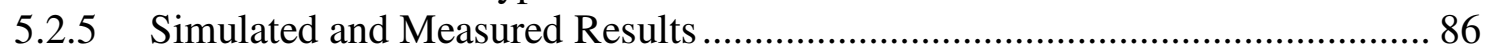

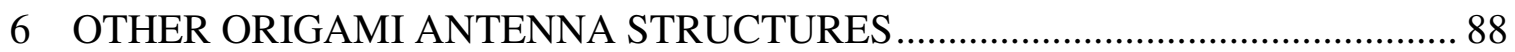

6.1 Mode Reconfigurable Bistable Spiral Antenna Based on Kresling Origami ......... 88

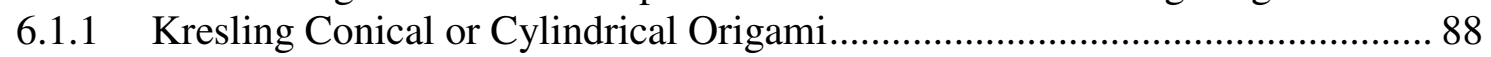

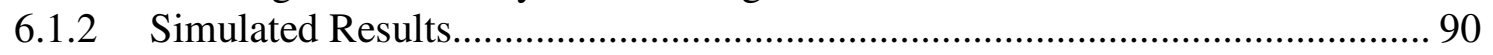

6.2 A Frequency Tunable Origami Spherical Helical Antenna...................................... 91

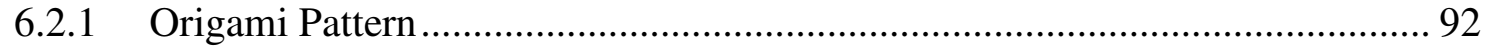

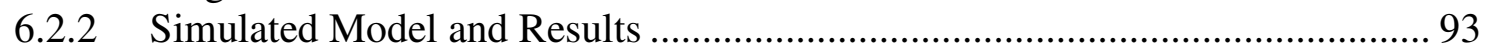

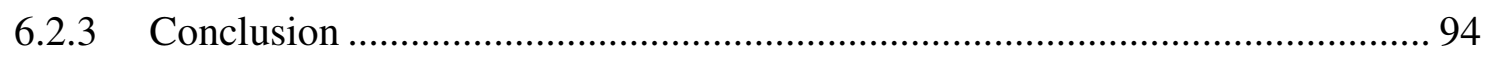

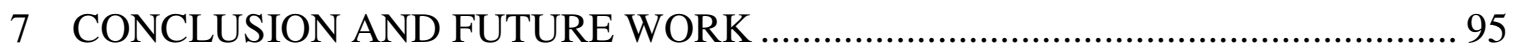

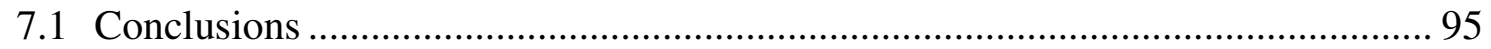

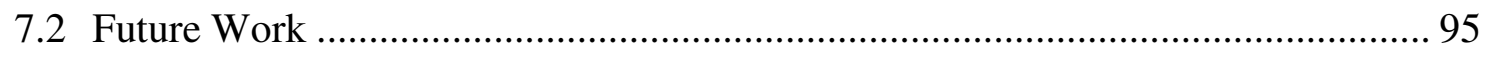

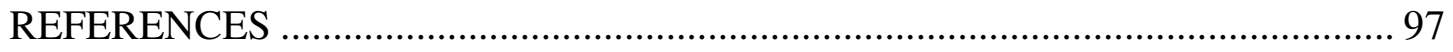

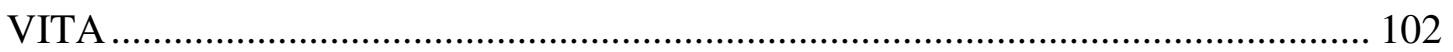




\section{LIST OF TABLES}

TABLE

PAGE

Table 3.1 Empirical Optimum Parameters of Monofilar Helical Antenna.........................8

Table 3.2 Geometric Parameters of Origami Helical Antennas......................................11

Table 3.3 Relationships between Standard and Origami Helices...................................12

Table 3.4 Geometric Parameters of the Standard Helical Antenna.................................12

Table 3.5 Calculated Parameters of Equivalent Origami Helical Antennas with Different Folding Patterns.

Table 3.6 Performance Comparison of Standard Helical Monofilar Antenna and Its Equivalent Origami Helical Monofilar Antennas....................................15

Table 3.7 Values of Geometrical Parameters of the Antenna...........................................20

Table 3.8 Summarized Measured Results of The Antenna..............................................24

Table 3.9 Measured Realized Gain (dB) at the Operating Frequencies of the 3 States of the Origami Bifilar Helix......................................................................22

Table 3.10 Measured Performances of the Bifilar Helical Origami Antenna for Three Different Heights...................................................................... 30

Table 3.11 Performance Comparison of QHAs on Helical Tube and Bellow Tube............36

Table 3.12 Summarized Measured Results of Kapton QHA..........................................40

Table 4.1 Primary Geometric Parameters of Origami Base..........................................43

Table 4.2 Secondary geometric Parameters of Origami base........................................44

Table 4.3 Performance Comparison of Standard, Standard Multi-Radii, and Origami Multi-Radii Helices.

Table 4.4 Performance Comparison of Origami Multi-Radii Monofilar with Origami Monofilar..............................................................................56

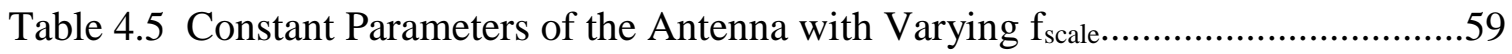

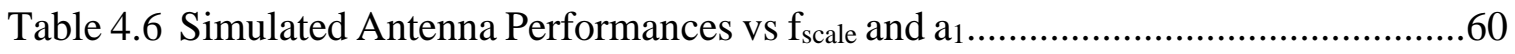

Table 4.7 Constant Parameters of the Antenna with Varying m.....................................60

Table 4.8 Simulated Antenna Performances vs m.........................................................60

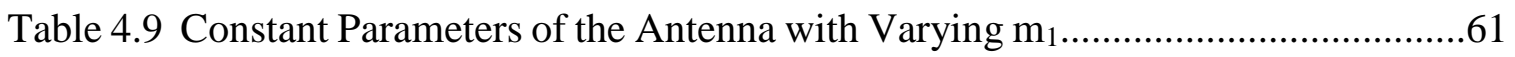




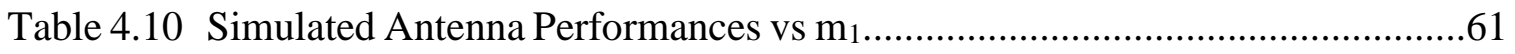

Table 4.11 Constant Parameters of the Antenna with Varying ratio ..............................61

Table 4.12 Simulated Antenna Performances vs S....................................................62

Table 4.13 Constant Parameters of the Antenna with Varying ratio................................63

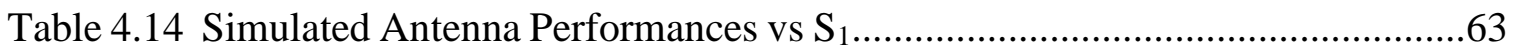

Table 4.15 Dimensions of Actuation Mechanism...........................................................65

Table 4.16 Simulated and Measured Results of the Origami Multi-Radii Helix at 3

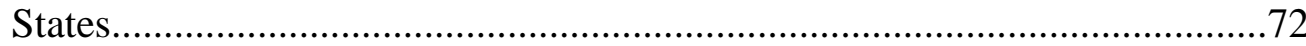

Table 5.1 Simulated and Measured Results at Designated Frequencies of the 10:1

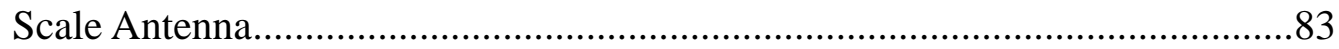

Table 5.2 Geometrical Parameters of Single Helical Element........................................84

Table 5.3 Geometrical parameters of Single Reflector Element.....................................85

Table 5.4 Geometrical parameters at Each State...........................................................85

Table 5.5 Simulated and Measured Results of the Array.............................................87 


\section{LIST OF FIGURES}

FIGURE

PAGE

Figure 3.1 Geometry of standard helical antenna..................................................

Figure 3.2 Folding pattern of origami helix........................................................... 9

Figure 3.3 Procedure of folding the origami cylinder substrate base ...............................

Figure 3.4 Geometry of each step of the origami cylinder substrate base.........................10

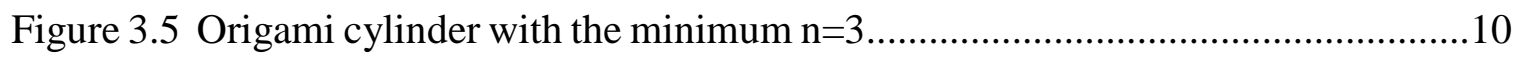

Figure 3.6 Comparison of $S_{11}$ of a standard helical monofilar antenna and its equivalent origami helical monofilar antennas: (a) equivalent origami helix with $n=4, m=13,15,18$; (b) equivalent origami helix with $m=13$, $\mathrm{n}=4,5,6$.......

Figure 3.7 Compactness factor vs.: (a) the length, a, of each parallelogram unit in the origami pattern; (b) thickness of substrate $\mathrm{t}(\mathrm{mm})$; (c) ratio of b/a

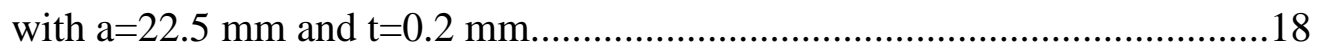

Figure 3.8 Geometry of: (a) origami pattern, and (b) folded antenna.............................20

Figure 3.9 Model of one step: (a) perspective view, and (b) top view.............................20

Figure 3.10 Prototype of the helical antenna on Neoprene at: (a) unfolded state, and (b) folded state.

Figure 3.11 Simulated and measured $S_{11}$ at unfolded and folded states. ........................22

Figure 3.12 Simulated and measured realized gain at unfolded and folded states. ...........23

Figure 3.13 Simulated and measured AR at unfolded and folded states..........................23

Figure 3.14 Measured radiation efficiency at unfolded and folded states........................23

Figure 3.15 Origami bifilar helical antenna model at different states of H......................24

Figure 3.16 Prototype of reconfigurable origami bifilar helical antenna with different heights $\mathrm{H}$ : (a) $\mathrm{H}=273 \mathrm{~mm}$; (b) $\mathrm{H}=154 \mathrm{~mm}$; (c) $\mathrm{H}=25 \mathrm{~mm}$................26

Figure 3.17 Return loss of origami bifilar helix for different antenna heights, H.............27

Figure 3.18 Realized gain at zenith for three heights of the origami bifilar helix in three different operating frequency bands.

Figure 3.19 Normalized elevation patterns of the origami bifilar helical antenna at the operating frequencies of the three states (i.e., Heights): (a) $\mathrm{H}=273 \mathrm{~mm}$ 
at $0.86 \mathrm{GHz}$; (b) $\mathrm{H}=154 \mathrm{~mm}$ at $1.27 \mathrm{GHz}$; (c) $\mathrm{H}=154 \mathrm{~mm}$ at $1.7 \mathrm{GHz}$;

(d) $\mathrm{H}=154 \mathrm{~mm}$ at $1.98 \mathrm{GHz}$; (e) $\mathrm{H}=25 \mathrm{~mm}$ at $2.49 \mathrm{GHz}$; (f) $\mathrm{H}=25 \mathrm{~mm}$ at

$2.81 \mathrm{GHz} ;(\mathrm{g}) \mathrm{H}=25 \mathrm{~mm}$ at $3 \mathrm{GHz}$

Figure 3.20 (a) Origami helical tube and (b) Origami bellow tube .32

Figure 3.21 Folding patterns of: (a) helical tube based QHA and (b) bellow tube based QHA

Figure 3.22 Geometry of one step of origami tube: (a) perspective view and

(b) top view.

Figure 3.23 Simulation models of origami antennas based on: (a) helical tube; and (b) bellow tube. 33

Figure 3.24 Simulated RHCP realized gain of QHA on helical tube...............................34

Figure 3.25 Simulated RHCP realized gain of QHA on bellow tube ................................35

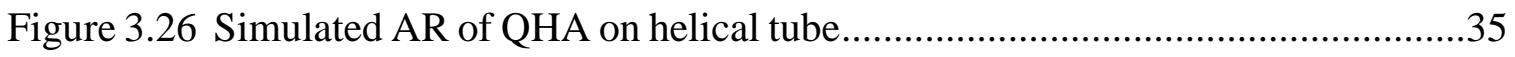

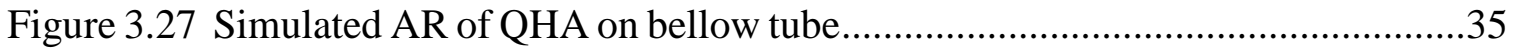

Figure 3.28 (a) Planar antenna layout, and (b) origami QHA on Kapton helical tube.

Figure 3.29 $\mathrm{S}_{11}$ results of QHA on helical tube at: (a) state 1, (b) state 2, (c) state 3 and $(\mathrm{d})$ state 4 .

Figure 3.30 RHCP gain of QHA on helical tube at: (a) state 1, (b) state 2, (c) state 3 and (d) state 4 .

Figure 3.31 RHCP radiation patterns of QHA on helical tube at: (a) state 1 at $1.08 \mathrm{GHz}$, (b) state 2 at $1.56 \mathrm{GHz}$, (c) state 3 at $2.18 \mathrm{GHz}$ and (d) state 4 at $3.34 \mathrm{GHz}$.

Figure 4.1 Geometries of the origami multi-radii monofilar helix: (a) origami folding pattern, (b) perspective view of multi-radii folded-up transitional section, and (c) top view of multi-radii folded-up transitional section.

Figure 4.2 Model and geometries of the origami multi-radii monofilar helix at three different heights (i.e., states): (a) state 1 (unfolded state), (b) state 2 (semi-folded state), and (c) state 3 (folded state)

Figure 4.3 The geometries of: (a) standard helix, and (b) standard multi-radii helix. .50

Figure 4.4 Comparison of simulated $\mathrm{S}_{11}$ of standard monofilar, standard multi-radii, and origami multi-radii helices.

Figure 4.5 Comparison of simulated zenithal RHCP realized gain of standard, 
standard multi-radii, and origami multi-radii helices

Figure 4.6 Comparison of simulated zenithal axial ratio of standard, standard multi-radii, and origami multi-radii helices.

Figure 4.7 Comparison of simulated radiation patterns of standard, Standard multi-radii, and origami multi-radii helices at their center frequency of operation, $\mathrm{f}_{\mathrm{c}}$

Figure 4.8 The origami monofilar to be compared with the origami multi-radii monofilar at: (a) state 1 (unfolded state), (b) state 2 (semi-folded state), and (c) state 3 (folded state)

Figure 4.9 Comparison of simulated S11 of origami single-radius and multi-radii helices at three states (blue lines: state 1; black lines: state 2; red lines: state 3 ).

Figure 4.10 Comparison of simulated realized RHCP gain of origami single-radius and multi-radii helices at three states (blue lines: state 1; black lines: state 2 ; red lines: state 3 ).

Figure 4.11 Comparison of simulated axial ratio of origami single-radius and multi-radii helices at three states (blue lines: state 1; black lines: state 2; red lines: state 3 )

Figure 4.12 Comparison of simulated elevational radiation patterns of the origami single-radius and multi-radii helices at the center frequencies $\mathrm{f}_{\mathrm{c}}$ in their 2-dB realized gain bandwidths at: (a) state 1; (b) state 2; and (c) state 3........58

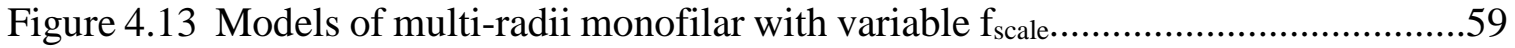

Figure 4.14 Models of multi-radii helix with variable S.............................................62

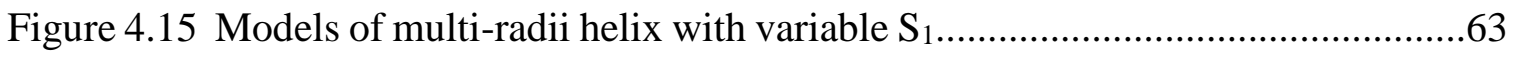

Figure 4.16 Prototype of origami multi-radii helix at 3 reconfigurable states..................66

Figure 4.17 Actuation mechanism of the origami multi-radii helix................................66

Figure 4.18 Simulated and measured $\mathrm{S}_{11}$ results of the origami multi-radii helix at: (a) state 1, (b) state 2 and (c) state 3. 68

Figure 4.19 Simulated and measured realized RHCP gain of the origami multi-radii helix at: (a) state 1 , (b) state 2 and (c) state 3.

Figure 4.20 Simulated and measured axial ratio of the origami multi-radii helix at:

(a) state 1 , (b) state 2 and (c) state 3 .70

Figure 4.21 Simulated and measured elevational radiation patterns of the origami multi-radii helix at: (a) state 1 at $1.56 \mathrm{GHz}$, (b) state 2 at $3.16 \mathrm{GHz}$, 
and (c) state 3 at $3.88 \mathrm{GHz}$.

Figure 5.1 Origami folding pattern of the QHA cylinder base.......................................74

Figure 5.2 Origami quadrifilar helical antenna model................................................74

Figure 5.3 The three states of the reconfigurable origami QHA with the foldable reflector and the folding patterns of the reflector.....

Figure 5.4 Simulated $S_{11}$ of the reconfigurable origami QHA with the reflector at

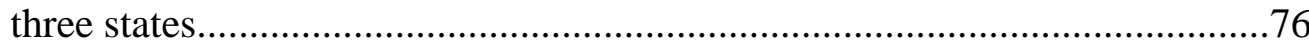

Figure 5.5 Simulated realized RHCP gain of the reconfigurable origami QHA with the reflector at three states.

Figure 5.6 Simulated axial ratio of the reconfigurable origami QHA with the reflector at three states.

Figure 5.7 RHCP patterns at three states of the reconfigurable origami reflector QHA at designated operating frequencies...................................................78

Figure 5.8 RHCP patterns of reconfigurable QHA resonating at 3 designated operating frequencies with one common reflector state.

Figure 5.9 Geometry of the 10:1 scale model of the origami QHA. (a) origami folding pattern, and (b) 3D model. .80

Figure 5.10 Geometry of 10:1 scale model of the origami QHA with its reflector at three states: (a) state $1(\mathrm{H}=120 \mathrm{~mm})$; (b) state $2(\mathrm{H}=75 \mathrm{~mm})$; (c) state 3 $(\mathrm{H}=105 \mathrm{~mm})$

Figure 5.11 Geometry of 10:1 scale model of the origami QHA with its reflector.

Figure 5.12 Comparison of simulated and measured $\mathrm{S}_{11}$ at the three states

Figure 5.13 Simulated and measured normalized radiation patterns at the three states:

(a) state 1 at $2.07 \mathrm{GHz}$, (b) state 2 at $3 \mathrm{GHz}$, and (c) state 3 at $4.45 \mathrm{GHz} \ldots \ldots . . .83$

Figure 5.14 Geometry of single reflector element: (a) top view; and (b) side view...........85

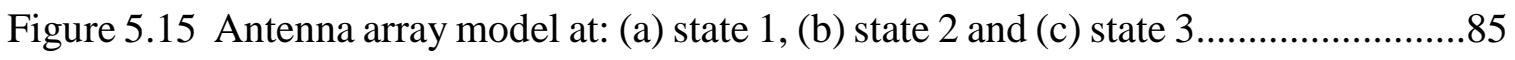

Figure 5.16 Fabricated prototype of the 7-element origami helical array..... .86

Figure 5.17 Simulated and measured radiation patterns of the helical array at (a) state 1 at $2.07 \mathrm{GHz}$, (b) state 2 at $3 \mathrm{GHz}$ and (c) state 3 at $4.45 \mathrm{GHz}$.. .86

Figure 6.1 (a) Kresling origami pattern, (b) Top view and perspective view of one step of the pattern.

Figure 6.2 Model of the conical and planar spiral antenna...... .90 
Figure 6.3 Simulated realized gain at the two states...............................................90

Figure 6.4 Radiation patterns at $2.7 \mathrm{GHz}$ (a) conical spiral; (b) planar spiral...................91

Figure 6.5 Front to back ratio at the two states...................................................... 91

Figure 6.6 (a) The 4-step origami pattern of spherical helical antenna; and

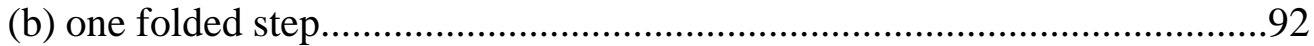

Figure 6.7 The 4 states of the spherical antenna: (a) state1 ( $h=8.69 \mathrm{~mm})$; (b) state 2 $(\mathrm{h}=21.8 \mathrm{~mm}) ;(\mathrm{c})$ state $3(\mathrm{~h}=11.6 \mathrm{~mm})$; and $(\mathrm{d})$ state $4(\mathrm{~h}=6.5 \mathrm{~mm})$...............93

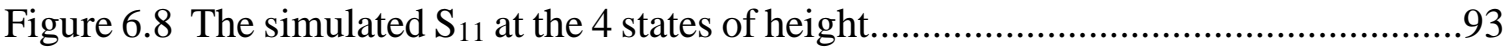

Figure 6.9 Simulated radiation patterns of the 4 states at their resonant frequencies: (a) h=28.6 $\mathrm{mm}$ at $2.32 \mathrm{GHz}$; (b) $\mathrm{h}=21.8 \mathrm{~mm}$ at $1.77 \mathrm{GHz}$; (c) h=11.6 mm at $2.07 \mathrm{GHz}$; (d) $\mathrm{h}=6.5 \mathrm{~mm}$ at $2.12 \mathrm{GHz}$ 


\section{CHAPTER 1}

\section{INTRODUCTION}

\subsection{Problem Statement}

During the last twenty years, mathematicians and engineers have done extensive research focusing on the mathematical basis of origami and reconfigurable systems [1]-[2]. Mathematical analysis of origami geometries were demonstrated by generations of origami artists [3]-[5], and it took several years for origami scientists to solve the fundamental problem of defining the folded state of an origami [6]. The issues the origami scientists and engineers aim to solve are either paper folding, or the construction of a reconfigurable object or a suitable mechanism to reconfigure it. The reconfiguration of an object serving a certain purpose usually means folding and unfolding, and the property of an object being able to unfold is often referred to as deployability, while its ability to fold is referred to as stowability. Such reconfigurable objects can be stowed compactly to fit in a very small volume and be deployed to occupy a larger volume. Therefore, they can have practical applications in numerous scenarios, such as, a telescopic lens that has to fit into a small compartment before it can be launched into orbit and then be unfolded into a large size to operate [7], or a deployable heart stent that can travel through human blood vessel to an optimum operational location where it will unfold in response to temperature to carry out invasive heart surgery [8]. Also, origami has been applied on the design of automobile airbags that deploy fast and are stowed compactly [9]. Different kinds of inflatable origami cylindrical booms to pack or rigidize space structures have been introduced [10]. In addition, origami has been used to make hollow cell structures for the next-generation medical devices, e.g., stents that are more compatible to human body [11]. Furthermore, 
self-folding robots have been proposed for rapid prototyping and self-assembly of devices in space [12].

Various complex geometries have been used in electromagnetics to develop components with enhanced performance and unique capabilities, such as fractal antennas [14]. Dr. Tentzeris has also performed 3-D folding of antennas for various flexible and wearable applications [25]. Dr. Georgakopoulos has worked on 2-D and 3-D folding of Strongly Coupled Magnetic Resonance elements used to wirelessly power devices [26]. Limited previous work on origami electromagnetic structures has been performed by others [20].

Also, to our knowledge no mathematical optimization of origami foldable antennas has been performed and no methodologies that address the challenges of designing origami foldable electromagnetic structures on paper, fabric and other flexible substrates have been developed before our work.

\subsection{Research Objectives and Contributions}

The first aim of this research is to develop new deployable, collapsible, light-weight and robust reconfigurable antennas based on origami. The designs will be validated through simulations and measurements. Beyond paper, other substrates, such as, Kapton and fabric, will be used to develop robust origami antennas and their mechanical performance will be studied. The second aim of this research is to derive integrated analytical and simulation models for designing optimal origami antennas for various applications, such as, satellite and ground communications. 


\subsection{Methodology}

Today's complex antennas are typically designed using full-wave simulation software, such as the ANSYS HFSS. However, there is no direct way to parameterize models of complicated structures such as origami antennas, because the surfaces of such antennas are not continuous curves due to the existence of creases (hills and valleys). Also, development of purely analytical methods for origami structures with more than two degrees of freedom (i.e., more than two dimensions are changing simultaneously) would be extremely difficult to derive. In this research, parameterized models of origami antennas and reflectors will be derived based on various origami designs to expedite the design and optimization process. The reconfigurability of origami antennas will be examined for different performance parameters, such as, reflection coefficient, radiation pattern, axial ratio and realized gain. The designs will be validated using measurements conducted with vector network analyzers and anechoic chambers.

Suitable substrates will be studied to build robust foldable origami antennas with improved reliability compared to conventional paper substrate, such as fabric or DuPont Kapton. Origami antennas will be designed and printed on such materials and their electromagnetic and mechanical performance will be validated through simulations and measurements.

\subsection{Dissertation Outline}

The background work will be discussed in chapter 2. New reconfigurable origami helical antennas will be proposed in chapter 3 and their performance will be characterized and validated using simulations and measurements. A tri-band multi-radii monofilar helix 
with improved circular polarization will be developed and analyzed in chapter 4. A quadrifilar helical origami antenna with a reconfigurable and an array of this antenna will be discussed in chapter 5. Also, novel origami antennas such as origami kresling conical spiral antennas and origami spherical helical antennas will be presented in chapter 6 . Finally, the conclusions or this work and future research will be discussed in chapter 7. 


\section{CHAPTER 2}

\section{BACKGROUND AND RELATED WORK}

\subsection{Origami Art}

Origami is the art of paper folding. Origami is composed from two Japanese words: oru which means folding, and kami which means paper. Art historians believe that Japanese origami was invented sometimes in the centuries after Buddhist monks carried paper to Japan during the $6^{\text {th }}$ century [21]. Abstract folded paper forms were used in religious ceremonies over many years, and by the 1600s, decorative shapes that we recognize today (i.e., traditional crane) were being folded [22]. Modern origami art emerged in 1950s and inspired a new generation of not only artists but also scientists. There are two categories of origami: rigidly foldable origami, where stiff panels are folded along hinged creases, which are geodesically fixed within the paper [23]; and non-rigidlyfoldable origami, where deformation is allowed on each individual face and/or vertices and creases can move within the paper [24].

\subsection{Reconfigurable Antennas}

Antennas play a crucial role in communication systems since they are the transmitting/receiving elements that transition information from guided transmission to open-space propagation [13]. Antennas are used in many different applications such as aerospace communications, mobile phones, TVs and radios. Since the dimensions of antennas are usually physically proportional to the wavelength at their operating frequencies, it is important to develop large antennas and arrays that can be stowed compactly and easily deployed. Also, it is important to minimize the number of antennas 
on a platform by developing multifunctional antennas. Various complex geometries have been used in electromagnetics to, such as, fractal antenna [14]. A self-folding origami antenna was proposed that can be converted from a patch antenna to a monopole antenna in seconds, but this transition is not reversible [15]. Antennas with reflectors are preferred in satellite communications for their high gain [16]-[17]. However, their large size and heavy weight create significant problems, especially when these antennas need to be carried by satellites into space. Compact foldable antennas have proposed using conventional ways of fabrication [18]-[19], but they do not have the ability to reconfigure their performance. Concepts of deployable antennas have been proposed in [20], but no rigorous antenna models were developed. 


\section{CHAPTER 3}

\section{ORIGAMI HELICAL ANTENNA}

\subsection{Standard Axial Mode Helical Monofilar Antenna}

Helical antennas have two principal modes: the normal (broadside) mode and the axial (end-fire) mode. The axial mode has its maximum pattern along the axis of the helix. This mode is usually the most practical because it can achieve circular polarization over a wider bandwidth (usually 2:1) and it is more efficient [27]. The empirical optimum parameters for an axial-mode circularly polarized monofilar helical antenna (geometry is shown in Figure 3.1) are given in Table 3.1; where, $\mathrm{S}$ is the spacing between each turn and $C=\pi D$ is the circumference of the helix [27]-[28], and $\lambda_{0}$ is the operational wavelength. Also, the pitch angle, $\alpha$, and the total length of conductive line, L, are given by Eqn. (3.1) and (3.2) [27] below.

$$
\begin{gathered}
\tan \alpha=S / C \\
L=N \sqrt{S^{2}+C^{2}}
\end{gathered}
$$

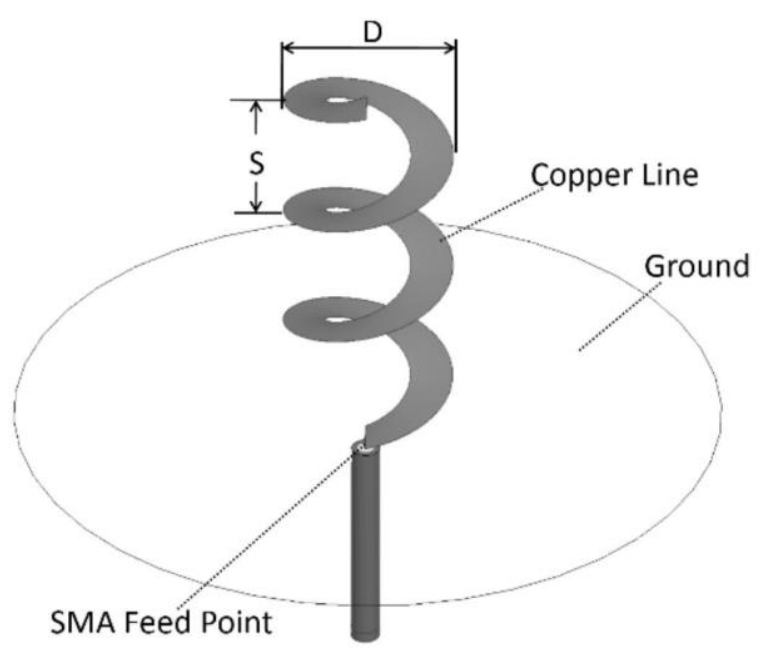

Figure 3.1. Geometry of standard helical antenna. 
Table 3.1. Empirical Optimum Parameters of Monofilar Helical Antenna.

\begin{tabular}{cc}
\hline Parameter & Optimum Range \\
\hline Circumference & $3 \lambda_{0} / 4<C<4 \lambda_{0} / 3$ \\
\hline Spacing Between Each Turn & $S \approx \lambda_{0} / 4$ \\
\hline Pitch Angle & $12^{\circ}<\alpha<14^{\circ}$ \\
\hline Number of Turns & $3<N$ \\
\hline Ground Plane Diameter & At least $0.5 \lambda_{0}$ \\
\hline
\end{tabular}

\subsection{Analysis of Origami Helical Model}

In this section, an analytical method is presented for designing an origami helical antenna that mimics a standard helical antenna with specific defining parameters $D, \alpha$, and $N$. The folding pattern [29], which is used to fold the origami cylinder base of the helix, is shown in Figure 3.2. The solid lines are hills and dashed lines are valleys. As illustrated in Figure 3.2, the conductive (i.e., copper) lines are placed only along creases $b$, in order for the origami helical antenna to achieve the maximum tunability of $S$. The number of conductive lines can be 1,2 , or 4 , and the total length of each conductive line is $L$.

The origami cylinder base of the helical antenna, as shown in Figure 3.3 (b), is obtained by first folding the pattern of Figure 3.2 to obtain the geometry of Figure 3.3 (a), and then connecting the left side of Figure 3.3 (a) to its right side from top to bottom. As shown in Figure 3.4, the height of each step of the origami cylinder is defined as $h$ and the angle between each step and its adjacent step is defined as $\theta$. Also, $r$ is the distance from the center of the polygon at the intersection to its furthest perimeter point, and $\varphi$ is the angle between two adjacent radial lines $r$.

The relationships between all the geometric parameters that define the origami helical antenna are listed in Table 3.2, where ratio=b/a is the aspect ratio of each parallelogram unit of the pattern in Figure 3.2, $c$ is the length of the diagonal line in each 
parallelogram unit and $m$ is the total number of steps. Also, the minimum number of sides $n$ of a foldable pattern of the origami cylinder should be 3, as expressed in Eqn. (3.3). An example of origami cylinder with the minimum $n=3$ is shown in Figure 3.5. Also, the ratio should be properly chosen to achieve the desired antenna geometry and foldability according to the analytical method that will be described below.

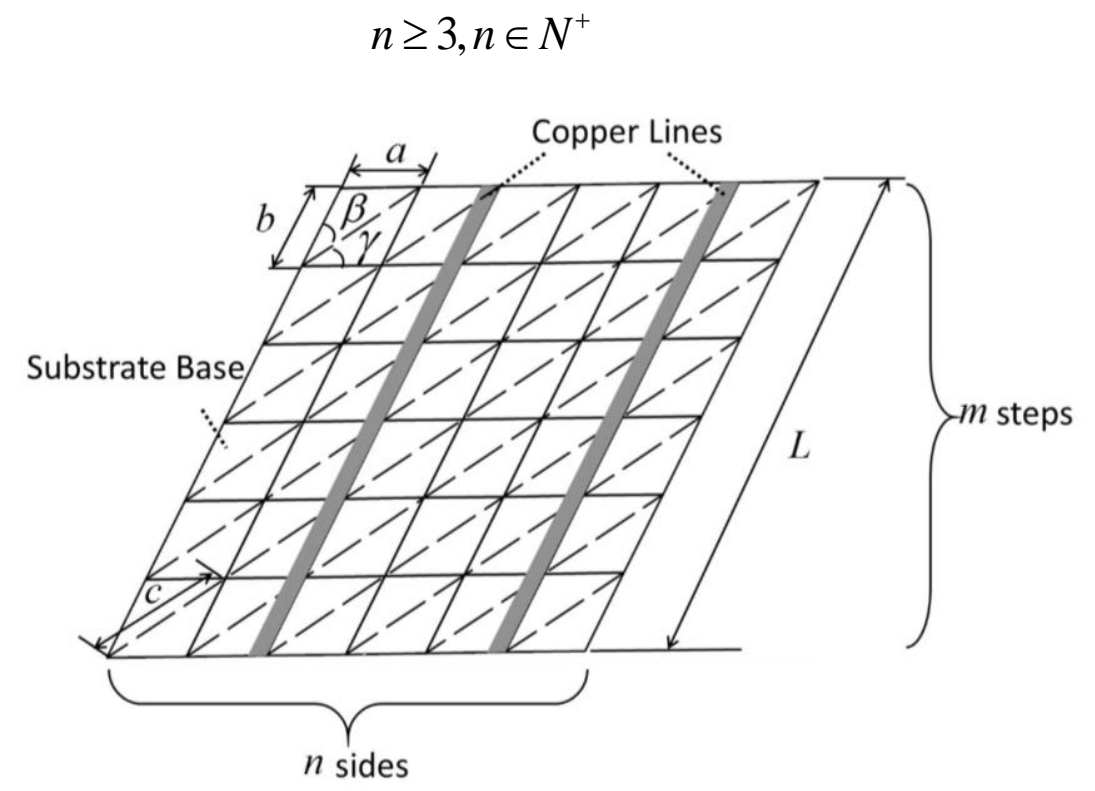

Figure 3.2. Folding pattern of origami helix.

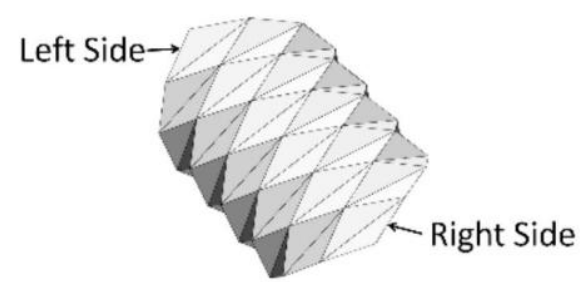

(a)

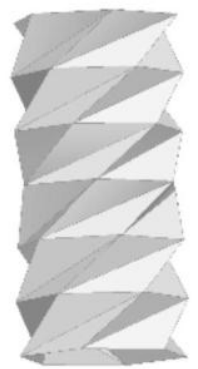

(b)

Figure 3.3. Procedure of folding the origami cylinder substrate base. [29] 


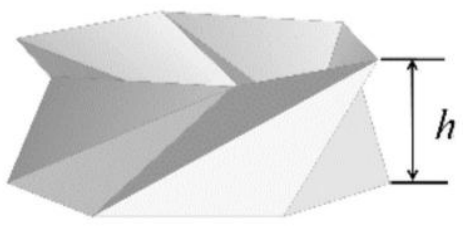

(a)

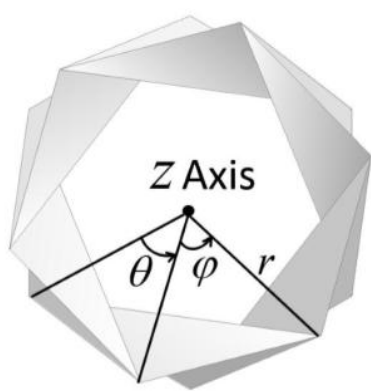

(b)

Figure 3.4. Geometry of each step of the origami cylinder substrate base.

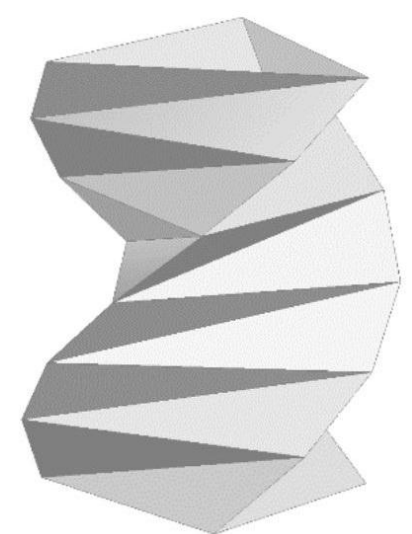

Figure 3.5. Origami cylinder with the minimum $n=3$.

For any given standard helical antenna, an equivalent origami helical antenna can be derived when $m$ and $n$ are specified, and vice versa, as listed in Table 3.1. Specifically, the standard helix and origami helix are equivalent in terms of the values of the spacing between each turn $S$, pitch angle $\alpha$, number of turns $N$, and total length $L$. Also, the circumference of the standard helix is equal to the perimeter of the origami helix.

The empirical maximum gain of a numerically modeled standard helix can be expressed as [27]

$$
G_{\max }(d B)=10.25+1.22 L / \lambda_{0}-0.0726\left(L / \lambda_{0}\right)^{2}
$$


Table 3.2. Geometric Parameters of Origami Helical Antennas.

\begin{tabular}{|c|c|}
\hline $\begin{array}{c}\text { Parameters of Origami } \\
\text { Helix }\end{array}$ & Relationships among Parameters \\
\hline \multirow[t]{2}{*}{$\begin{array}{c}m, n, L, a, b, c, \text { ratio } \\
\beta, \gamma, h, \theta, r, \varphi\end{array}$} & $\begin{array}{c}\text { ratio }=b / a \\
\beta=\pi / n \text { [32] } \\
\gamma=\sin ^{-1}\left[\text { ratio } \cdot \sin \left(\frac{\pi}{n}\right)\right] \\
L=m \cdot b=m \cdot a \cdot \text { ratio, } m \in N^{+} \\
h=\sqrt{b^{2}-\frac{a^{2} \cdot \sin ^{2}\left(\frac{\theta}{2}\right)}{\sin ^{2}\left(\frac{\pi}{n}\right)}} \\
\varphi=2 \pi / n \\
r=\frac{a}{2 \sin \left(\frac{\varphi}{2}\right)}\end{array}$ \\
\hline & $c=a \sqrt{\text { atio }^{2}+\cos \theta+\frac{\sin \theta \sin \varphi}{1-\cos \varphi}}$ \\
\hline
\end{tabular}

Also, if we substitute in the Eqn. (3.4) $L=m b$ and the approximation $\lambda_{0}=C \approx n a$ (where $C$ is the circumference of the origami cylinder) to design an axial-mode origami helix, which satisfies the conditions of Table 3.1, the empirical maximum gain of this axialmode origami monofilar helical antenna can be expressed as

$$
G_{\max }(d B)=10.25+1.22 \frac{m}{n} \cdot \text { ratio }-0.0726\left(\frac{m}{n} \cdot \text { ratio }\right)^{2}
$$


Table 3.3. Relationships between Standard and Origami Helices.

\begin{tabular}{|c|c|c|}
\hline Standard Helix & Relationships & Equivalent Origami Helix \\
\hline$D, \alpha, N$ & $\begin{array}{c}a=\pi D / n \\
\theta=2 \arcsin \left[N \cdot \frac{n}{m} \cdot \sin \left(\frac{\pi}{n}\right)\right] \\
\text { ratio }=\sec \alpha \cdot \sin \left(\frac{\theta}{2}\right) / \sin \left(\frac{\pi}{n}\right)\end{array}$ & $\begin{array}{l}m \text { (given), } \\
n \text { (given), } \\
a, \theta, \text { ratio }\end{array}$ \\
\hline Origami Helix & Relationships & Equivalent Standard Helix \\
\hline$m, n, a, b, \theta$ & $\begin{array}{c}S=n \sqrt{\frac{b^{2} \cdot \sin ^{2}\left(\frac{\pi}{n}\right)}{\sin ^{2}\left(\frac{\theta}{2}\right)}-a^{2}} \\
\tan \alpha=\sqrt{\frac{\left(\frac{b}{a}\right)^{2} \cdot \sin ^{2}\left(\frac{\pi}{n}\right)}{\sin ^{2}\left(\frac{\theta}{2}\right)}-1} \\
N=m \cdot \sin \left(\frac{\theta}{2}\right) /\left[n \cdot \sin \left(\frac{\pi}{n}\right)\right]\end{array}$ & $S, \alpha, N$ \\
\hline
\end{tabular}

\subsection{Comparison of Standard Helical Antennas with Equivalent Origami Helical}

\section{Antennas}

An axial-mode standard helical monofilar antenna is designed and its parameters are described in Table 3.4. The parameters of the equivalent origami helical monofilar antennas are calculated according to Table 3.3 for different values of $n$ or $m$, and are shown in 0 .

Table 3.4. Geometric Parameters of the Standard Helical Antenna.

\begin{tabular}{cccc}
\hline$D$ & $S$ & $\tan \alpha$ & $N$ \\
\hline $48 \mathrm{~mm}$ & $37 \mathrm{~mm}$ & 0.245 & 3 \\
\hline
\end{tabular}


Table 3.5. Calculated Parameters of Equivalent Origami Helical Antennas with Different Folding Patterns.

\begin{tabular}{|c|c|c|c|}
\hline & $m=13$ & $m=15$ & $m=18$ \\
\hline \multirow{3}{*}{$n=4$} & $\begin{array}{c}a=37.7 \mathrm{~mm} \\
\text { ratio }=0.95 \\
\theta=81.5^{\circ}\end{array}$ & $\begin{array}{c}a=37.7 \mathrm{~mm} \\
\text { ratio }=0.82 \\
\theta=689^{\circ}\end{array}$ & $\begin{array}{c}a=37.7 \mathrm{~mm} \\
\text { ratio }=0.69 \\
\theta=56.3^{\circ}\end{array}$ \\
\hline & & & \\
\hline & $n=4$ & $n=5$ & $n=6$ \\
\hline \multirow{4}{*}{$m=13$} & $\begin{array}{c}a=37.7 \mathrm{~mm} \\
\text { ratio }=0.95 \\
\theta=81.5^{\circ}\end{array}$ & $\begin{array}{c}a=30.2 \mathrm{~mm} \\
\text { ratio }=1.19 \\
\theta=85.4^{\circ}\end{array}$ & $\begin{array}{c}a=25.1 \mathrm{~mm} \\
\text { ratio }=1.43 \\
\theta=87.6^{\circ}\end{array}$ \\
\hline & & & 4 \\
\hline & & 1 & 12 \\
\hline & & & 8 \\
\hline
\end{tabular}

The simulated $S_{11}$ of both the standard helical antenna and the equivalent origami helical antennas are shown in Figure 3.6. The offset distances between these antennas and their corresponding ground planes are kept the same, so are the radii of their circular ground planes and the widths and thicknesses of their copper traces. All the models are excited with $50 \Omega$ SMA connectors. The simulated performances between the proposed standard helical antenna and its equivalent origami helical antennas are listed in Table 3.6. In the 3$\mathrm{dB}$ gain bandwidths, the side lobes stay $10 \mathrm{~dB}$ lower than the main lobe for all the antennas. 


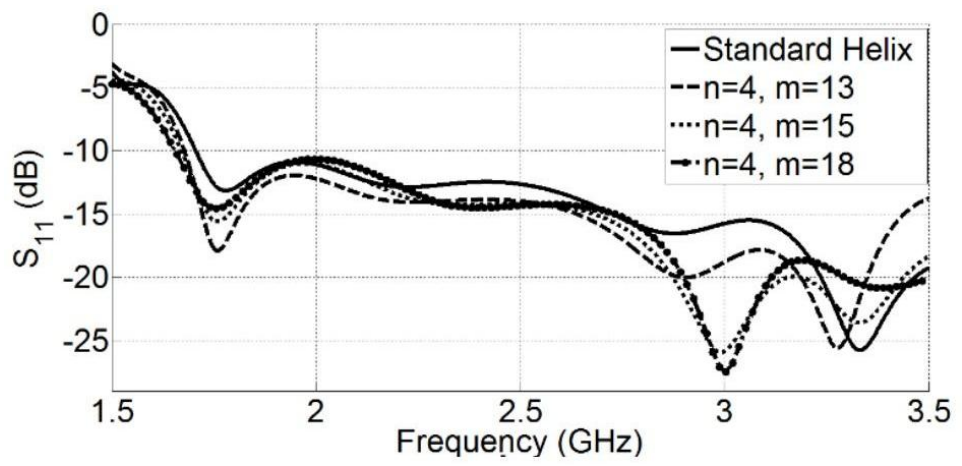

(a)

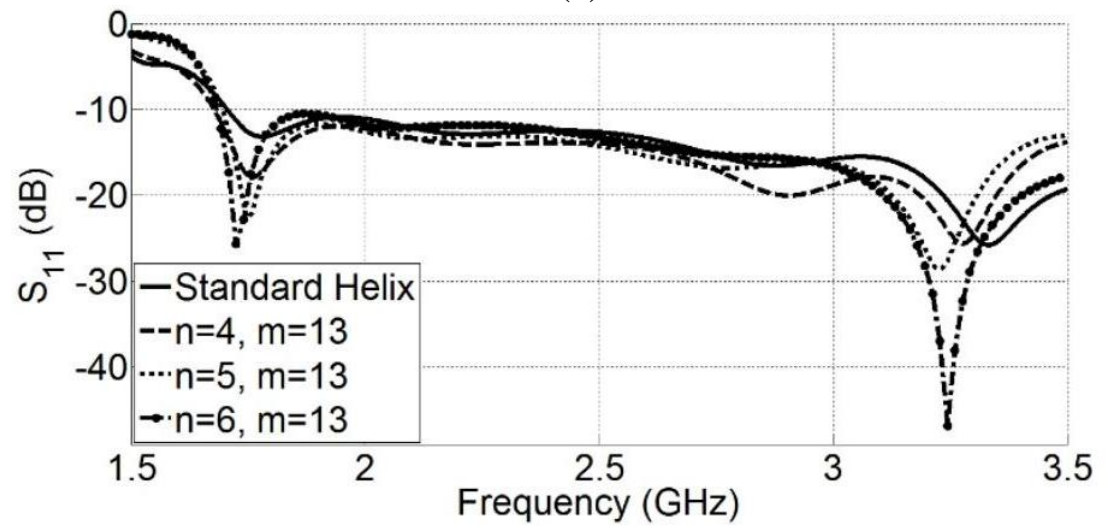

(b)

Figure 3.6. Comparison of $S_{11}$ of a standard helical monofilar antenna and its equivalent origami helical monofilar antennas: (a) equivalent origami helix with $n=4$, $m=13,15$, 18; (b) equivalent origami helix with $m=13, n=4,5,6$.

The following conclusions can be drawn from Table 3.6:

1) The equivalent origami helical antennas can operate equally well to the standard helical antenna in terms of maximum gain $(<1 \mathrm{~dB}$ difference) and $3-\mathrm{dB}$ gain bandwidth $( \pm 2.6 \%$ difference $)$.

2) The RHCP bandwidth of the standard antenna is $5.1 \%-10.8 \%$ larger than that of the equivalent origami antennas. 
3) A different $m$ or $n$ in the origami pattern will change the geometry of the origami antenna, and a larger $n$ improves the $\mathrm{CP}$ bandwidth because the $n$-side polygon at the intersection of the origami helix has a geometry that resembles a circle more closely.

Table 3.6. Performance Comparison of Standard Helical Monofilar Antenna and Its Equivalent Origami Helical Monofilar Antennas.

\begin{tabular}{|c|c|c|c|c|}
\hline \multicolumn{2}{|c|}{ Antennas } & $\begin{array}{l}\text { 3-dB Gain } \\
\text { Bandwidth }\end{array}$ & $\begin{array}{l}\text { RHCP Bandwidth } \\
\text { (axial ratio }<3 \mathrm{~dB} \text { ) }\end{array}$ & $\begin{array}{c}\text { Maximum } \\
\text { Realized Gain }\end{array}$ \\
\hline \multicolumn{2}{|c|}{ Standard Helix } & $\begin{array}{c}1.75-3.3 \mathrm{GHz} \\
(1.89: 1)\end{array}$ & $\begin{array}{c}1.78-3.3 \mathrm{GHz} \\
(1.85: 1)\end{array}$ & $12.87 \mathrm{~dB}$ \\
\hline \multirow{3}{*}{$\begin{array}{c}\text { Origami } \\
\text { Helix }\end{array}$} & $\begin{array}{c}n=4 \\
m=13\end{array}$ & $\begin{array}{c}1.65-3.15 \mathrm{GHz} \\
(1.91: 1)\end{array}$ & $\begin{array}{c}1.89-3.15 \mathrm{GHz} \\
(1.67: 1)\end{array}$ & $12.23 \mathrm{~dB}$ \\
\hline & $\begin{array}{c}n=4 \\
m=15\end{array}$ & $\begin{array}{c}1.7-3.2 \mathrm{GHz} \\
(1.88: 1)\end{array}$ & $\begin{array}{c}1.87-3.2 \mathrm{GHz} \\
(1.71: 1)\end{array}$ & $12.29 \mathrm{~dB}$ \\
\hline & $\begin{array}{c}n=4 \\
m=18\end{array}$ & $\begin{array}{c}1.65-3.1 \mathrm{GHz} \\
(1.88: 1)\end{array}$ & $\begin{array}{c}1.81-3.1 \mathrm{GHz} \\
(1.71: 1)\end{array}$ & $12.28 \mathrm{~dB}$ \\
\hline \multirow{3}{*}{$\begin{array}{c}\text { Origami } \\
\text { Helix }\end{array}$} & $\begin{array}{c}n=4 \\
m=13\end{array}$ & $\begin{array}{c}1.65-3.15 \mathrm{GHz} \\
(1.9: 1)\end{array}$ & $\begin{array}{c}1.89-3.15 \mathrm{GHz} \\
(1.67: 1)\end{array}$ & $12.23 \mathrm{~dB}$ \\
\hline & $\begin{array}{c}n=5 \\
m=13\end{array}$ & $\begin{array}{c}1.7-3.25 \mathrm{GHz} \\
(1.91: 1)\end{array}$ & $\begin{array}{c}1.88-3.25 \mathrm{GHz} \\
(1.73: 1)\end{array}$ & $11.94 \mathrm{~dB}$ \\
\hline & $\begin{array}{c}n=6 \\
m=13\end{array}$ & $\begin{array}{c}1.7-3.3 \mathrm{GHz} \\
(1.94: 1)\end{array}$ & $\begin{array}{c}1.88-3.3 \mathrm{GHz} \\
(1.76: 1)\end{array}$ & $12.08 \mathrm{~dB}$ \\
\hline
\end{tabular}

Based on Table 3.2, reconfigurable origami helical antennas that can operate at various frequencies of interest can be parametrically modeled and designed. As an example, a bifilar reconfigurable origami helical antenna is presented in 3.4. Furthermore, the proposed origami helical antennas can be folded to fit in compact storage/launching compartments thereby providing significant savings of volume for space-borne and airborne applications, such as, satellites. 
For an origami cylinder to be collapsible to a compact volume, then the diagonal length, $c$, of one parallelogram unit in the origami pattern in Figure 3.2 should be less than the diameter of the origami cylinder, $2 r$, in Figure 3.4 when the origami cylinder is completed collapsed $(h \approx 0)$. When a collapsible origami cylinder substrate is folded and completely collapsed, the height of each layer $h=4 t$ where $t$ is the thickness of the substrate, so the total height of the collapsed origami cylinder structure is $4 m t$. On the other hand, when the origami cylinder structure is fully deployed, it has a total height of $m b \sin (\beta+\gamma)$.

Since the footprint of the origami cylinder structure can be expressed as $\frac{n^{2} a^{2}}{4 \pi}$, the minimum and maximum volume of a collapsible origami cylinder are respectively expressed as:

$$
\begin{gathered}
\text { Volume }_{\text {min }}=\frac{m n^{2} a^{2}}{\pi} \\
\text { Volume }_{\text {max }}=\frac{m b \sin (\beta+\gamma) n^{2} a^{2}}{4 \pi}
\end{gathered}
$$

To quantify the volume savings achieved by this collapsible origami cylinder when it is stored, the compactness factor is defined as the ratio between the maximum and minimum volume of a collapsible origami cylinder, and is expressed in Eqn. (3.8).

$$
F_{\text {compact }}=\frac{\text { Volume }_{\text {max }}}{\text { Volume }_{\text {min }}}=\frac{b \sin (\beta+\gamma)}{4 t}
$$

When $c \in R^{+}$and $c<2 r$, by applying expressions of $\beta$ and $\gamma$ in Table 3.2, the compactness factor depends only on the geometric parameters ( $n, a$ and ratio) defined in Figure 3.2 and thickness $t$ of the origami pattern, as shown in Eqn. (3.9). 


$$
F_{\text {compact }}=\frac{a \cdot \text { ratio }}{4 t} \sin \left\{\frac{\pi}{n}+\sin ^{-1}\left[\text { ratio } \cdot \sin \left(\frac{\pi}{n}\right)\right]\right\}
$$

The plots of compactness factor versus each parameter for a collapsible origami cylinder are shown in Figure 3.7. It is shown in Figure 3.7 (a)-(c) that $F_{\text {compact }}$ is proportional to $a$ and the ratio, and inversely proportional to $t$, regardless the values of all other parameters. Also, Figure 3.7(c) shows that an optimum value of ratio exists for each different $n$, which provides the maximum compactness factor, $F_{\text {compact }}$. Also, when ratio is fixed, an optimum $n$ needs to be selected to achieve the maximum $F_{\text {compact }}$. Furthermore, when $n$ increases, the maximum $F_{\text {compact }}$ also increases.

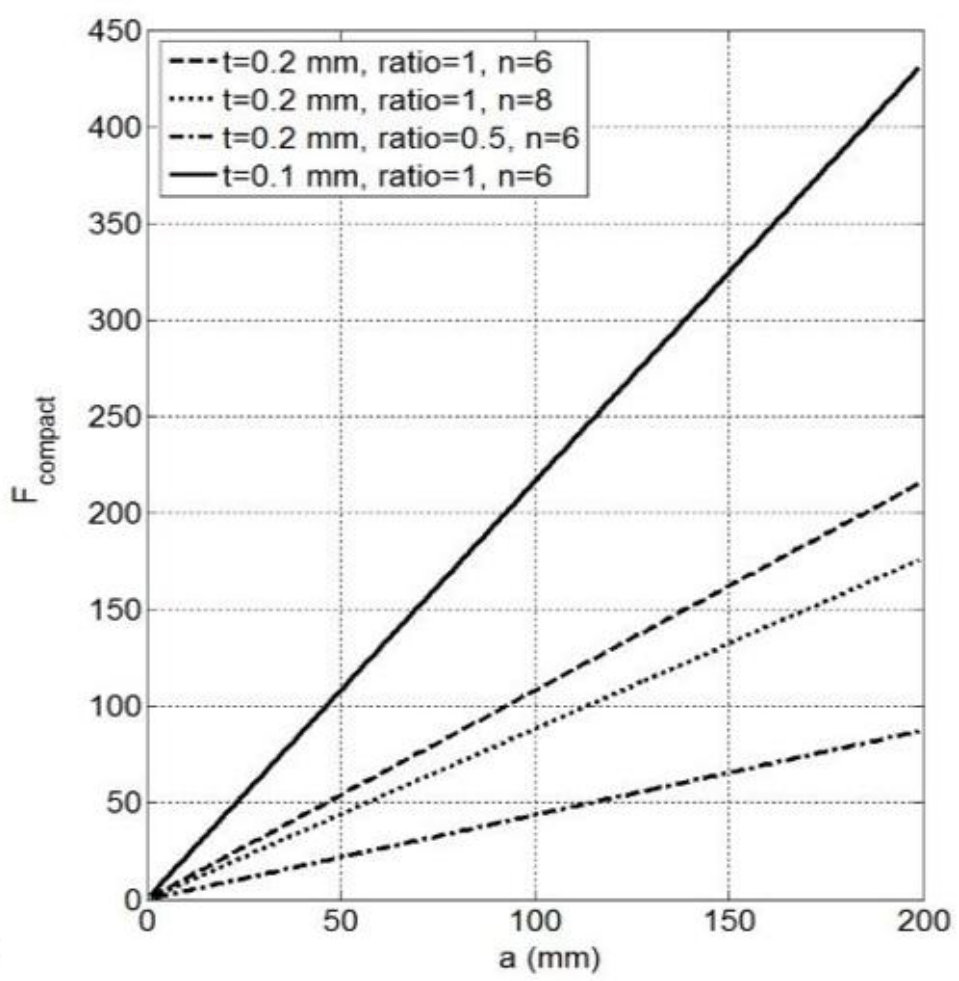

(a) 


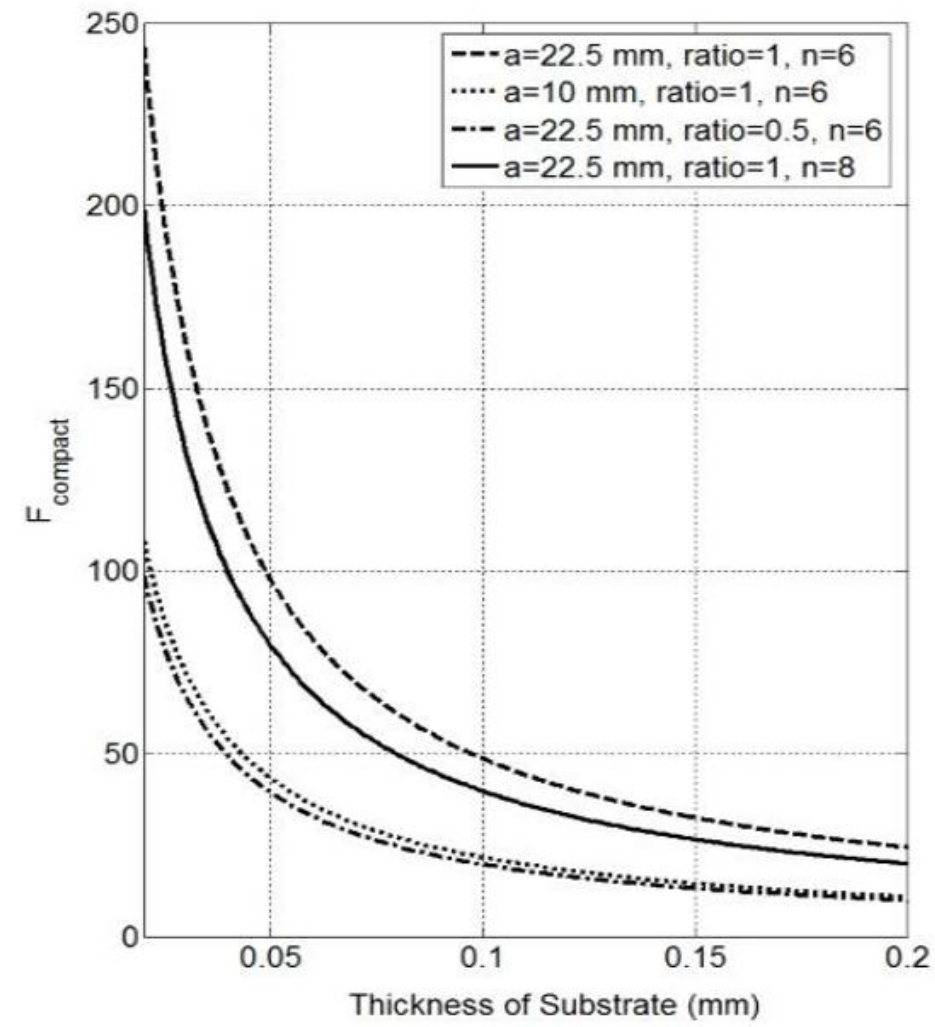

(b)

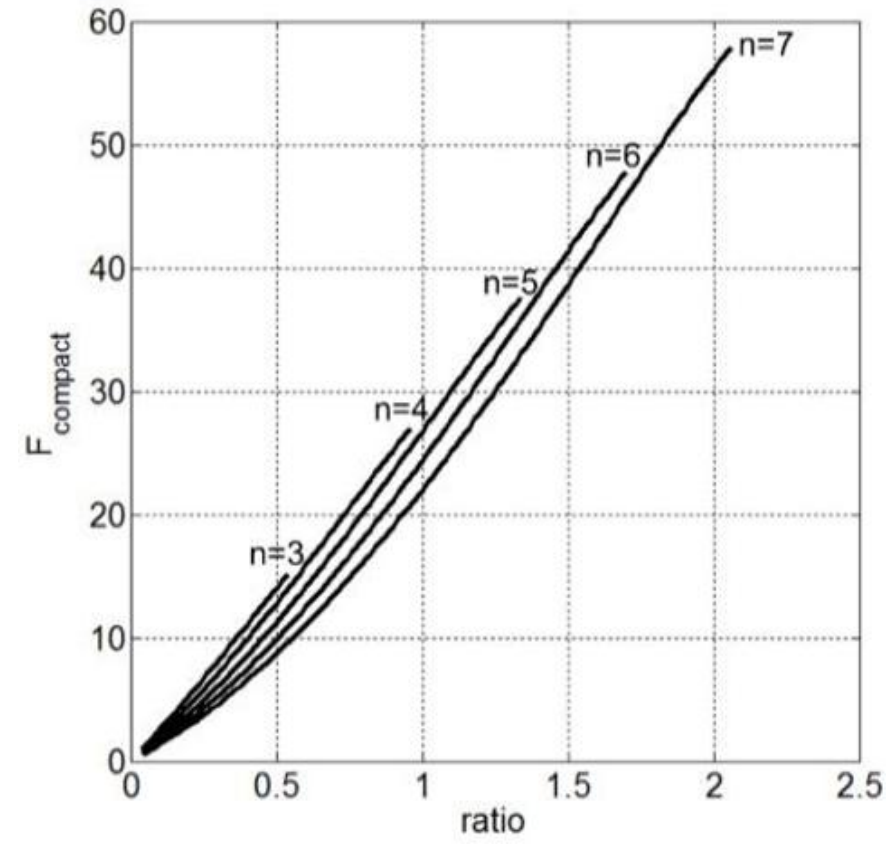

(c)

Figure 3.7. Compactness factor vs.: (a) the length, $a$, of each parallelogram unit in the origami pattern; (b) thickness of substrate $\mathrm{t}(\mathrm{mm})$; (c) ratio of $b / a$ with $a=22.5 \mathrm{~mm}$ and $t=0.2 \mathrm{~mm}$. 
Using Table 3.1 and Table 3.3 , and by applying $\lambda_{0}=\frac{c}{f_{0}}$, we can conclude that the empirical operational frequency range of an origami monofilar helical antenna is:

$$
\frac{3 c}{4 n a}<f_{0}<\frac{4 c}{3 n a}
$$

or

$$
\left.f_{0} \approx c / \sqrt[4 n]{\frac{b^{2} \cdot \sin ^{2}\left(\frac{\pi}{n}\right)}{\sin ^{2}\left(\frac{\theta}{2}\right)}-a^{2}}\right)
$$

where $c$ is the speed of light. Also, the proposed origami helical antenna can be designed to achieve optimal gain at multiple frequencies in the frequency range of Eqn. 3.10 and exhibit frequency reconfigurability by changing $\theta$, as shown by Eqn. 3.11.

\subsection{Reconfigurable Helical Antenna Based on Origami Neoprene with High Radiation Efficiency}

\subsubsection{Antenna Geometry}

This paper presents a novel way of building a reconfigurable helical antenna that improves its mechanical robustness. The origami folding pattern of the cylindrical base is shown in Figure 3.8 (a), where the conductive trace is placed along the diagonal lines in the parallelogram unit to achieve more turns than along the side $b$. The folded antenna based on the cylindrical origami substrate is shown in Figure 3.8 (b). The geometrical parameters are listed in Table 3.7. 


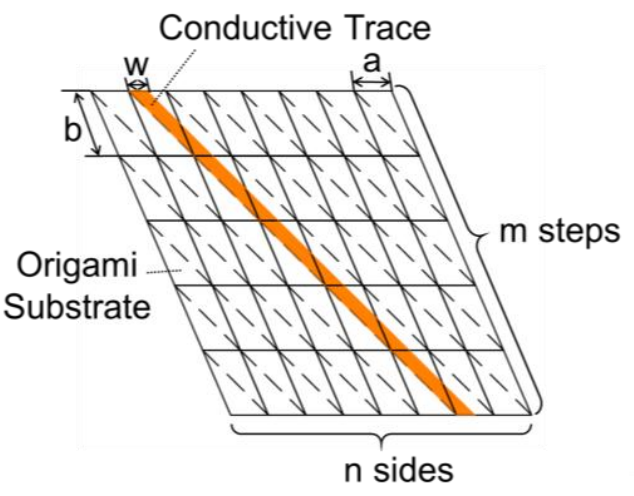

(a)

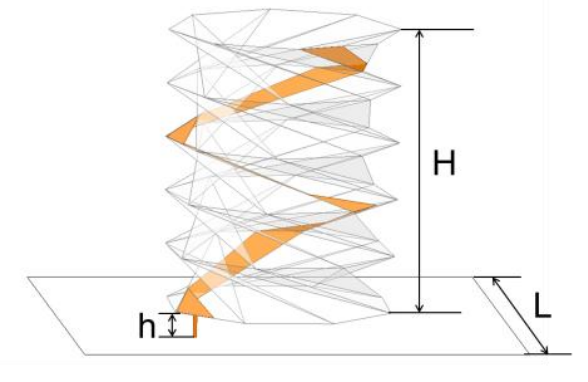

(b)

Figure 3.8. Geometry of: (a) origami pattern, and (b) folded antenna.

Table 3.7. Values of Geometrical Parameters of the Antenna.

\begin{tabular}{|c|c|c|c|c|c|c|}
\hline$m$ & $n$ & $w$ & $a$ & $b$ & $h$ & $L$ \\
\hline 5 & 8 & $18 \mathrm{~mm}$ & $40 \mathrm{~mm}$ & $75 \mathrm{~mm}$ & $5 \mathrm{~mm}$ & $200 \mathrm{~mm}$ \\
\hline
\end{tabular}

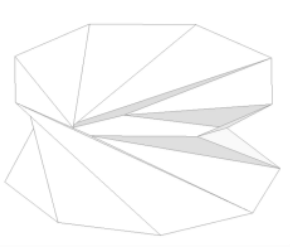

(a)

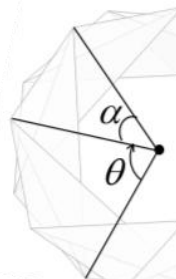

(b)

Figure 3.9. Model of one step: (a) perspective view, and (b) top view.

The total height $H$ and number of turns $N$ of the antenna are expressed below:

$$
\begin{gathered}
H=m \cdot \sqrt{b^{2} \cdot \frac{\sin ^{2}\left(\frac{\alpha}{2}\right)}{\sin ^{2}\left(\frac{\theta}{2}\right)}-a^{2}} \\
N=\frac{m \cdot(\alpha+\theta)}{360^{\circ}}
\end{gathered}
$$

where $\theta$ is the folding angle between adjacent step, and $\alpha$ is the inner angle between two radial lines in the n-polygonal plane, as shown in Figure 3.9 (b). 


\subsubsection{Prototype of the Helical Antenna}

Neoprene can withstand extreme temperature and weather and has exceptional durability. Therefore, it is used here as the origami base for our antenna. The origami folding pattern on the neoprene substrate can be generated by preheating the neoprene, placing it inside a heated metal mold cavity and then applying pressure. A $0.1 \mathrm{~mm}$-thick polyester fiber cloth coated with high conductive copper and nickel is used as the antenna conductive trace to achieve abrasion and high temperature resistance, excellent flexibility and conduction. This conductive cloth is sewn onto the 3-mm thick neoprene substrate using conductive textile threads [30], as shown in Figure 3.10. At the unfolded state $H=310 \mathrm{~mm}$ and $N=1.29$; while at the folded state $H=125 \mathrm{~mm}$ and $N=1.8$.

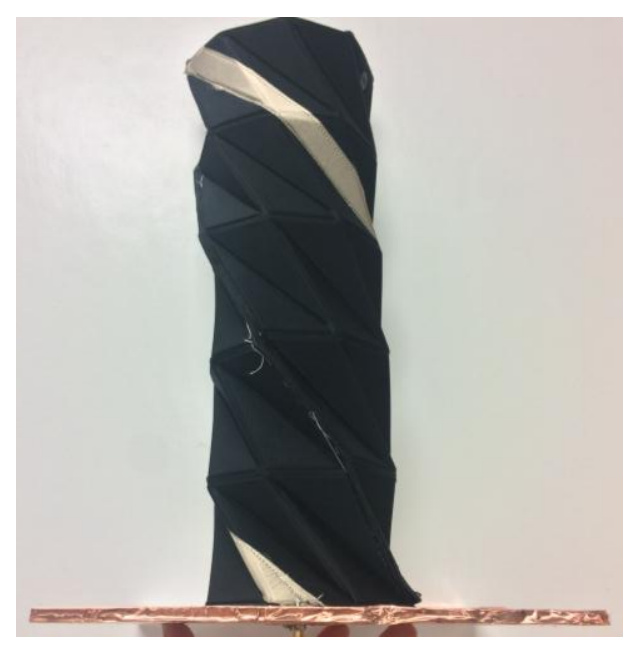

(a)

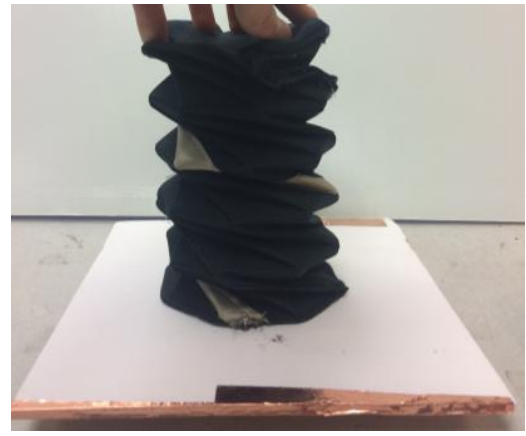

(b)

Figure 3.10. Prototype of the helical antenna on Neoprene at: (a) unfolded state, and (b) folded state.

\subsubsection{Simulated and Measured Results}

The antenna was simulated in ANSYS HFSS and measured with Agilent VNA and StarLab Anechoic Chamber. The simulated and measured $S_{11}$ is shown in Figure 3.11. It 
can be seen that the simulated resonant frequencies are higher than the measured ones, which is because of the effect of the neoprene substrate, which is not included in simulation.

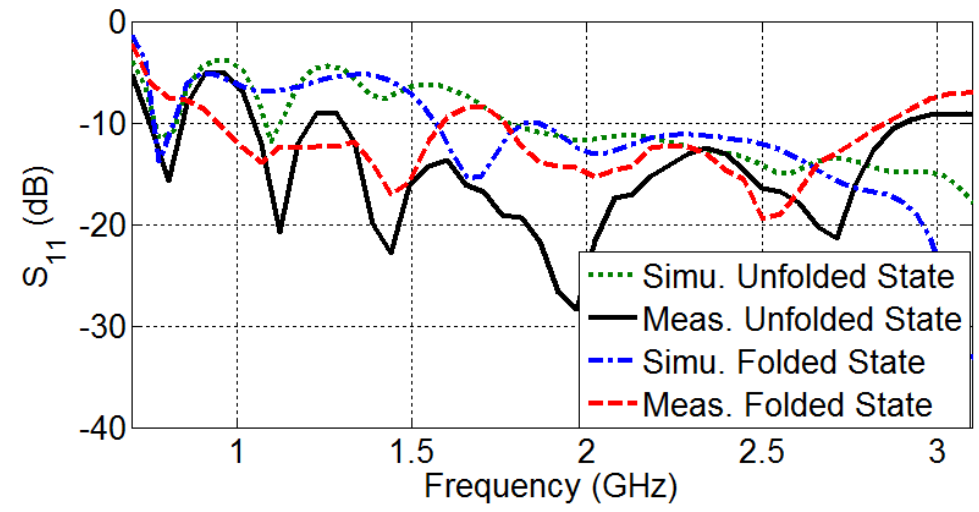

Figure 3.11. Simulated and measured $S_{11}$ at unfolded and folded states.

The simulated and measured realized gain and AR are compared in Figure 3.12-

Figure 3.13, and the measured results are summarized in Table 3.8. It is verified that the helical antenna on neoprene radiates directionally at the two states and achieves reconfigurable frequency in wide bandwidth with maximum gain of at least $9.2 \mathrm{~dB}$ at the two states. Also, the prototype fabricated with conductive polyester on neoprene substrate has very good radiation efficiency, which is greater than $80 \%$, as shown in Figure 3.14. Furthermore, this antenna exhibits improved robustness compared to origami antennas made on flexible substrates, such as, paper and Kapton. Therefore, this antenna is a good candidate for real-world applications as it can easily deploy/collapse and reconfigure its performance while maintaining it mechanical performance through a large number of folding/unfolding cycles without experiencing cracking of the substrate or the conductive trace. 


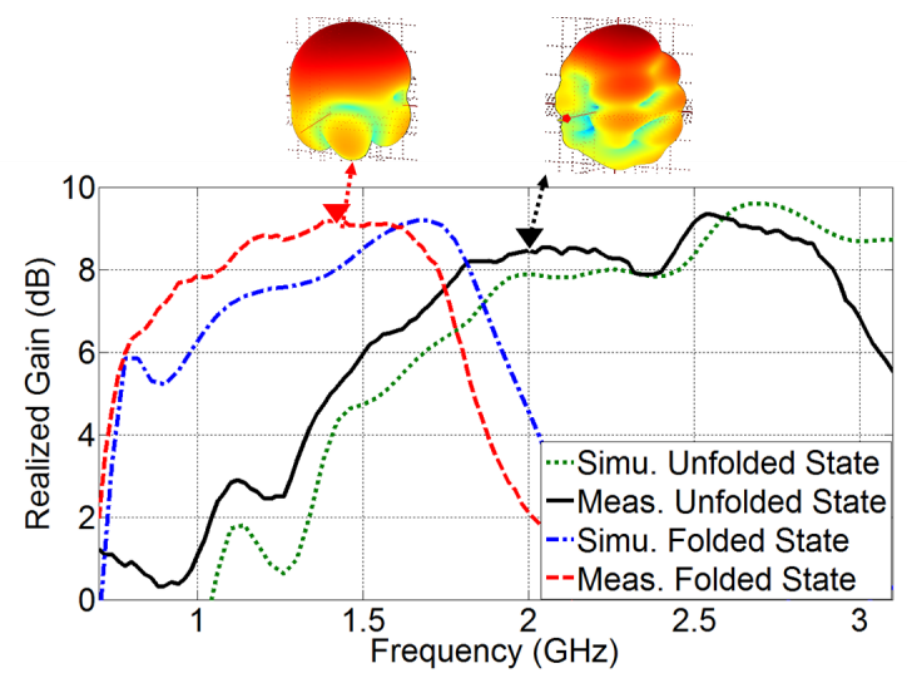

Figure 3.12. Simulated and measured realized gain at unfolded and folded states.

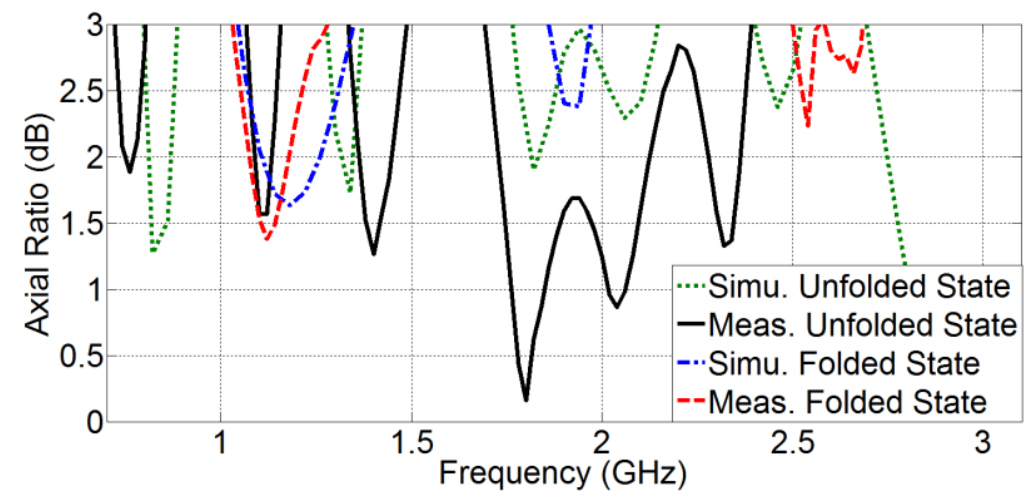

Figure 3.13. Simulated and measured AR at unfolded and folded states.

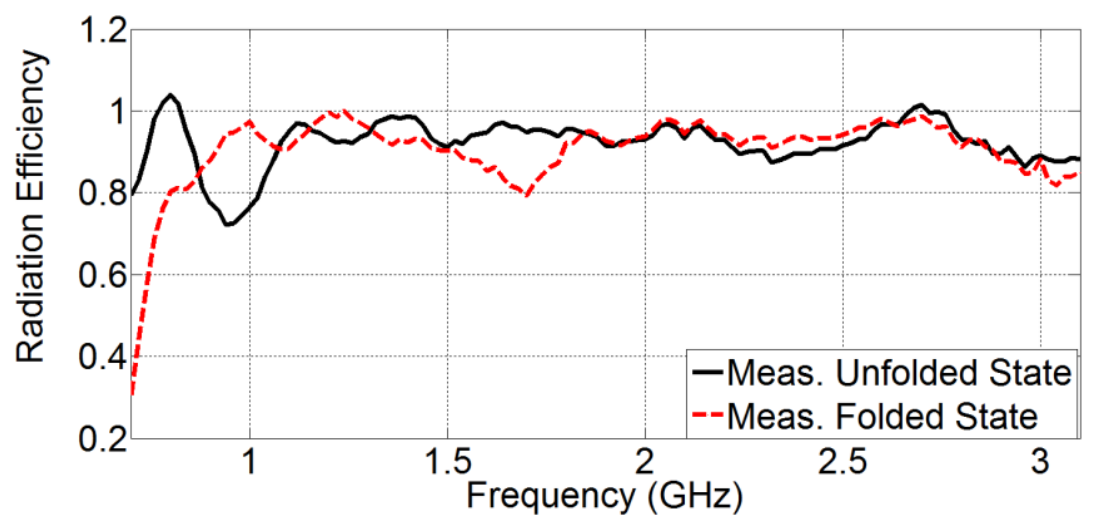

Figure 3.14. Measured radiation efficiency at unfolded and folded states. 
Table 3.8. Summarized Measured Results of The Antenna.

\begin{tabular}{|c|c|c|c|}
\hline & Max. Realized Gain & 3-dB Realized Gain BW & CP BW (AR<3 dB) \\
\hline Unfolded State & $9.4 \mathrm{~dB}$ & $1.56 \mathrm{GHz}-3.04 \mathrm{GHz}(64.3 \%)$ & $2.57 \mathrm{GHz}-2.8 \mathrm{GHz}(8.6 \%)$ \\
\hline Folded State & $9.2 \mathrm{~dB}$ & $0.8 \mathrm{GHz}-1.78 \mathrm{GHz}(76 \%)$ & $1.04 \mathrm{GHz}-1.28 \mathrm{GHz}(20.7 \%)$ \\
\hline
\end{tabular}

\subsection{Reconfigurable Origami Bifilar Helical Antenna}

Here, an example of an origami bifilar antenna is shown in Figure 3.15. One helix is connected to the signal excitation (center conductor of SMA) and another identical helix is grounded for more symmetric radiation patterns especially at lower resonant frequencies. Moreover, the grounded helix enables the bifilar helical antenna to operate in axial mode at its lowest resonant frequency, which occurs when it is fully deployed (i.e., helix is deployed to its maximum height).

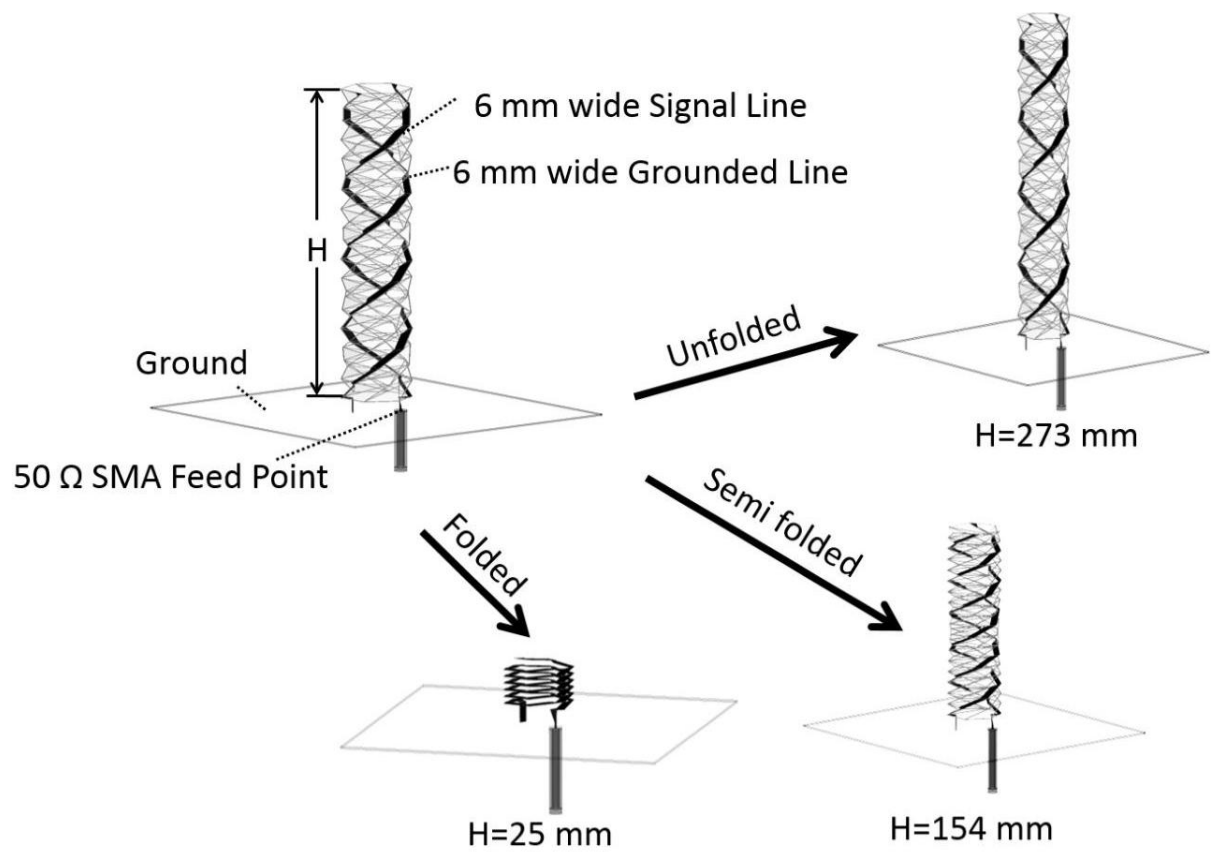

Figure 3.15. Origami bifilar helical antenna model at different states of $H$.

The height of the antenna can vary as the origami structure can collapse and expand. The total height of this antenna is $H=m \cdot h$. The number of steps $m=18$, the number of sides $n=6$, the side length of each parallelogram unit in the pattern $a=22.5 \mathrm{~mm}$, and the ratio $=1$. 
The side length of the square ground is $200 \mathrm{~mm}$. A polyethylene base $\left(\varepsilon_{r}=1.2\right)$ is placed between the antenna and the ground in the prototype to provide a physical support for the antenna and prevent it from being shorted. The prototype of the origami bifilar is shown in Figure 3.16. This antenna was constructed using $0.1 \mathrm{~mm}$ thick copper tape on $0.2 \mathrm{~mm}$ thick sketching-paper substrate without any coating. The height, $H$, of the prototype antenna is controlled by applying a force at its top face.

The compactness factor of this reconfigurable bifilar helical antenna according to Eqn. 12.9 is 24.36 . Figure 3.7 (c) shows that for $n=6$, the optimum compactness factor of 47.79 is achieved when ratio $=1.7$. While for ratio $=1$, the optimum compactness factor of 26.75 is achieved when $n=5$.

The simulated and measured $S_{11}$ for three different heights $H$, is illustrated in Figure 3.17. The simulated and measured realized gains at zenith for the fully unfolded state $(H=273 \mathrm{~mm})$, the semi-folded state $(H=154 \mathrm{~mm})$ and the fully folded state $(H=25 \mathrm{~mm})$ in different operating frequency bands are illustrated in Figure 3.18. The operating frequencies of each state are depicted with solid triangles in Figure 3.18. The measured results validate that this collapsible reconfigurable origami bifilar helical antenna can operate at different frequencies by changing its height. 


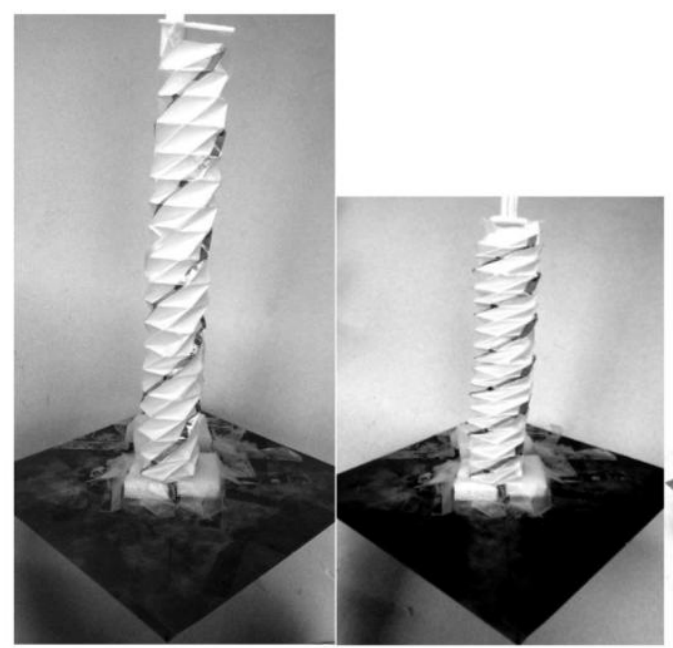

(a)

(b)

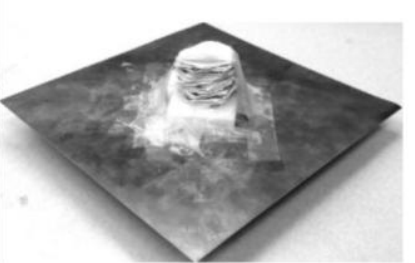

(c)

Figure 3.16. Prototype of reconfigurable origami bifilar helical antenna with different heights $H$ : (a) $H=273 \mathrm{~mm}$; (b) $H=154 \mathrm{~mm}$; (c) $H=25 \mathrm{~mm}$.

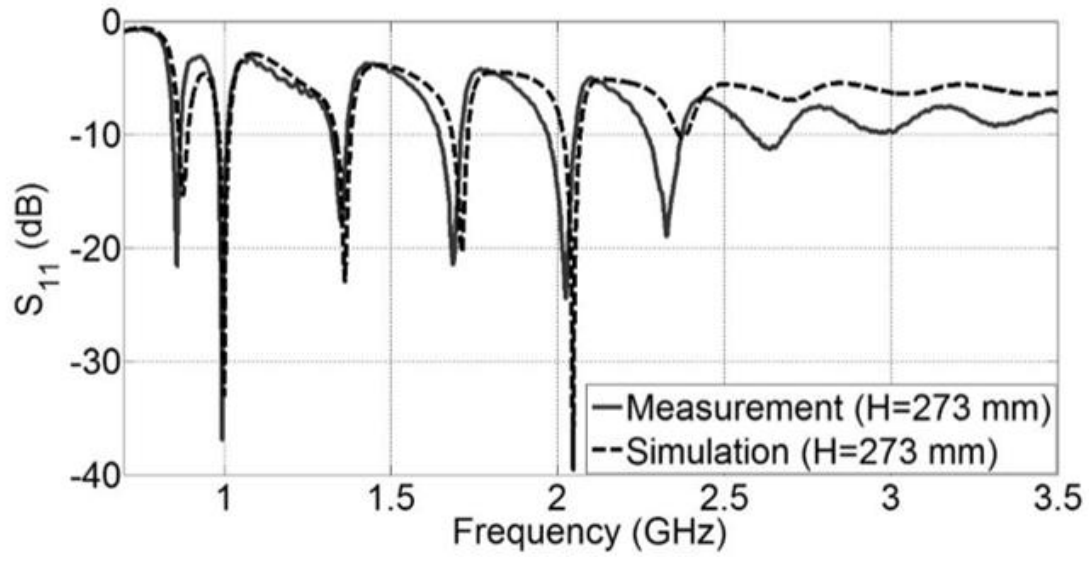

(a)

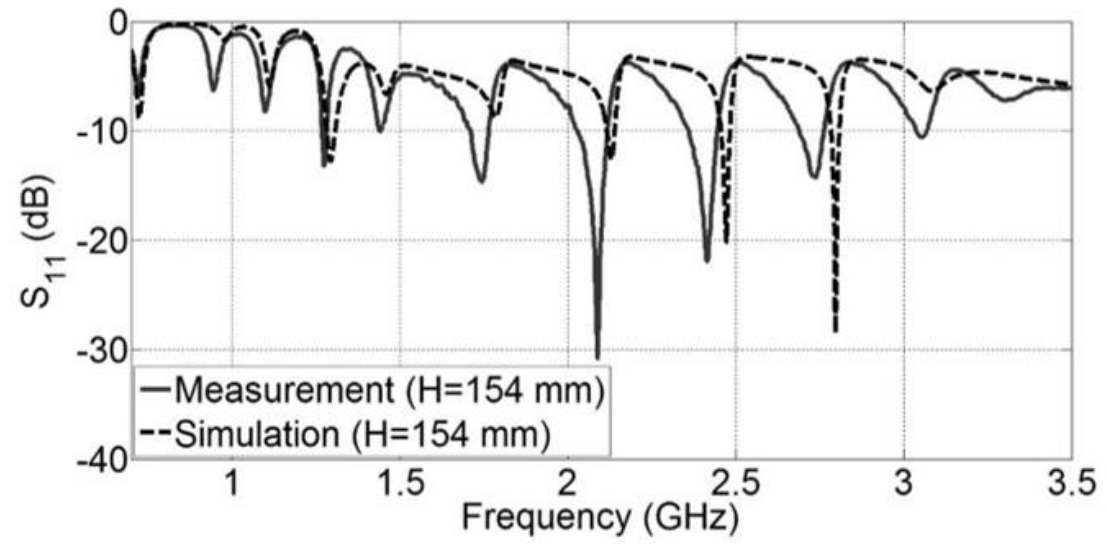

(b) 


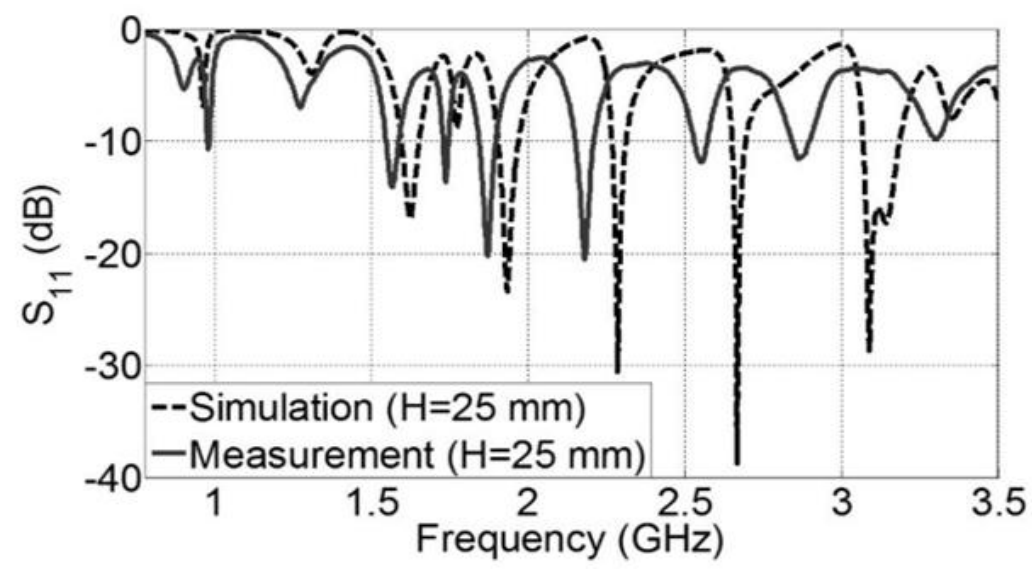

(c)

Figure 3.17. Return loss of origami bifilar helix for different antenna heights, $H$.

The differences between simulated and measured results occurring in Figure 3.17 and Figure 3.18 can be attributed to the fact that the prototype was constructed manually.

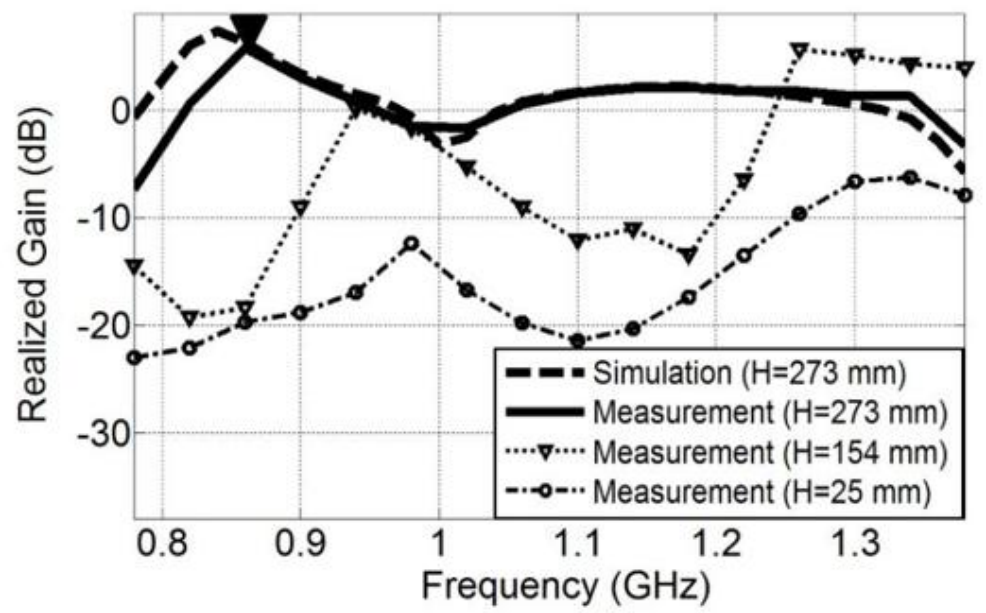

(a) 


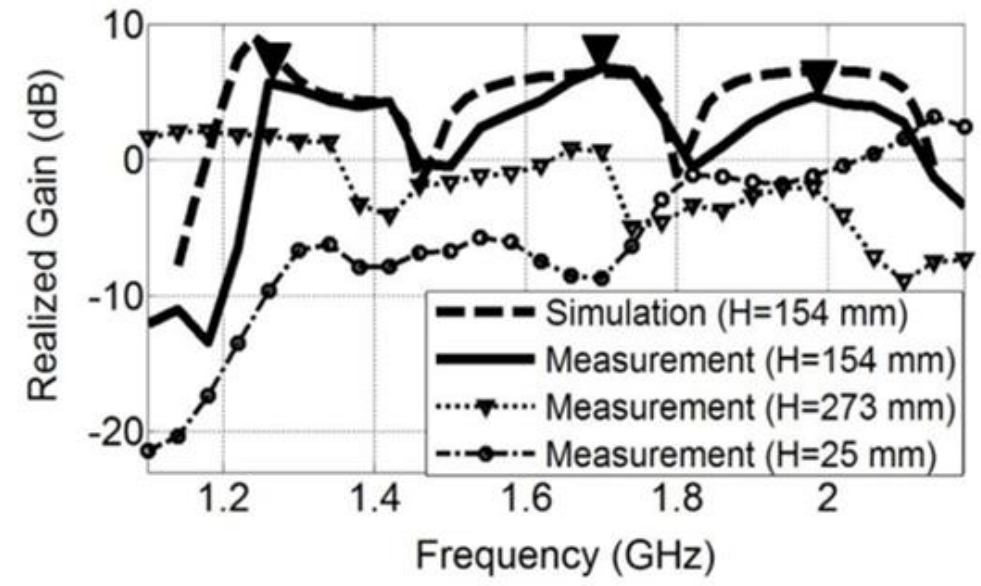

(b)

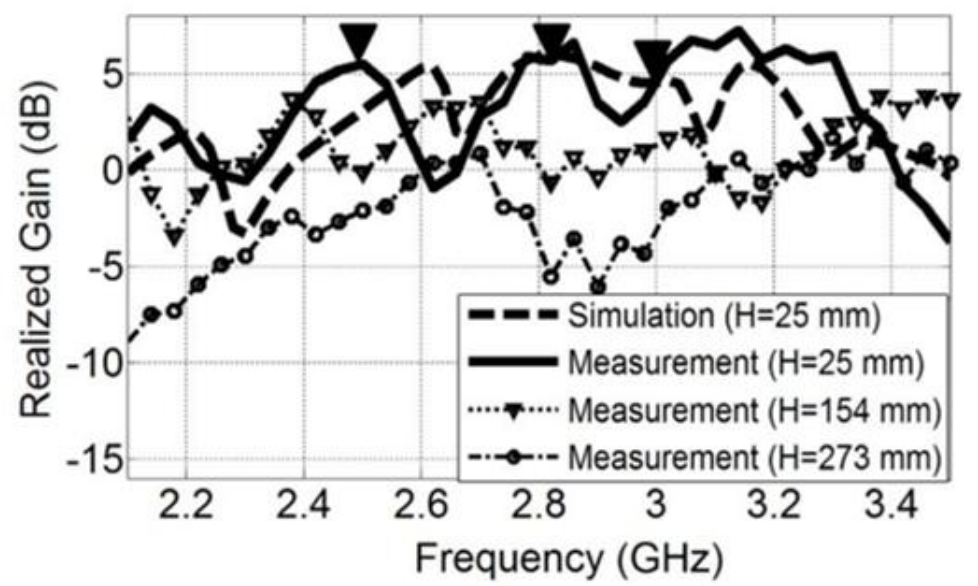

(c)

Figure 3.18. Realized gain at zenith for three heights of the origami bifilar helix in three different operating frequency bands.

It should be also noted that this origami bifilar helical antenna is designed to operate in axial mode at all the indicated operating frequencies of the three states (i.e., heights). Table 3.9 shows that each state exhibits a higher gain at its own operating frequencies than the gains of the other two states at these frequencies.

Table 3.10 illustrates the measured performances of the origami antenna for three different antenna heights. Measured AR validated that this antenna is circularly polarized $(\mathrm{AR}<2 \mathrm{~dB}$ ) at $1.27 \mathrm{GHz}, 1.7 \mathrm{GHz}$ and $1.98 \mathrm{GHz}$ when $H=154 \mathrm{~mm}$, while at the other two 
states when $H=273 \mathrm{~mm}$ and $H=25 \mathrm{~mm}$, this antenna operates with either linear or elliptical polarization.

The normalized elevation-plane patterns are shown in Figure 3.19 at the operating frequencies of each state. Figure 3.19 illustrates that this origami bifilar helical antenna operates in axial mode at all the listed operating frequencies above with maximum gain at zenith. It is seen that at higher operating frequencies the back lobes become smaller, which is expected since at higher frequencies the ground plane is electrically larger.

Table 3.9. Measured Realized Gain $(\mathrm{dB})$ at the Operating Frequencies of the 3 States of the Origami Bifilar Helix.

\begin{tabular}{cccccccc}
\hline \multirow{2}{*}{$\begin{array}{c}\text { Antenna Height } H \\
(\mathrm{~mm})\end{array}$} & 0.86 & 1.27 & 1.7 & 1.98 & 2.49 & 2.81 & 3 \\
\cline { 2 - 8 } & 5.85 & 1.80 & -0.58 & -2.06 & -2.11 & -5.54 & -2.00 \\
\hline 273 & -18.35 & 6.53 & 6.79 & 4.69 & -0.13 & -0.69 & 1.62 \\
\hline 154 & -19.73 & -9.63 & -8.7 & -1.18 & 5.98 & 5.81 & 5.70 \\
\hline 25 & & & & &
\end{tabular}

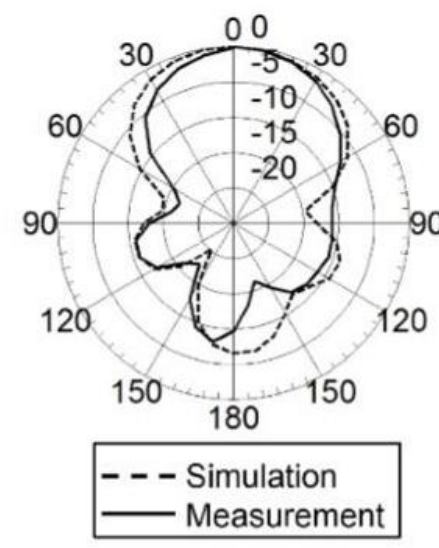

(a)

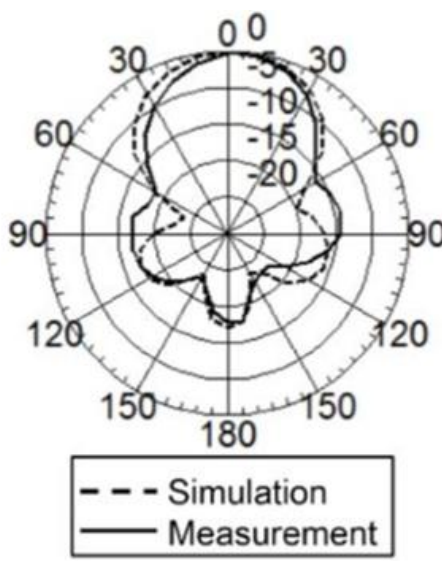

(b)

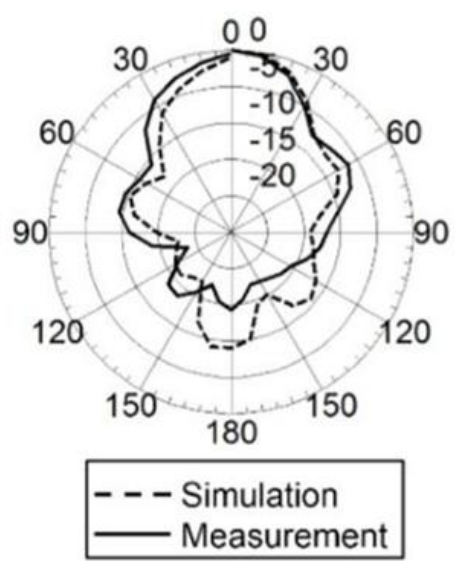

(c) 


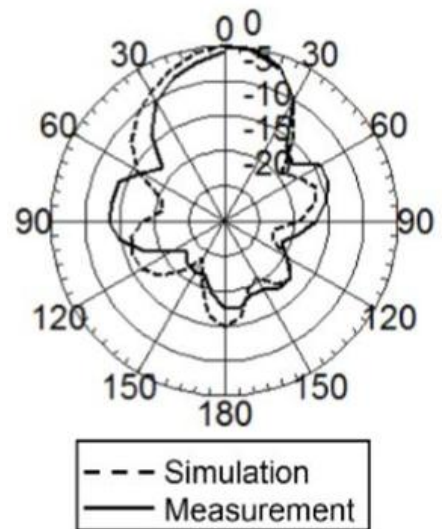

(d)

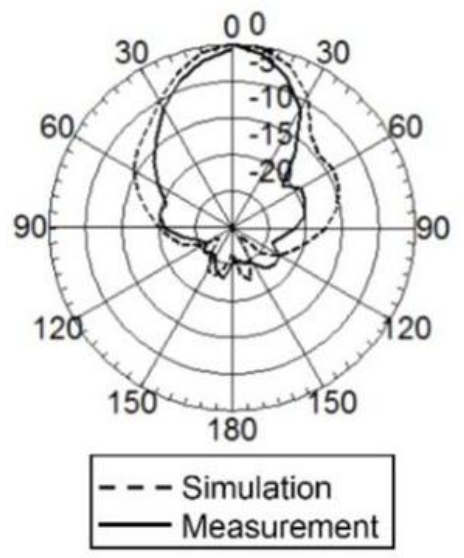

(f)

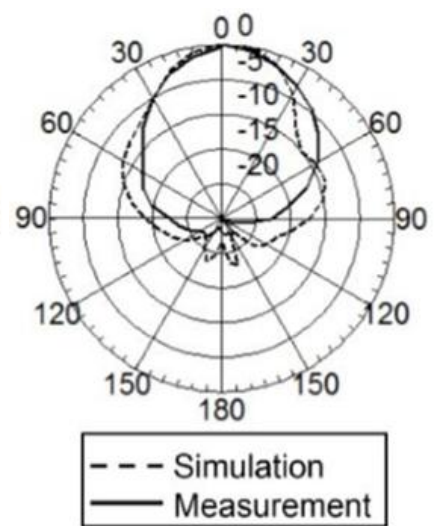

(e)

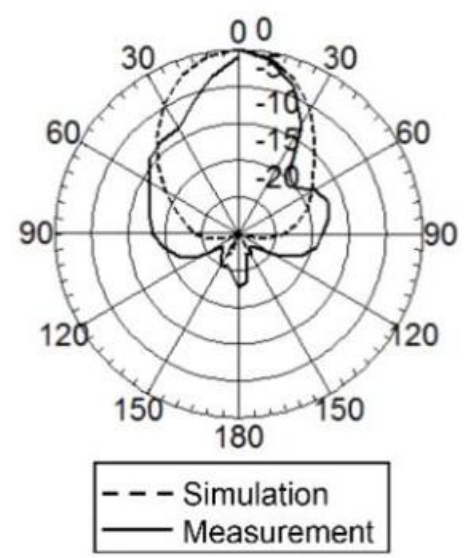

(g)

Figure 3.19. Normalized elevation patterns of the origami bifilar helical antenna at the operating frequencies of the three states (i.e., Heights): (a) $H=273 \mathrm{~mm}$ at $0.86 \mathrm{GHz}$; (b) $H=154 \mathrm{~mm}$ at $1.27 \mathrm{GHz}$; (c) $H=154 \mathrm{~mm}$ at $1.7 \mathrm{GHz}$; (d) $H=154 \mathrm{~mm}$ at $1.98 \mathrm{GHz}$; (e) $H=25 \mathrm{~mm}$ at $2.49 \mathrm{GHz}$; (f) $H=25 \mathrm{~mm}$ at $2.81 \mathrm{GHz}$; (g) $H=25 \mathrm{~mm}$ at $3 \mathrm{GHz}$.

Table 3.10. Measured Performances of the Bifilar Helical Origami Antenna for Three Different Heights.

\begin{tabular}{|c|c|c|c|c|c|c|c|}
\hline \multirow[b]{3}{*}{ Operating Frequency $(\mathrm{GHz})$} & \multicolumn{7}{|c|}{ Antenna Height $H(\mathrm{~mm})$} \\
\hline & \multirow{2}{*}{$\begin{array}{c}273 \\
0.86\end{array}$} & \multicolumn{3}{|c|}{154} & \multicolumn{3}{|c|}{25} \\
\hline & & 1.27 & 1.7 & 1.98 & 2.49 & 2.81 & 3 \\
\hline $\begin{array}{l}\text { Measured Realized Gain } \\
(\mathrm{dB})\end{array}$ & 5.85 & 6.53 & 6.79 & 4.69 & 5.98 & 5.81 & 5.7 \\
\hline Measured E-Plane BW $\left(^{\circ}\right)$ & 82 & 59 & 45 & 44 & 61 & 44 & 41 \\
\hline Measured H-Plane BW $\left(^{\circ}\right)$ & 75 & 50 & 44 & 40 & 57 & 46 & 40 \\
\hline Measured AR (dB) & 19.2 & 0.56 & 0.24 & 0.55 & 5.78 & 3.21 & 2.23 \\
\hline
\end{tabular}




\subsection{Frequency Reconfigurable QHA Based on Kapton Origami Helical Tube for GPS, Radio and Wimax Applications}

\subsubsection{Analysis of origami structures of QHA}

The origami helical tube was firstly proposed by Guest and Pellegrino [31] as shown in Figure 3.20 (a). Origami bellow tube is a mutation of the origami helical tube by simply rotating each adjacent step in different directions, as shown in Figure 3.20 (b). Here, we propose new QHAs that are based on a 4-sided origami helical tube and an 8-sided origami bellow tube. The folding patterns for these antennas are shown in Figure 3.21. Solid lines are hills and dashed lines are valleys, and the orange parts denote the antenna copper traces. The detailed geometry of one step of a helical or bellow tube is shown in Figure 3.22. If the coordinates of point $\mathrm{A}$ in the parallelogram unit is $(a, 0,0)$, then the coordinates of points $B, C$ and $D$ are calculated as shown in Figure 3.22 (a), where $\alpha=360^{\circ} / n$ is the inner angle of the polygon at the intersection of the origami tube. Also, $l_{a}$, $l_{b}$ and $l_{c}$ can be calculated by the coordinates of their endpoints. Figure 3.22 (b) shows the relative rotation angle $\theta$ between the top and bottom of each step. If we define ratio $=l_{b} /$ $l_{a}$, then $l_{c} / l_{a}$ can be expressed as:

$$
\frac{l_{c}}{l_{a}}=\sqrt{1-2 \cos (\alpha+\theta)+\text { ratio }^{2}-4 \sin ^{2} \frac{\theta}{2}}
$$

where the ratios in helical and bellow tubes are respectively 0.7 and 0.45 , and $l_{a}$ of helical and bellow tubes are respectively $30 \mathrm{~mm}$ and $16.6 \mathrm{~mm}$. Also, the height of each step increases as folding angle $\theta$ decreases. The linear elastic strain can be analyzed as 
$w=\frac{W}{E}=\frac{1}{2}\left(\frac{l_{c}-l_{c 0}}{l_{c}}\right)^{2}$ [32]. In this case, as $\theta$ decreases, the strain of both tubes increases, so there is a maximum height both structures can achieve.

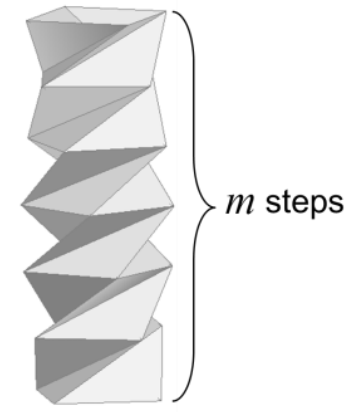

(a)

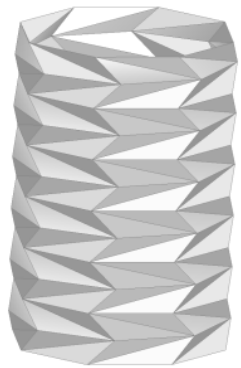

(b)

Figure 3.20. (a) Origami helical tube and (b) Origami bellow tube.

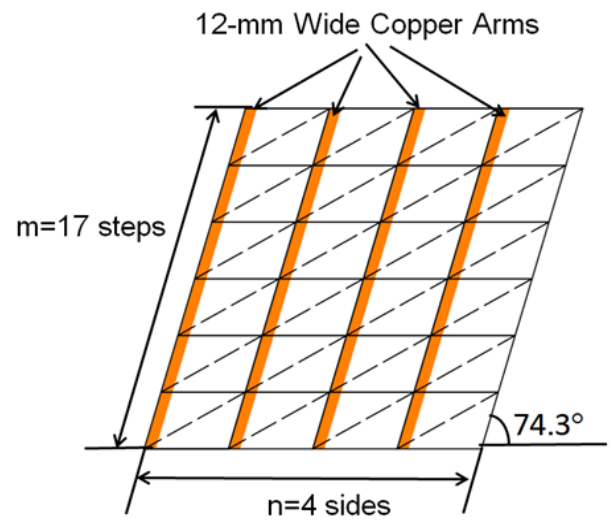

(a)

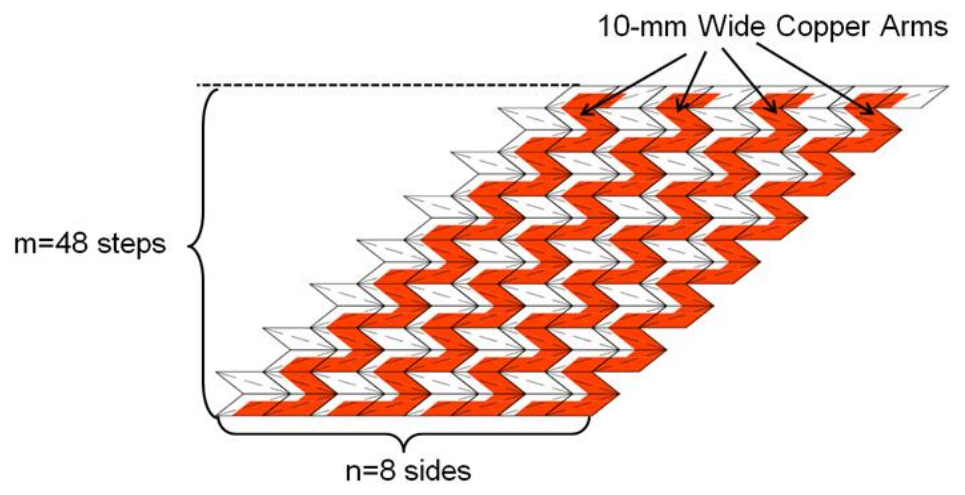

(b)

Figure 3.21. Folding patterns of: (a) helical tube based QHA and (b) bellow tube based QHA. 


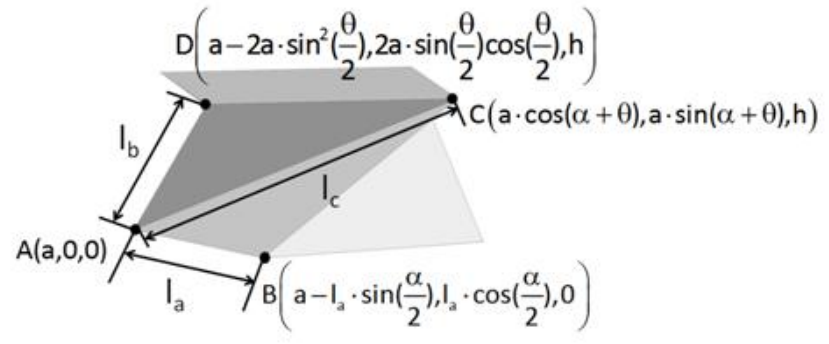

(a)

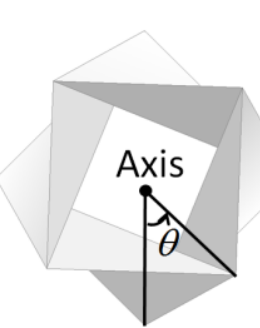

(b)

Figure 3.22. Geometry of one step of origami tube: (a) perspective view and (b) top view.

\subsubsection{Helical and Bellow origami tube QHAs}

Through analytical methods, models of helical and bellow origami tube QHAs are parametrically modeled and simulated with HFSS. Examples of these simulation models are shown in Figure 3.23, where $N$ is the total number of turns, and pitch is the axial length of each turn. They both are fed with four 50 Ohm-ports with a phase difference of $90^{\circ}$ between adjacent ports. By increasing the folding angle $\theta$, the height of each step, $h$, pitch and the total height of antenna $H$ decrease so that the antenna can operate at designated frequency bands. The helical tube can be reconfigured by applying a rotating force at the top of the helix, while the bellow tube can be reconfigured by an axial force only.

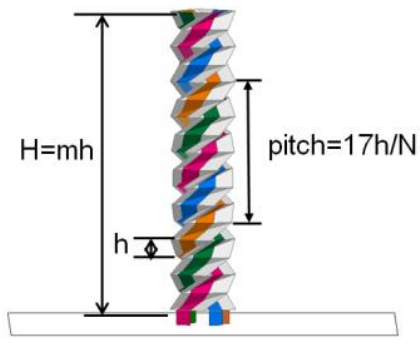

(a)

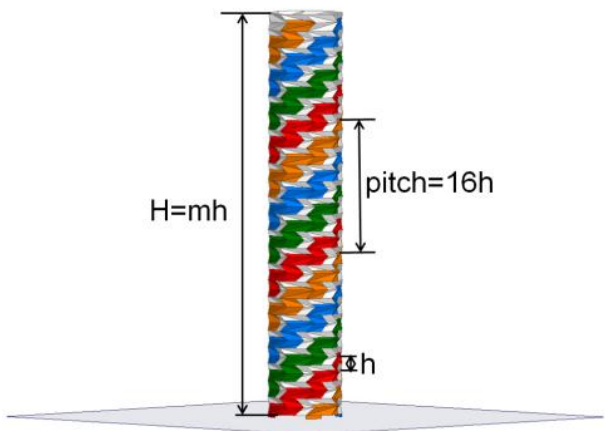

(b)

Figure 3.23. Simulation models of origami antennas based on: (a) helical tube; (b) bellow tube. 
The simulated realized RHCP gain and axial ratio of the QHA on helical and bellow tubes are shown in Figure 3.24-Figure 3.27. Shaded blocks denote their $\pm 1 \mathrm{~dB}$ gain bandwidth of each state. It can be seen that the QHA on the bellow tube only needs two states to cover the GPS, radio and WiMax bands from $1.17 \mathrm{GHz}$ to $3.5 \mathrm{GHz}$, because its unfolded state has a higher gain than the helical tube based QHA at higher frequencies, i.e. 3-4 GHz. This happens because as the tube is unfolding the number of turns $N(N=m / n)$ of the bellow-tube QHA stays the same, whereas the number of turns $N$ of the helical-tube QHA decreases, as shown below:

$$
N=m \times \sin \left(\frac{\theta}{2}\right) /\left[n \times \sin \left(\frac{180^{\circ}}{n}\right)\right]
$$

The performance of the QHAs on the two origami tubes are compared in Table 3.11.

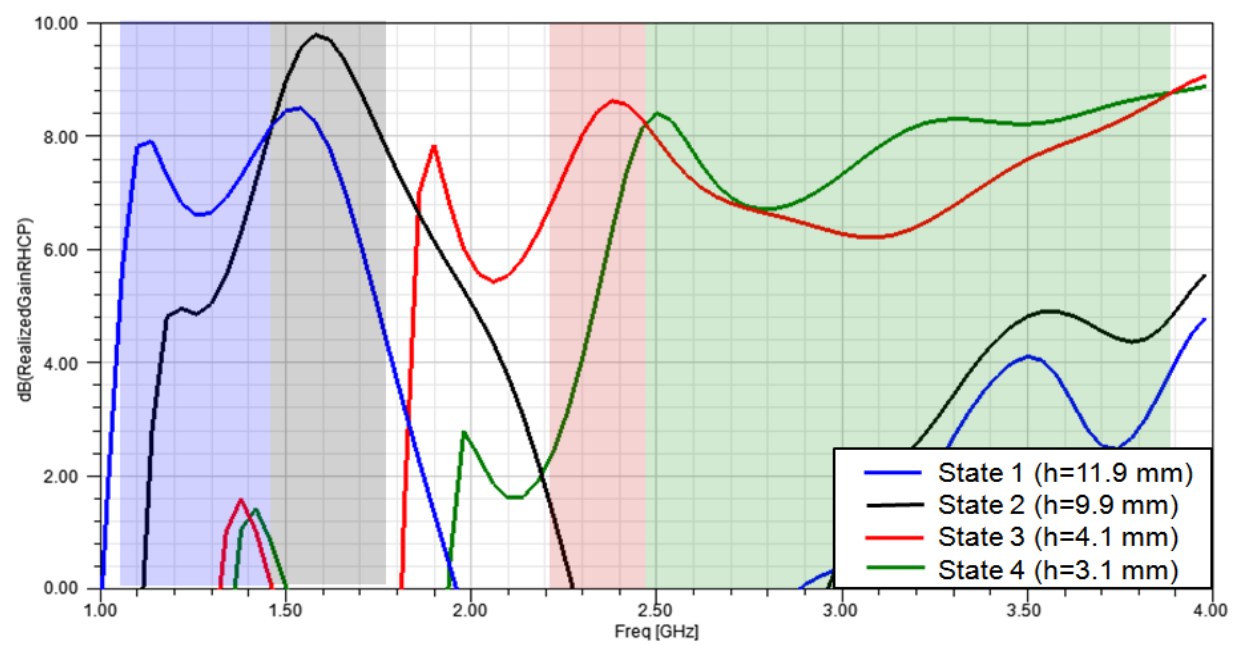

Figure 3.24. Simulated RHCP realized gain of QHA on helical tube. 


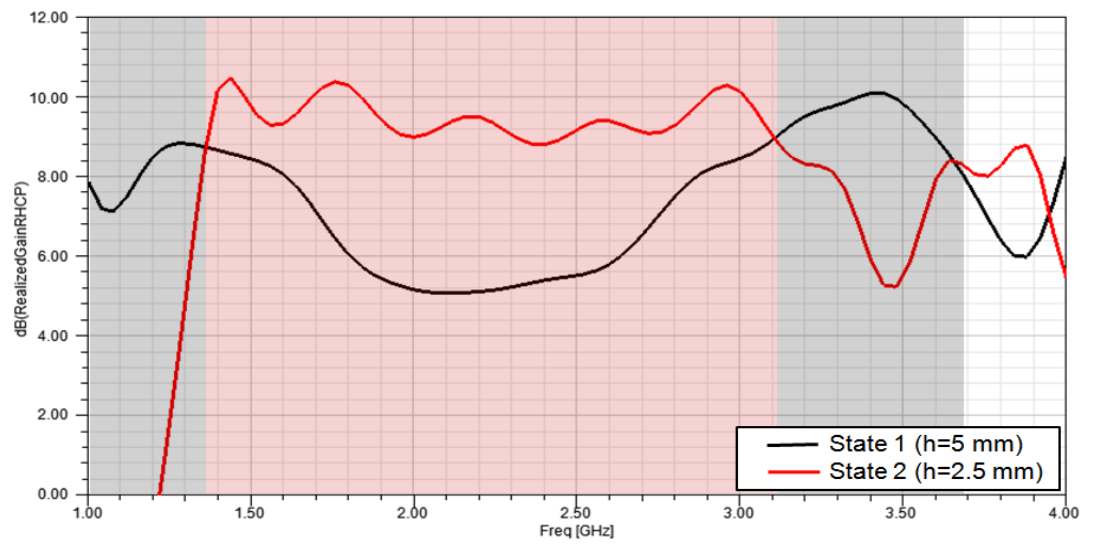

Figure 3.25. Simulated RHCP realized gain of QHA on bellow tube.

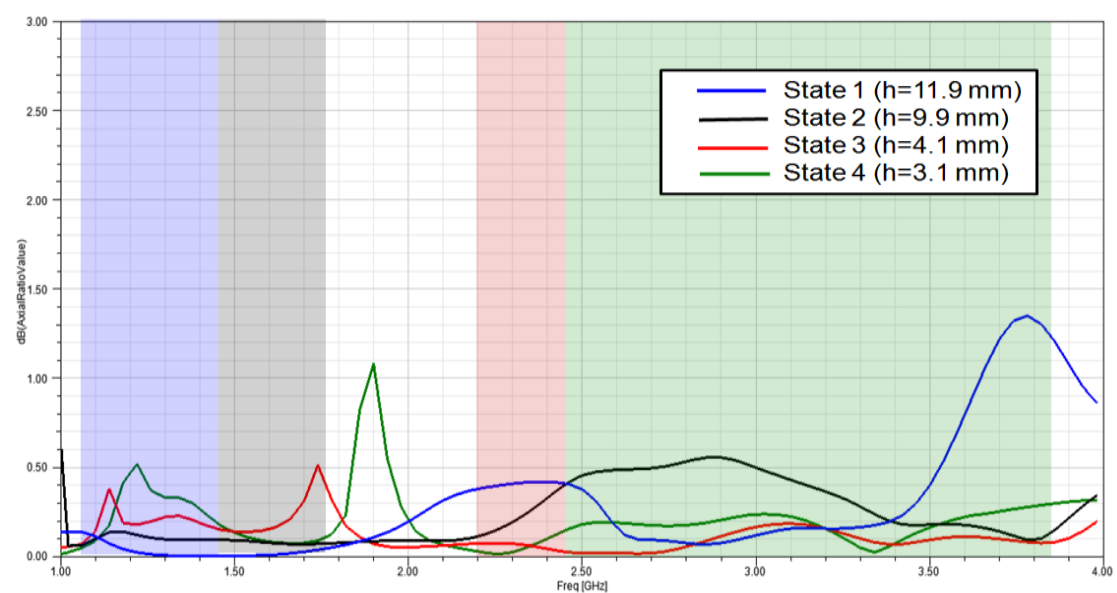

Figure 3.26. Simulated AR of QHA on helical tube.

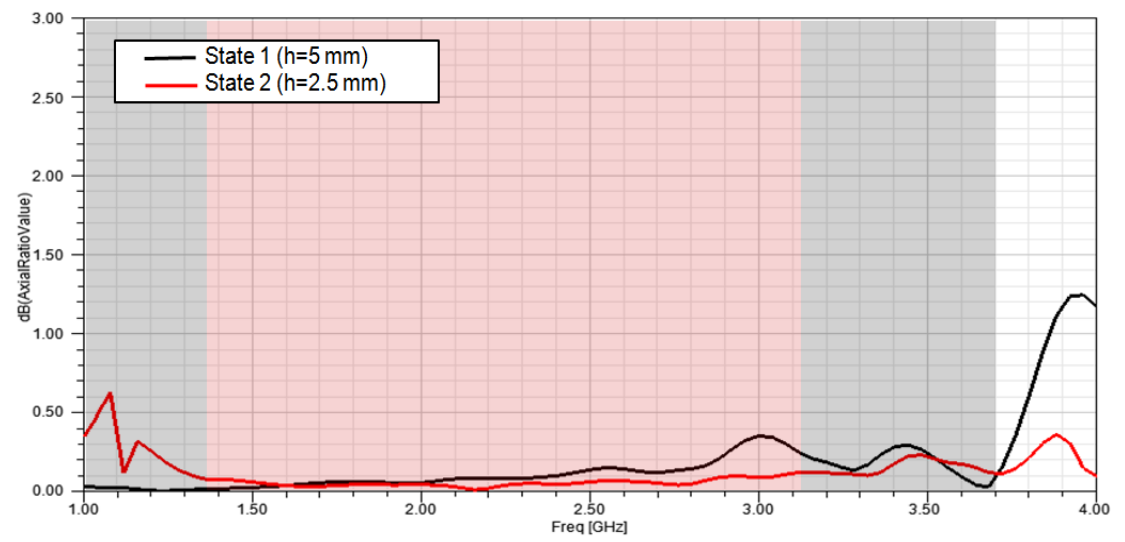

Figure 3.27. Simulated AR of QHA on bellow tube. 
Table 3.11. Performance Comparison of QHAs on Helical Tube and Bellow Tube.

\begin{tabular}{|c|c|c|c|c|c|c|}
\hline & $\begin{array}{c}\text { Designated Frequency } \\
\text { Bands }\end{array}$ & \multicolumn{3}{|c|}{$\begin{array}{c}\text { GPS Band } \\
1.17 \mathrm{GHz}-1.58 \mathrm{GHz}\end{array}$} & $\begin{array}{c}\text { Radio Band } \\
2.305 \mathrm{GHz}-2.325 \\
\mathrm{GHz}\end{array}$ & $\begin{array}{l}\text { WiMax } \\
3.5 \mathrm{GHz}\end{array}$ \\
\hline \multirow{6}{*}{$\begin{array}{l}\text { Helical } \\
\text { tube } \\
\text { QHA }\end{array}$} & Operating State & $\begin{array}{c}\text { State } 1 \\
(\mathrm{~h}=11.9 \mathrm{~mm})\end{array}$ & \multicolumn{2}{|r|}{$\begin{array}{c}\text { State } 2 \\
(\mathrm{~h}=9.9 \mathrm{~mm})\end{array}$} & $\begin{array}{c}\text { State } 3 \\
(\mathrm{~h}=4.1 \mathrm{~mm})\end{array}$ & $\begin{array}{c}\text { State } 4 \\
(\mathrm{~h}=3.1 \mathrm{~mm})\end{array}$ \\
\hline & Number of Turns & 2.4 & \multicolumn{2}{|r|}{2.6} & 2.9 & 2.9 \\
\hline & $\begin{array}{c}\text { Bandwidth with } \pm 1 \mathrm{~dB} \\
\text { RHCP Gain Variation } \\
\left(\mathrm{f}_{\max } / \mathrm{f}_{\min }\right)\end{array}$ & $\begin{array}{c}1.07 \mathrm{GHz}-1.46 \\
\mathrm{GHz} \\
(1.36: 1)\end{array}$ & \multicolumn{2}{|c|}{$\begin{array}{c}1.46 \mathrm{GHz}-1.76 \mathrm{GHz} \\
(1.21: 1)\end{array}$} & $\begin{array}{c}2.18 \mathrm{GHz}-2.48 \\
\mathrm{GHz} \\
(1.14: 1)\end{array}$ & $\begin{array}{c}2.48 \mathrm{GHz}-3.66 \\
\mathrm{GHz} \\
(1.48: 1)\end{array}$ \\
\hline & AR in the Bandwidth & $<0.15 \mathrm{~dB}$ & \multicolumn{2}{|r|}{$<0.1 \mathrm{~dB}$} & $<0.1 \mathrm{~dB}$ & $<0.3 \mathrm{~dB}$ \\
\hline & Maximum RHCP Gain & $7.9 \mathrm{~dB}$ & \multicolumn{2}{|r|}{$9.8 \mathrm{~dB}$} & $8.6 \mathrm{~dB}$ & $8.4 \mathrm{~dB}$ \\
\hline & $\begin{array}{l}\text { Designated Frequency } \\
\text { Bands }\end{array}$ & \multicolumn{3}{|c|}{$\begin{array}{c}\text { GPS Band } \\
1.17 \mathrm{GHz}-1.58 \mathrm{GHz}\end{array}$} & $\begin{array}{c}\text { Radio Band } \\
2.305 \mathrm{GHz}-2.325 \\
\mathrm{GHz}\end{array}$ & $\begin{array}{l}\text { WiMax } \\
3.5 \mathrm{GHz}\end{array}$ \\
\hline \multirow{4}{*}{$\begin{array}{l}\text { Bellow } \\
\text { Tube } \\
\text { QHA }\end{array}$} & Operating State & State $1(h=5 n$ & & \multicolumn{2}{|c|}{ State $2(\mathrm{~h}=2.5 \mathrm{~mm})$} & $\begin{array}{c}\text { State } 1 \\
(\mathrm{~h}=10 \mathrm{~mm})\end{array}$ \\
\hline & $\begin{array}{c}\text { Bandwidth with } \pm 1 \mathrm{~dB} \\
\text { RHCP Gain Variation } \\
\left(\mathrm{f}_{\max } / \mathrm{f}_{\min }\right)\end{array}$ & \multicolumn{2}{|c|}{$\begin{array}{c}1 \mathrm{GHz}-1.36 \mathrm{GHz} \\
(1.36: 1)\end{array}$} & \multicolumn{2}{|c|}{$\begin{array}{c}1.36 \mathrm{GHz}-3.1 \mathrm{GHz} \\
(2.28: 1)\end{array}$} & $\begin{array}{c}3.1 \mathrm{GHz}-3.68 \\
\mathrm{GHz} \\
(1.19: 1)\end{array}$ \\
\hline & AR in the Bandwidth & \multicolumn{2}{|l|}{$<0.02 \mathrm{~dB}$} & \multicolumn{2}{|c|}{$<0.4 \mathrm{~dB}$} & $<0.3 \mathrm{~dB}$ \\
\hline & Maximum RHCP Gain & \multicolumn{2}{|l|}{$8.8 \mathrm{~dB}$} & \multicolumn{2}{|c|}{$10.4 \mathrm{~dB}$} & $10.1 \mathrm{~dB}$ \\
\hline
\end{tabular}

\subsubsection{Prototypes and Results of Helical Tube Based QHA}

The helical-tube QHA was built with copper traces sandwiched by Kapton substrate for fabrication convenience since there are less creases in its folding pattern. The overall thickness of the Kapton substrate is approximately 4 mils. The planar antenna layout is shown in Figure 3.28 (a). The folded-up 3-D origami QHA is shown in Figure 3.28 (b). It is centered at the square ground with $250 \mathrm{~mm}$ side-length which is fabricated with copper foil glued on the back side of the black cardboard. The left and right sides of the substrate are soldered together to build a robust cylinder. The 3-D printed cubic support beneath the cylinder is $20 \mathrm{~mm} \times 20 \mathrm{~mm} \times 10 \mathrm{~mm}$. 


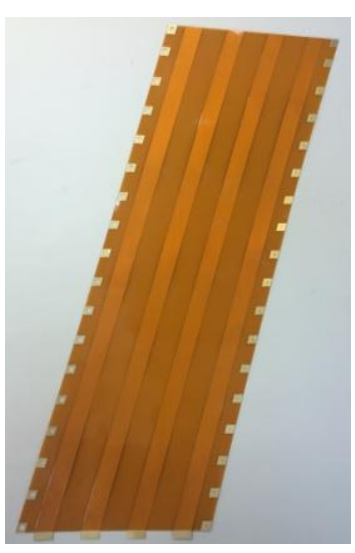

(a)

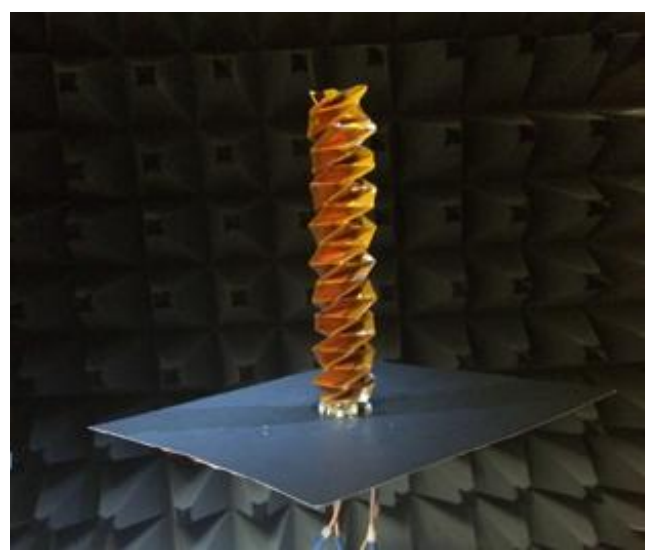

(b)

Figure 3.28. (a) Planar antenna layout, and (b) origami QHA on Kapton helical tube.

Measurements were carried out with an Agilent VNA and a StarLab Anechoic Chamber. The ports of the antenna are fed with $0^{\circ},-90^{\circ},-180^{\circ}$ and $-270^{\circ}$ in a right-handed order. Measured and simulated $S_{11}$ results are compared in Figure 3.30.

The comparison of the simulated and measured RHCP gain at the four reconfigurable states is depicted in Figure 3.31. It is seen that that the peak gain shifts to higher frequencies as the antenna height, $H$, decreases. Also, at higher frequencies the disagreement between measurements and simulations is bigger than the one at lower frequencies. This is due to the fact that the Kapton substrate is not included in the simulation models and at higher frequencies the effects of the Kapton substrate are more pronounced. There is also a maximum 2-dB gain difference between simulated and measured peak gains. This is mostly attributed to the insertion loss of the quadrature feeding network. Typical operational frequencies of the 4 states are marked with triangles on measured gain curves. Simulated and measured RHCP radiation patterns are compared at the typical operational frequencies of the 4 states in Figure 3.31. The measured results are summarized in Table 3.12 with the radiation pattern at the optimum gain points. 


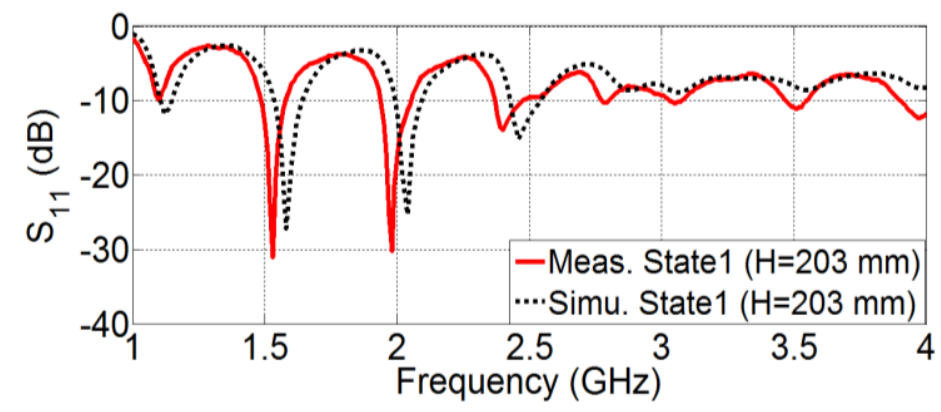

(a)

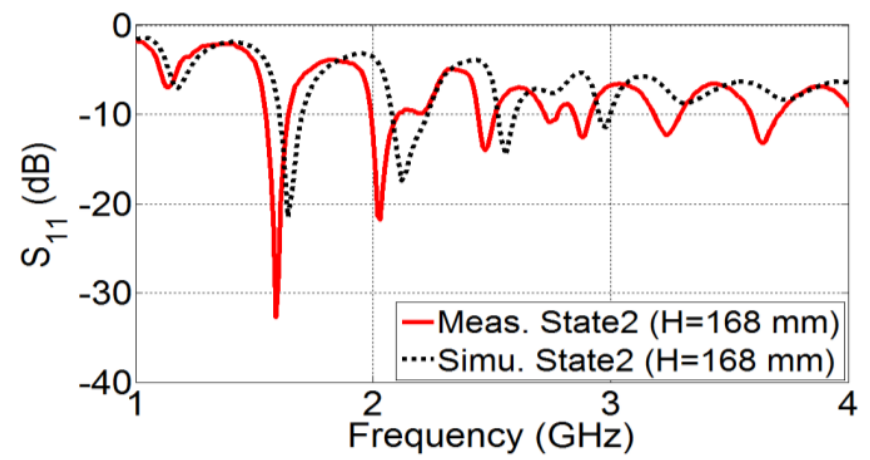

(b)

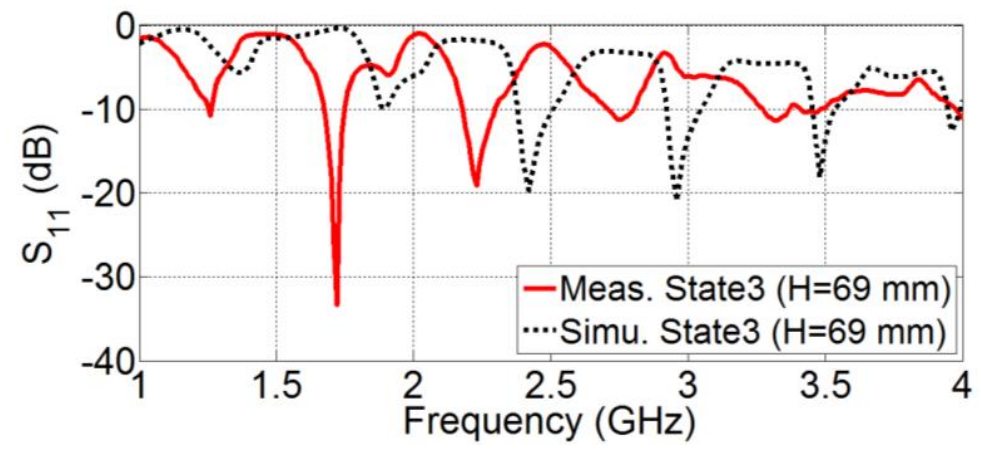

(c)

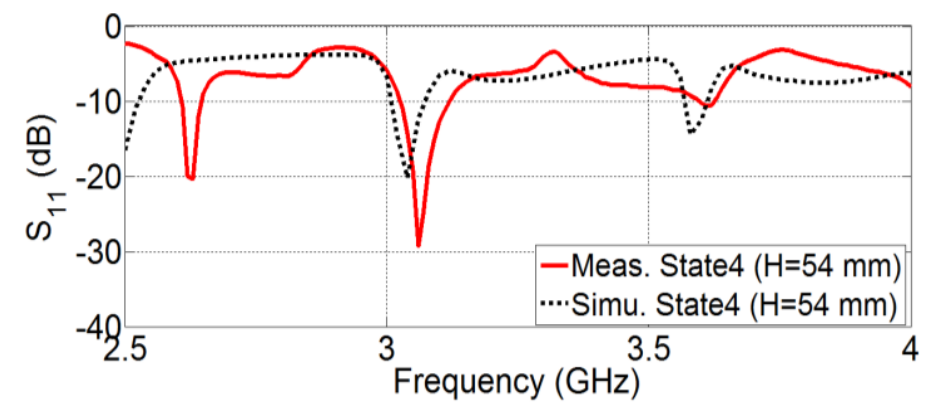

(d)

Figure 3.29. $S_{11}$ results of QHA on helical tube at: (a) state 1, (b) state 2, (c) state 3 and (d) state 4 . 


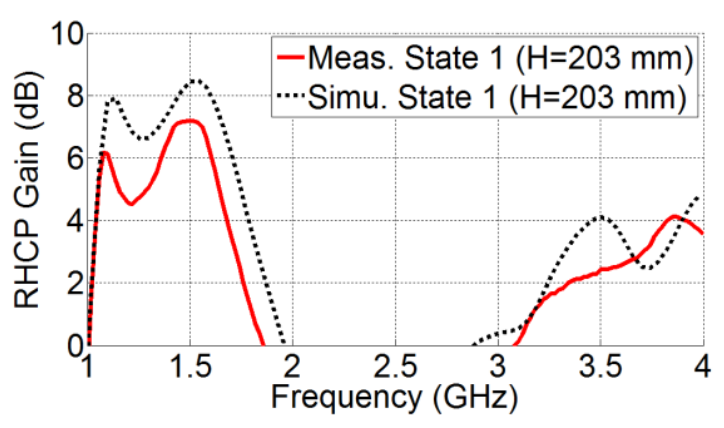

(a)

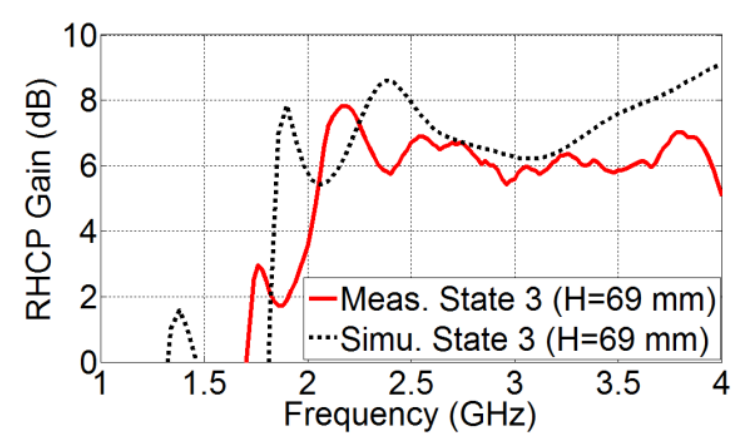

(c)

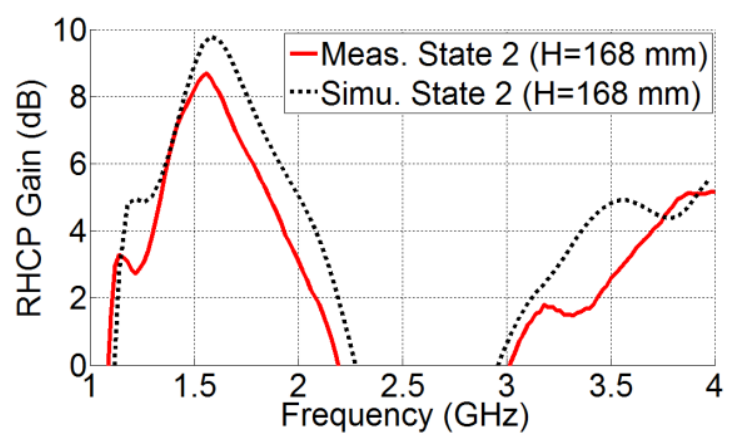

(b)

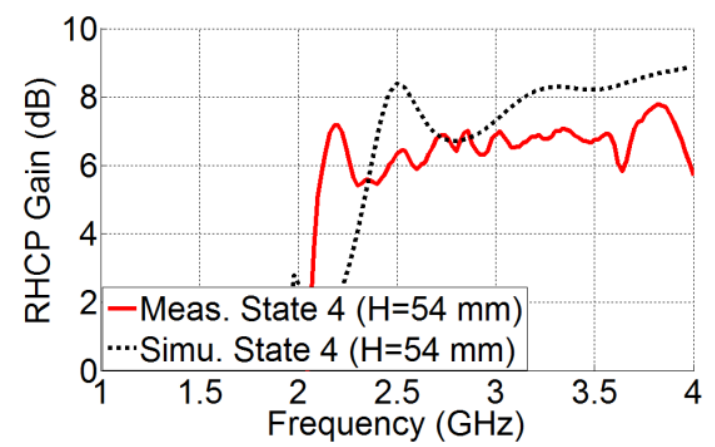

(d)

Figure 3.30. RHCP gain of QHA on helical tube at: (a) state 1, (b) state 2, (c) state 3 and (d) state 4.

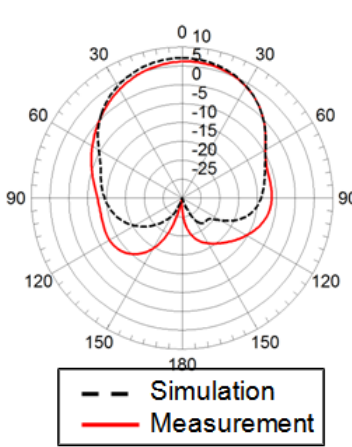

(a)

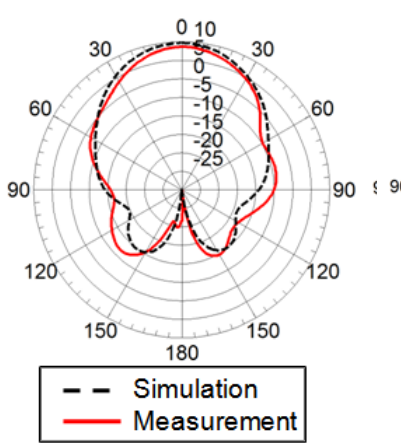

(b)

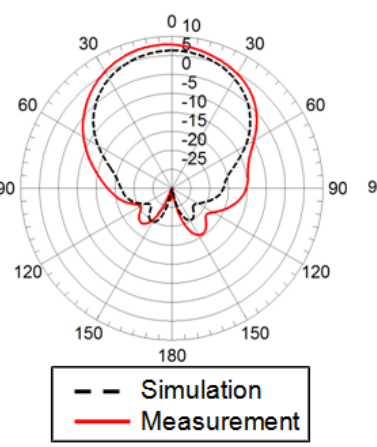

(c)

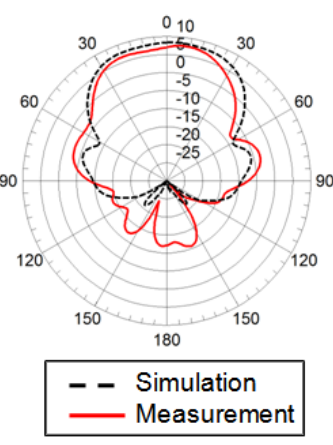

(d)

Figure 3.31. RHCP radiation patterns of QHA on helical tube at: (a) state 1 at $1.08 \mathrm{GHz}$, (b) state 2 at $1.56 \mathrm{GHz}$, (c) state 3 at $2.18 \mathrm{GHz}$ and (d) state 4 at $3.34 \mathrm{GHz}$. 
Table 3.12. $\quad$ Summarized Measured Results of Kapton QHA.

\begin{tabular}{|c|c|c|c|c|c|}
\hline & $\begin{array}{c}\text { State } 1 \\
(\mathrm{H}=203 \mathrm{~mm})\end{array}$ & $\begin{array}{c}\text { State } 2 \\
(\mathrm{H}=168 \mathrm{~mm})\end{array}$ & $\begin{array}{c}\text { State } 3 \\
(\mathrm{H}=69 \mathrm{~mm})\end{array}$ & $\begin{array}{c}\text { State } 4 \\
(\mathrm{H}=54 \mathrm{~mm})\end{array}$ \\
\hline \multicolumn{2}{|c|}{$\begin{array}{l}\text { Bandwidth with } \pm 1 \mathrm{~dB} \\
\text { RHCP Gain Variation }\end{array}$} & $1.05 \mathrm{GHz}-1.4 \mathrm{GHz}$ & $1.4 \mathrm{GHz}-1.73 \mathrm{GHz}$ & $2.07 \mathrm{GHz}-2.7 \mathrm{GHz}$ & $\begin{array}{l}2.7 \mathrm{GHz}-2.94 \mathrm{GHz} \& \\
3.26 \mathrm{GHz}-3.66 \mathrm{GHz}\end{array}$ \\
\hline \multicolumn{2}{|c|}{ AR in the Bandwidth } & $0.4 \mathrm{~dB}-1.4 \mathrm{~dB}$ & $0.8 \mathrm{~dB}-1.9 \mathrm{~dB}$ & $0.1 \mathrm{~dB}-1.8 \mathrm{~dB}$ & $0.4 \mathrm{~dB}-3 \mathrm{~dB}$ \\
\hline \multirow{2}{*}{$\begin{array}{l}\text { Maximum } \\
\text { RHCP Gain } \\
\text { at Typical } \\
\text { Operational } \\
\text { Frequencies }\end{array}$} & Measured & $\begin{array}{c}6.2 \mathrm{~dB} @ 1.08 \mathrm{GHz} \\
\text { (Insertion loss of the } \\
\text { feeding network is } \\
0.52 \mathrm{~dB} \text { ) }\end{array}$ & $\begin{array}{c}8.7 \mathrm{~dB} @ 1.56 \mathrm{GHz} \\
\text { (Insertion loss of } \\
\text { the feeding network } \\
\text { is } 0.64 \mathrm{~dB} \text { ) }\end{array}$ & $\begin{array}{c}7.9 \mathrm{~dB} @ 2.18 \mathrm{GHz} \\
\text { (Insertion loss of } \\
\text { the feeding network } \\
\text { is } 0.75 \mathrm{~dB} \text { ) }\end{array}$ & $\begin{array}{c}7.6 \mathrm{~dB} @ 3.34 \mathrm{GHz} \\
\text { (Insertion loss of the } \\
\text { feeding network is } \\
1.08 \mathrm{~dB} \text { ) }\end{array}$ \\
\hline & Simulated & $7.1 \mathrm{~dB}$ & $9.7 \mathrm{~dB}$ & $6.1 \mathrm{~dB}$ & $8.3 \mathrm{~dB}$ \\
\hline
\end{tabular}

\subsubsection{Conclusion}

QHAs on origami helical tubes and bellow tubes were proposed in this chapter. The bellow-tube QHA has wide bandwidth and it can reconfigure its height more easily by only an axial force. On the other hand, the helical tube QHA has smaller number of creases and it is easier to fabricate. The prototype of the helical-tube QHA was fabricated on Kapton substrate, and its measured results show that it can successfully operate in RHCP axial mode at reconfigurable states to cover GPS band in $1.17 \mathrm{GHz}-1.58 \mathrm{GHz}$, satellite radio band in $2.305 \mathrm{GHz}-2.325 \mathrm{GHz}$ and WiMax frequency at $3.5 \mathrm{GHz}$. 


\section{CHAPTER 4}

\section{A RECONFIGURABLE PACKABLE AND MULTIBAND ORIGAMI MULTI-RADII HELICAL ANTENNA}

Quasi-tapered helical antenna with multiple radii has been proved to have improved gain, pattern, bandwidth and circular-polarization performances than conventional uniform-diameter helical antennas [36]. Also, an analytical method to design origami monofilar helices with a uniform diameter has been proposed in the last chapter. Despite its frequency reconfigurability, this origami monofilar is only primarily circularly polarized at the semi-folded state. In this chapter, we propose an origami multi-radii monofilar helix with simple feed that operates in reconfigurable bandwidths with $\mathrm{CP}$ at three states.

The proposed reconfigurable origami multi-radii monofilar helix exhibits improved bandwidth, gain, pattern, and $\mathrm{CP}$ performance compared to those of the uniform-radius standard monofilar or origami monofilar helices. The geometrical details of the multi-radii origami base for the proposed antenna are demonstrated in $\S 4.1$. The geometrical details of the origami multi-radii helical antenna and the design process for this antenna are discussed in $\S 4.2$. The performance of this antenna is analyzed in $\S 4.3$ and $\S 4.4$. Also, an actuation mechanism for this collapsible antenna is proposed in $\S 4.5$. The performance of this antenna at three reconfigurable states is validated through simulations and measurements in $\S 4.6$.

\subsection{Geometries of Origami Base}

The proposed origami multi-radii helix consists of two helical sections (a top and a 
bottom one) with different radius and a transition step between them in order to serially connect the two helical sections, as shown in Figure 4.2. The planar origami folding pattern proposed to fold the origami cylindrical base for the origami multi-radii monofilar is shown in Figure 4.1(a), where only a few dominant parameters need to be determined, i.e., a, ratio, $f_{\text {scale, }}$ ratio $, m_{l}, m, n$ and $w$, whose designed values and descriptions are listed in Table 4.1. By folding along the hill and valley in Figure 4.1(a) as denoted by solid lines and dash lines respectively, combining the bottom and top sections together and then connecting the left and right side of the origami pattern together, the entire origami base is folded up. The two other dominant parameters in the 3-D folded-up origami base are $\theta$ and $\theta_{l}$ as denoted in Figure 4.1(c) and explained in Table 4.1. $\theta$ and $\theta_{1}$ are variable and thereby can adjust the height of each step in the origami base $h$ and $h_{l}$, as denoted in Figure 4.1(b) which can be calculated as in Table 4.3. The optimization process of these dominant parameters will be discussed in $\S 4.4$.

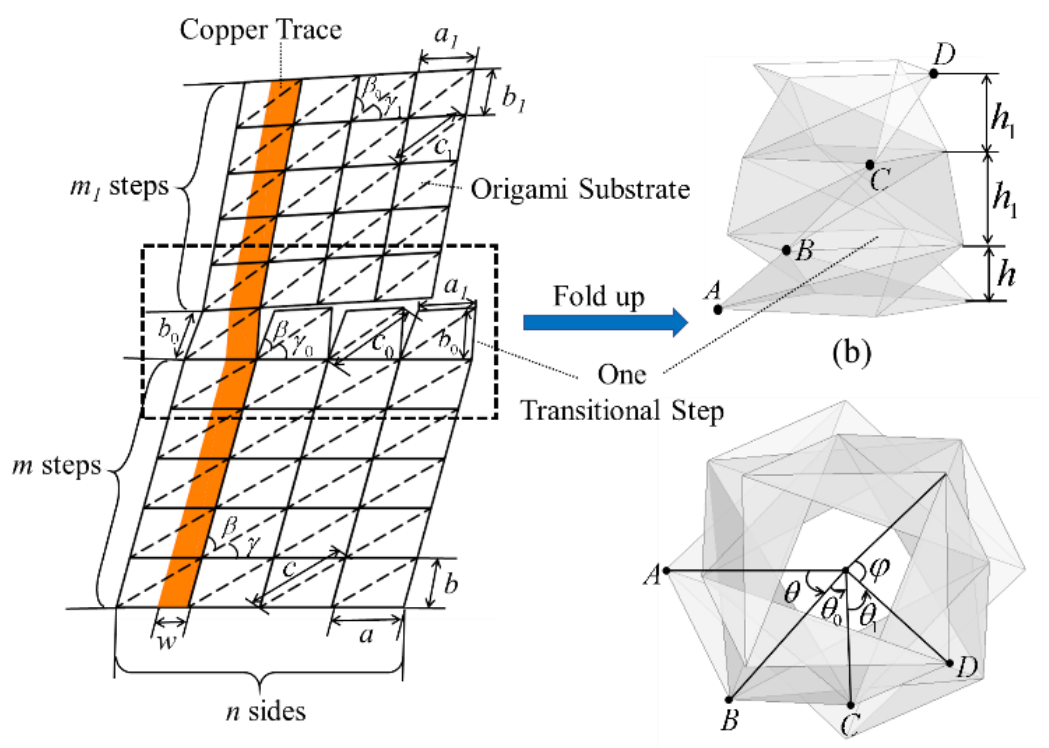

(a)

(c)

Figure 4.1. Geometries of the origami multi-radii monofilar helix: (a) origami folding pattern, (b) perspective view of multi-radii folded-up transitional section, and (c) top view of multi-radii folded-up transitional section. 
Table 4.1. Primary Geometric Parameters of Origami Base.

\begin{tabular}{|c|c|c|}
\hline $\begin{array}{c}\text { Primary } \\
\text { Parameter }\end{array}$ & Description & $\begin{array}{c}\text { Designed } \\
\text { Value }\end{array}$ \\
\hline$n$ & \# of sides of the intersectional polygon & 4 \\
\hline$a$ & $\begin{array}{c}\text { Horizontal length of each parallelogram unit in the bottom } \\
\text { cylinder }\end{array}$ & $35.4 \mathrm{~mm}$ \\
\hline ratio & $\begin{array}{c}\text { Length ratio between the vertical and horizontal lengths of } \\
\text { each parallelogram unit in the bottom cylinder }\end{array}$ & 0.7 \\
\hline$m$ & \# of steps of the bottom monofilar & 18 \\
\hline$f_{\text {scale }}$ & $\begin{array}{c}\text { Ratio of the radius of the top helix to the radius of the } \\
\text { bottom helix }\end{array}$ & 0.8 \\
\hline ratio 1 & $\begin{array}{c}\text { Length ratio between the vertical and horizontal lengths of } \\
\text { each parallelogram unit in the top cylinder }\end{array}$ & 0.79 \\
\hline$m_{1}$ & \# of steps of the top monofilar & 18 \\
\hline$w$ & Width of the copper trace & $15 \mathrm{~mm}$ \\
\hline$\theta$ & $\begin{array}{c}\text { Folding angle between adjacent intersectional polygonal } \\
\text { planes in the bottom cylinder }\end{array}$ & $\begin{array}{c}\text { Not } \\
\text { const. }\end{array}$ \\
\hline$\theta_{l}$ & $\begin{array}{c}\text { Folding angle between adjacent intersectional polygonal } \\
\text { planes in the top cylinder }\end{array}$ & $\begin{array}{c}\text { Not } \\
\text { const. }\end{array}$ \\
\hline
\end{tabular}

The relationships between the primary and the secondary geometrical parameters of our antenna are shown in Table 4.2. These secondary parameters are necessary to model, simulate and fabricate the proposed origami antenna accurately.

It can be seen from Table 4.2 that the lengths of diagonal lines (i.e., $c, c_{1}$ and $c_{0}$ ) in this origami pattern and the side length $b_{0}$ of the transitional step in Figure 4.1 (a) are not constant due to the varying $\theta$ and $\theta_{l}$. Therefore, the substrate applied to build the origami base should be stretchable along these hinges besides being foldable; also, internal strains will exist near these hinges. Angles in the transitional step (i.e., $\beta_{0}$ and $\gamma_{0}$ ) denoted in Figure 4.1 (a) are also not constant due to its non-constant side lengths, so this origami pattern is non-rigidly foldable, especially for the transitional step. 
Table 4.2. Secondary geometric Parameters of Origami base.

\begin{tabular}{|c|c|c|}
\hline $\begin{array}{c}\text { Secondary } \\
\text { Parameters }\end{array}$ & Calculation & Value \\
\hline$\varphi$ & $\varphi=2 \pi / n$ & $90^{\circ}$ \\
\hline$\beta$ & $\beta=\pi / n[32]$ & $45^{\circ}$ \\
\hline$\gamma$ & $\gamma=\sin ^{-1}($ ratio $\cdot \sin \beta)[29]$ & $29.7^{\circ}$ \\
\hline$b$ & $b=$ ratio $a[29]$ & $24.8 \mathrm{~mm}$ \\
\hline$c$ & $c=a \sqrt{\text { ratio }^{2}+\cos \theta+\frac{\sin \theta \sin \varphi}{1-\cos \varphi}}$ & $\begin{array}{l}\text { Not } \\
\text { const. }\end{array}$ \\
\hline$b_{0}$ & $b_{0}=a \sqrt{f_{\text {scale }}^{2} \text { ratio }^{2}+\frac{f_{\text {scale }}^{2}\left(\cos \theta_{1}-0.5\right)-f_{\text {scale }} \cos \theta_{1}+0.5}{1-\cos \varphi}}$ & $\begin{array}{c}\text { Not } \\
\text { const. }\end{array}$ \\
\hline$c_{0}$ & $c_{0}=a \sqrt{f_{\text {scale }}^{2} \text { ratio }^{2}+\frac{f_{\text {scale }}^{2}\left(\cos \theta_{1}-0.5\right)-0.5 f_{\text {scale }} \cos \left(\varphi+\theta_{1}\right)+0.5}{1-\cos \varphi}}$ & $\begin{array}{l}\text { Not } \\
\text { const. }\end{array}$ \\
\hline$\beta_{0}$ & $\beta_{0}=\cos ^{-1}\left(\frac{b_{0}^{2}+c_{0}^{2}-a_{1}^{2}}{2 b_{0} c_{0}}\right)$ & $\begin{array}{l}\text { Not } \\
\text { const. }\end{array}$ \\
\hline$\gamma_{0}$ & $\gamma_{0}=\cos ^{-1}\left(\frac{c_{0}^{2}+a^{2}-b_{0}^{2}}{2 a c_{0}}\right)$ & $\begin{array}{c}\text { Not } \\
\text { const. }\end{array}$ \\
\hline$\gamma_{1}$ & $\gamma=\sin ^{-1}\left(\right.$ ratio $\left._{1} \cdot \sin \beta\right)$ & $34^{\circ}$ \\
\hline$a_{1}$ & $a_{1}=f_{\text {scale }} \cdot a$ & $28.3 \mathrm{~mm}$ \\
\hline$b_{1}$ & $b_{1}=\operatorname{ratio}_{1} \cdot a_{1}$ & $22.4 \mathrm{~mm}$ \\
\hline$c_{1}$ & $c=a_{1} \sqrt{\text { ratio }_{1}^{2}+\cos \theta_{1}+\frac{\sin \theta_{1} \sin \varphi}{1-\cos \varphi}}$ & $\begin{array}{c}\text { Not } \\
\text { const. }\end{array}$ \\
\hline$h$ & $h=a \sqrt{\text { ratio }^{2}-\frac{\sin ^{2}\left(\frac{\theta}{2}\right)}{\sin ^{2}(\beta)}}[29]$ & $\begin{array}{l}\text { Not } \\
\text { const. }\end{array}$ \\
\hline$h_{1}$ & $h_{1}=a_{1} \sqrt{\operatorname{ratio}_{1}^{2}-\frac{\sin ^{2}\left(\frac{\theta_{1}}{2}\right)}{\sin ^{2}(\beta)}}$ & $\begin{array}{l}\text { Not } \\
\text { const. }\end{array}$ \\
\hline
\end{tabular}

\subsection{Geometries of Antenna Model}

The proposed reconfigurable multi-radii origami helix at 3 reconfigurable states of height is shown in Figure 4.2. The pitch sizes of the bottom and top helices $S$ and $S_{1}$ can be

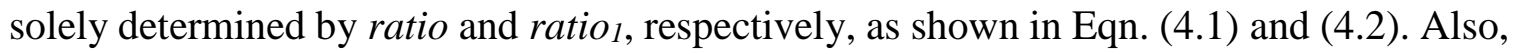


the number of turns of the bottom and top helices, $N$ and $N_{l}$ can be optimized independently solely by changing $m_{1}$ and $m$, respectively, without changing the values of the other primary geometric parameters, as expressed below in Eqn. (4.3) and (4.4) [29]:

$$
\begin{gathered}
S=n \cdot a \sqrt{\frac{\text { atio }^{2} \cdot \sin ^{2}\left(\frac{\varphi}{2}\right)}{\sin ^{2}\left(\frac{\theta}{2}\right)}-1} \\
S_{1}=n a \cdot f_{\text {scale }} \sqrt{\frac{\text { ratio }_{1}^{2} \cdot \sin ^{2}\left(\frac{\varphi}{2}\right)}{\sin ^{2}\left(\frac{\theta_{1}}{2}\right)}-1} \\
N=m \times \sin \left(\frac{\theta}{2}\right) /\left[n \times \sin \left(\frac{\varphi}{2}\right)\right] \\
N_{1}=m_{1} \times \sin \left(\frac{\theta_{1}}{2}\right) /\left[n \times \sin \left(\frac{\varphi}{2}\right)\right]
\end{gathered}
$$

Note that the number of turns $N_{O}$ and height $h_{1}$ of the transitional step do not significantly impact performance of the antenna, and $N_{0}$ is calculated as:

$$
N_{0}=\sin \left(\frac{\theta_{1}}{2}\right) /\left[n \times \sin \left(\frac{\varphi}{2}\right)\right]
$$

Therefore, the geometries of the two helices can be optimized in terms of axial ratio (AR) and 2-dB RHCP realized gain bandwidth by varying the geometric parameters of the origami pattern (i.e., ratio, ratio $1, m$ and $m_{1}$ ). The designing process for this antenna will be detailed in Section 4.4. The circumferences of both the bottom and top helices, $C$ and $C_{1}$, remain approximately constant for different heights (i.e., states of the antenna), as shown in Figure 4.2. Also, the total length of the antenna trace $L_{\text {total }}=m b+b_{0}+m_{1} b_{1}$ remains approximately constant at the 3 states. 


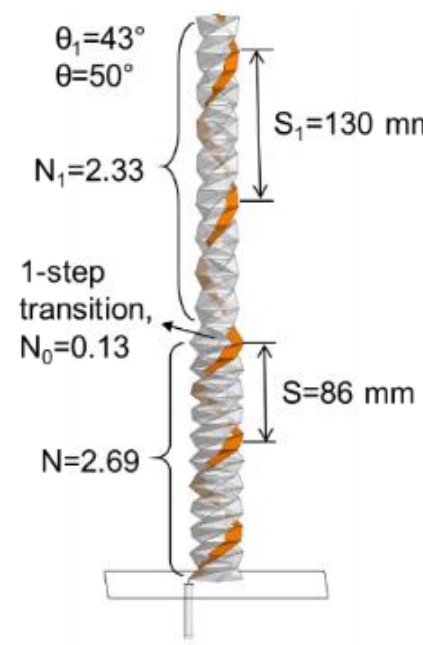

(a)

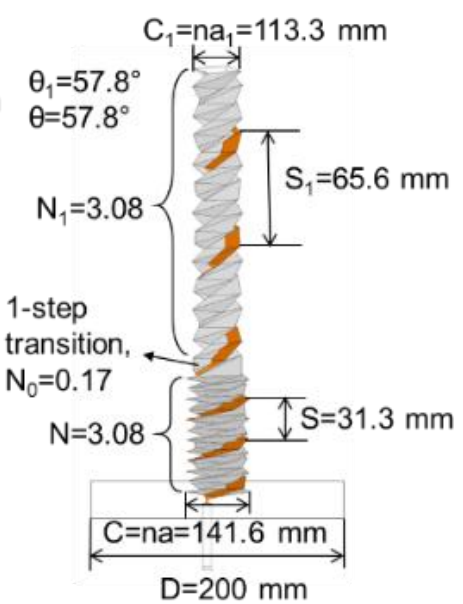

(b)

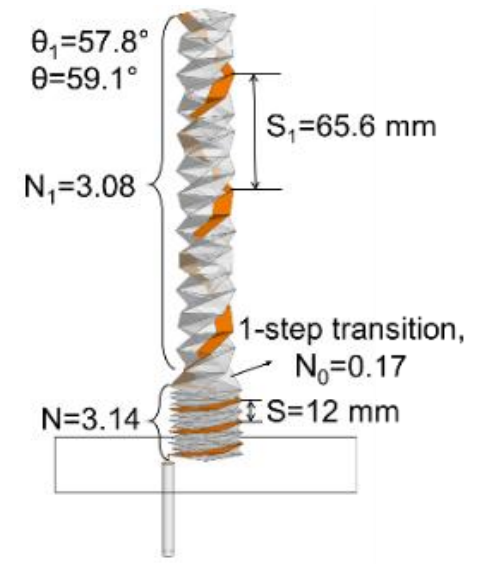

(c)

Figure 4.2. Model and geometries of the origami multi-radii monofilar helix at three different heights (i.e., states): (a) state 1 (unfolded state), (b) state 2 (semi-folded state), and (c) state 3 (folded state).

According to antenna theory [37] and previous analysis on axial-mode origami helical antenna [29]. The pitch size $S$, circumference $C$ and pitch angle $\alpha$ of a broadband single-radius origami helical antenna should satisfy the following conditions in order to achieve optimal performance:

$$
\begin{gathered}
S \approx \lambda_{0} / 4 \\
\frac{3}{4} \lambda_{0}<C<\frac{4}{3} \lambda_{0} \\
12^{\circ}<\alpha<14^{\circ}
\end{gathered}
$$

where,

$$
\alpha=\tan ^{-1} \frac{h}{\sqrt{b^{2}-h^{2}}}=\tan ^{-1} \sqrt{\frac{\operatorname{ratio}^{2} \cdot \sin ^{2}\left(\frac{\varphi}{2}\right)}{\sin ^{2}\left(\frac{\theta}{2}\right)}}-1
$$

Also, the sense of the circular polarization is determined by the winding direction of the helical trace from its feeding point. The proposed multi-radii origami helix is 
designed to be right-hand circularly polarized (RHCP).

It can be concluded from Eqn. (4.7) that our origami helix can operate in axial mode and have the following bandwidth:

$$
\frac{3 c}{4 n a}<f_{0}<\frac{4 c}{3 n a}
$$

Also, the length of one turn of the axial-mode CP helical antenna should be:

$$
L=\sqrt{S^{2}+C^{2}} \approx \lambda_{0}
$$

At lower frequencies than the ones covered by Eqn. (4.10), when $\lambda_{0}>>L$, a helical antenna operates in normal mode; while at higher frequencies, when $\lambda_{0}<<L$, a helical antenna operates in conical mode. Our origami helical antenna is collapsible and therefore, it can vary its height, which in turn changes $L$. The length of one turn $L$ can be written as a function of $\theta$, using $L=L_{\text {total }} / N$, where $N$ depends on $\theta$ as shown in Eqn. (4.3). As $L$ changes for different heights, our origami helix can be made to operate in axial-mode at different frequency bands, (i.e., exhibit multi-band operation). Specifically, if $L$ increases, the operating frequency band decreases and vice versa.

However, if we used a single-radius origami helix, then $\alpha, S$ and $C$ shown in Eqns. (4.6)-(4.8) would be out of the optimal CP range when the antenna operates at states $1 \& 3$ as shown in Figure 4.8, which would cause the gain and bandwidth of the antenna to decrease at both states, and the polarization not to be $\mathrm{CP}$ at state 3 .

Therefore, to address this problem and to improve RHCP gain, radiation pattern, 2$\mathrm{dB}$ realized RHCP gain bandwidth or $\mathrm{CP}$ performance at all three states of operation, a second helix with different radius is added on top of the single helix [36]. The geometric details of the proposed multi-radii origami helix are shown in Table 4.1 Table 4.2 and Figure 4.2. 
Here, we summarize the performance trends that were derived by our simulation analysis (see $\S 4.4$ for supportive data). When the circumference of the top helix, $C_{l}$, increases while staying smaller than $C$, the RHCP gain and AR are improved without impacting the 2-dB RHCP realized gain bandwidth. However, when $C_{l}$ increases beyond $C$, the RHCP gain stops increasing, and the bandwidth and AR worsen. When the number of turns of either the bottom or the top helix increases, the RHCP realized gain increases inside its 2-dB RHCP realized gain bandwidth, while the RHCP gain bandwidth first increases and then decreases. When the pitch size of the top helix, $S_{1}$, increases, the 2-dB RHCP realized gain bandwidth first increases and then decreases without significantly affecting the RHCP realized gain, and AR tends to improve. Adding a third smaller helical section on top of the multi-radii helix in Figure 4.2 does not improve bandwidth according to our simulated results. Therefore, the results of an antenna that is composed by three helices are omitted.

Based on these findings, the design process of a multi-radii helix is as follows:

1) a proper circumference of the bottom helix, $C$, is chosen for the desired operating frequency band;

2) a proper circumference of the top helix, $C_{l}$, is chosen to improve AR and RHCP gain in the designed frequency band;

3) the proper number of turns of the bottom helix is chosen to optimize the 2dB RHCP realized gain bandwidth;

4) the number of turns of the top helix is chosen to achieve a compromise between 2-dB RHCP realized gain bandwidth and the maximum zenithal RHCP gain;

5) the pitch size of the bottom helix, $S$, is optimized to achieve multiband 
operation;

6) pitch size of the top helix, $S_{1}$, is optimized for each reconfigurable state to improve their 2-dB RHCP realized gain bandwidth and CP performance.

\subsection{Comparison of Origami Multi-Radii Monofilar with Standard and Origami}

\section{Helices}

\subsubsection{Comparison of Origami Multi-Radii Monofilar with Standard Helix}

The performance of the semi-folded state of the origami multi-radii helix, shown in Figure 4.2(b), is compared with the performance of a standard helix and a standard multiradii helix, shown in Figure 4.3. The pitch sizes, circumferences, and pitch angles of the standard multi-radii helix are the same with the ones of the proposed origami multi-radii helix in Figure 4.2(b). The geometric parameters of the standard helix are the same with the ones of the bottom helix in the origami multi-radii antenna in Figure 4.2(b). Also, all three antennas have the same uniform copper width of $15 \mathrm{~mm}$ and a total number of turns of approximately 6.3. All other geometric parameters are also kept the same, including ground plane sizes $(D=200 \mathrm{~mm})$, distances from the ground $(3.5 \mathrm{~mm})$, SMA feeding ports and positions of the antennas for a fair comparison. The pitch angle for all three antennas, $\alpha$, are $12.5^{\circ}$ which fall into the optimum range $\left(12^{\circ}\right.$ to $\left.14^{\circ}\right)$ to achieve optimal circular polarization [29].

Figure 4.4-Figure 4.7 compare the performance (i.e., reflection coefficient, zenithal realized RHCP gain, zenithal AR and radiation patterns) of the three antennas. Also, Table 4.3 summarizes the performance of the three antennas and the best performance out of the three is shaded for each performance metric. The simulation analysis was performed by 
ANSYS HFSS. The fractional bandwidth $\Delta f$ is calculated as [37]:

$$
\Delta f=\frac{f_{\max }-f_{\min }}{\left(f_{\max }+f_{\min }\right) / 2} \times 100 \%
$$

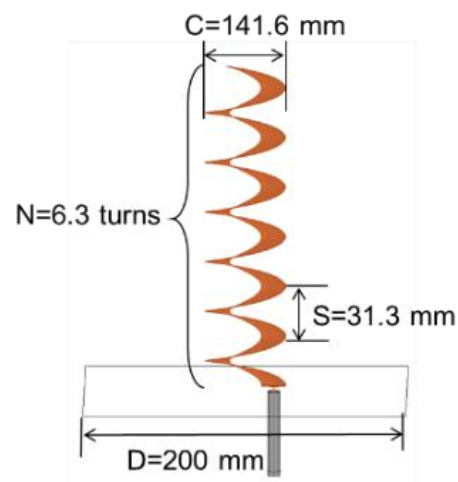

(a)

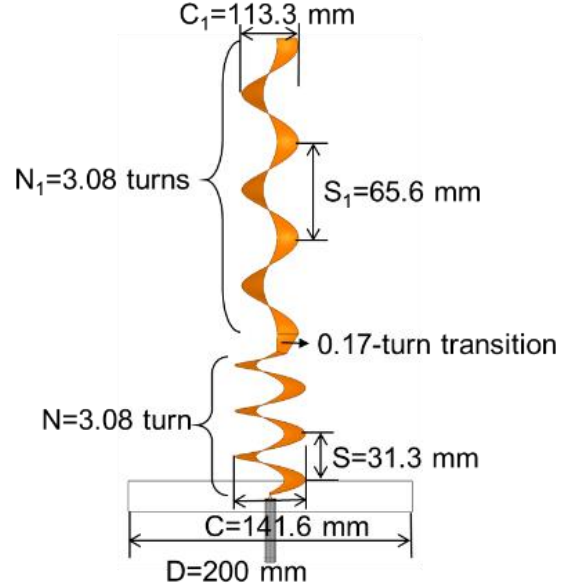

(b)

Figure 4.3. The geometries of: (a) standard helix, and (b) standard multi-radii helix.

It can be concluded from these results that:

1) The origami multi-radii helix exhibits widest $S_{11}$ bandwidth, as shown in Figure 4.4.

2) The standard multi-radii helix has the largest RHCP realized gain but has the narrowest 2-dB RHCP realized gain bandwidth $(\Delta f=35.9 \%)$.

3) Our origami multi-radii helix has the widest 2-dB RHCP realized gain bandwidth $(\Delta f=66.2 \%)$, which is approximately two times larger than the one of the standard multi-radii helix, while its maximum RHCP realized gain is smaller than the one of the standard multi-radii helix only by $1.1 \mathrm{~dB}$, as shown in Figure 4.5.

4) Our origami multi-radii helix has the widest $\mathrm{CP}$ bandwidth with $\mathrm{AR}<3 \mathrm{~dB}$ and the best $\mathrm{AR}$ performance (i.e., $\mathrm{AR}<0.7 \mathrm{~dB}$ ) during 2-dB RHCP gain $\mathrm{BW}$ out of all the three antennas compared here, as shown in Figure 4.6. 
5) The origami multi-radii helix also exhibits reconfigurable operating frequency band by changing its height as demonstrated in Section 4.2, whereas the two standard helical antennas do not.

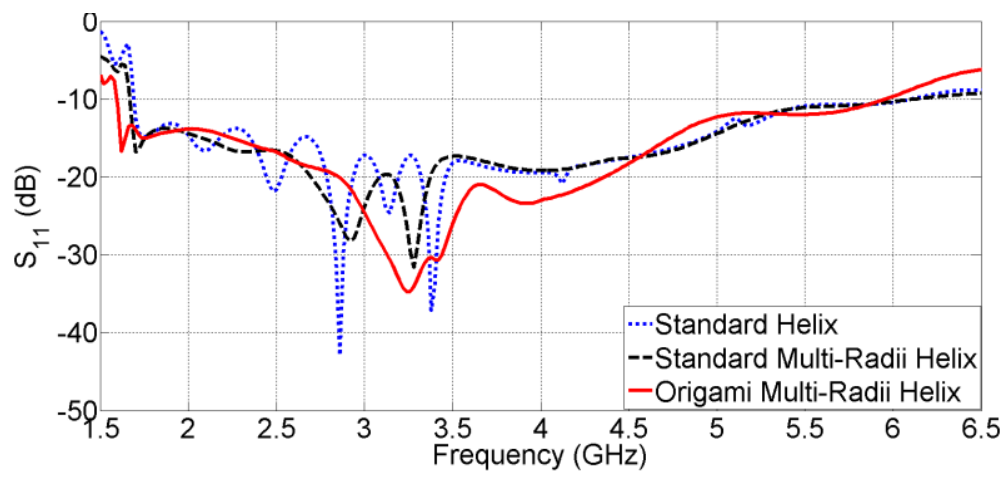

Figure 4.4. Comparison of simulated $S_{11}$ of standard monofilar, standard multi-radii, and origami multi-radii helices.

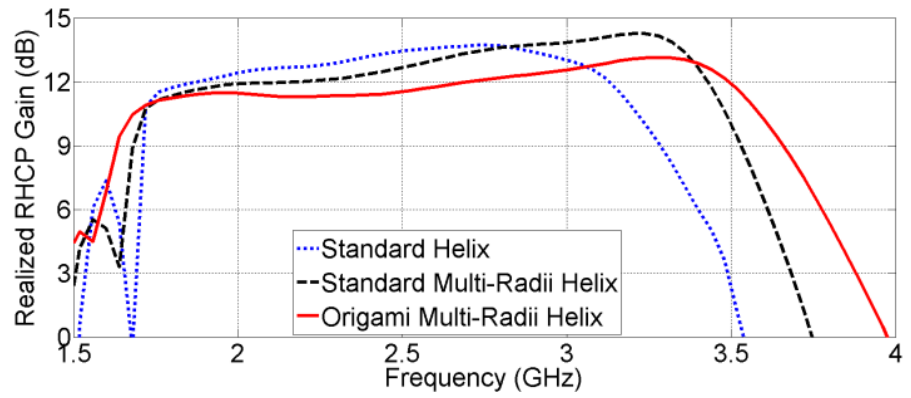

Figure 4.5. Comparison of simulated zenithal RHCP realized gain of standard, standard multi-radii, and origami multi-radii helices.

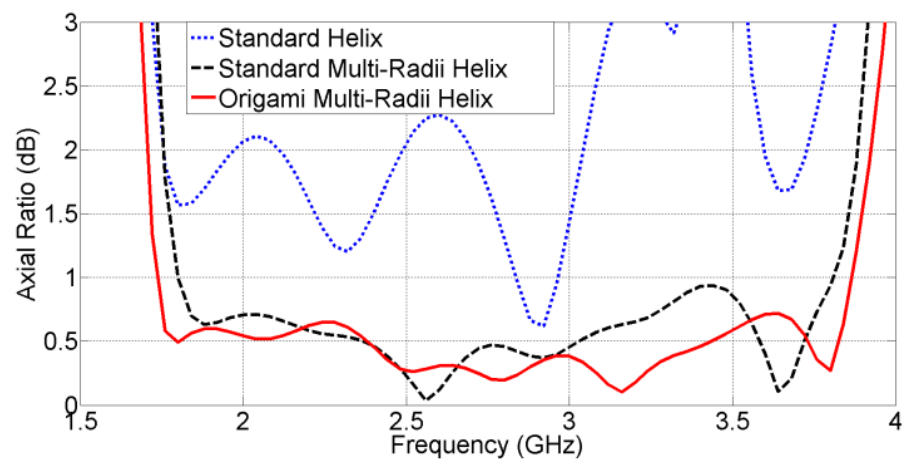

Figure 4.6. Comparison of simulated zenithal axial ratio of standard, standard multiradii, and origami multi-radii helices.

Also, the elevational radiation patterns of the three antennas at their corresponding center frequencies of operation, $f_{c}=\left(f_{\max }+f_{\min }\right) / 2$, are compared in Figure 4.7. Square ground 
planes of the same electrical size $\left(D=1.5 \lambda_{c}\right)$ at their $f_{c}$ were used for fair comparison of their sidelobes. It can be seen from Figure 4.7 that the multi-radii helices (origami and standard) have lower sidelobes than the ones of the standard helix.

Therefore, compared to the standard helices, the proposed origami multi-radii helix exhibits a larger $S_{11}$ bandwidth by up to $2 \%$, a larger CP BW by up to $22 \%$, a larger 2-dB RHCP realized gain bandwidth by up to $30.3 \%$ and the smallest AR. These outweigh the fact that the origami multi-radii helix exhibits a smaller RHCP gain by $1.1 \mathrm{~dB}$ compared to the standard multi-radii helix. In fact, the gain of the origami multi-radii helix can be further enhanced by adding a reflector without impairing its CP performance.

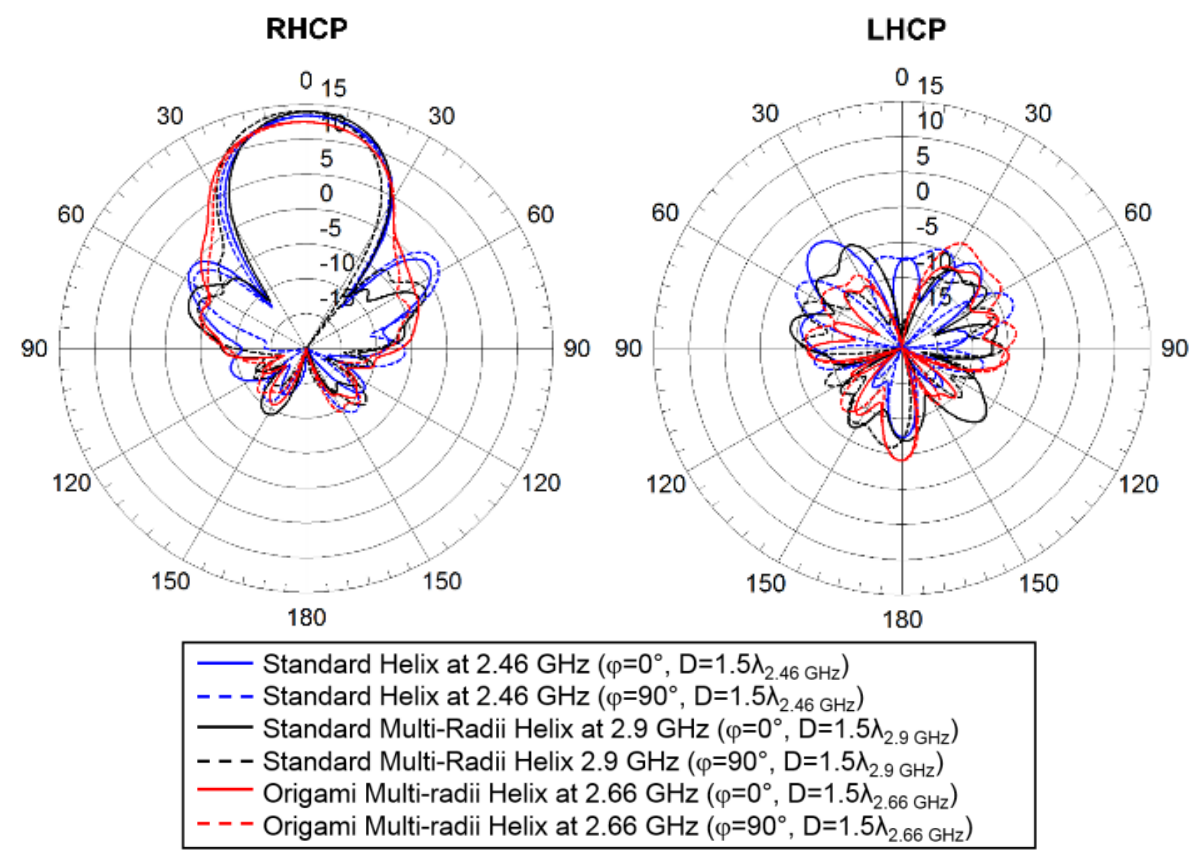

(a)

(b)

Figure 4.7. Comparison of simulated radiation patterns of standard, standard multiradii, and origami multi-radii helices at their center frequency of operation, $f_{c}$. 
Table 4.3. Performance Comparison of Standard, Standard Multi-Radii, and Origami Multi-Radii Helices.

\begin{tabular}{|c|c|c|c|}
\hline Antenna Performance & Standard Monofilar & $\begin{array}{l}\text { Standard Multi- } \\
\text { radii Monofilar }\end{array}$ & $\begin{array}{c}\text { Origami Multi-radii } \\
\text { Monofilar }\end{array}$ \\
\hline $\begin{array}{c}S_{11} B W \\
\left(S_{11}<-10 d B\right)\end{array}$ & $\begin{array}{c}1.69 \mathrm{GHz}-6.1 \mathrm{GHz} \\
(\Delta f=113 \%)\end{array}$ & $\begin{array}{c}1.67 \mathrm{GHz}-6.12 \mathrm{GHz} \\
(\Delta f=114 \%)\end{array}$ & $\begin{array}{c}1.6 \mathrm{GHz}-5.95 \mathrm{GHz} \\
(\Delta f=115 \%)\end{array}$ \\
\hline $\begin{array}{c}C P B W \\
(A R<3 d B)\end{array}$ & $\begin{array}{c}1.72 \mathrm{GHz}-3.12 \mathrm{GHz} \\
(\Delta f=57.9 \%)\end{array}$ & $\begin{array}{c}1.74 \mathrm{GHz}-3.9 \mathrm{GHz} \\
(\Delta f=76.6 \%)\end{array}$ & $\begin{array}{c}1.7 \mathrm{GHz}-3.96 \mathrm{GHz} \\
(\Delta f=79.9 \%)\end{array}$ \\
\hline Max. RHCP Gain & $13.7 \mathrm{~dB}$ & $14.3 \mathrm{~dB}$ & $13.2 \mathrm{~dB}$ \\
\hline $\begin{array}{l}\text { BW within -2 dB RHCP Gain } \\
\text { Variation from the Maximum }\end{array}$ & $\begin{array}{c}1.78 \mathrm{GHz}-3.12 \mathrm{GHz} \\
(\Delta f=54.7 \%)\end{array}$ & $\begin{array}{c}2.38 \mathrm{GHz}-3.42 \mathrm{GHz} \\
(\Delta f=35.9 \%)\end{array}$ & $\begin{array}{c}1.78 \mathrm{GHz}-3.54 \mathrm{GHz} \\
(\Delta f=66.2 \%)\end{array}$ \\
\hline $\begin{array}{c}\text { AR Range within RHCP } \\
\text { Gain } B W\end{array}$ & $0.6 \mathrm{~dB}-2.3 \mathrm{~dB}$ & $0.04 \mathrm{~dB}-0.9 \mathrm{~dB}$ & $0.1 \mathrm{~dB}-0.7 \mathrm{~dB}$ \\
\hline $\begin{array}{l}\text { Frequency Band } \\
\text { Reconfigurability }\end{array}$ & No & No & Yes \\
\hline
\end{tabular}

\subsubsection{Performance Comparison of Reconfigurable Origami Multi-Radii Monofilar with Previous Origami Monofilar}

The geometry of the single-radius (i.e., standard) origami helix at three states is shown in Figure 4.8. The pitch size $S$, circumference $C$ and pitch angle of the origami helix are the same with the ones of the bottom helix in the origami multi-radii helix at three states as shown in Figure 4.2. Also, both origami antennas have the same number of turns at the all three states. All other geometric parameters (i.e., $n, a$, ratio, $w, \theta$ ) are kept the same, including the ground plane size $(D=200 \mathrm{~mm})$, distance from the ground $(3.5 \mathrm{~mm})$, SMA feeding port and position of the antennas for a fair comparison.

The performances (i.e., $S_{11}$, zenithal realized RHCP gain, zenithal axial ratio and elevational radiation patterns) of the origami singe-radius and multi-radii helices is compared in all three states of operation in Figure 4.9-Figure 4.12. 


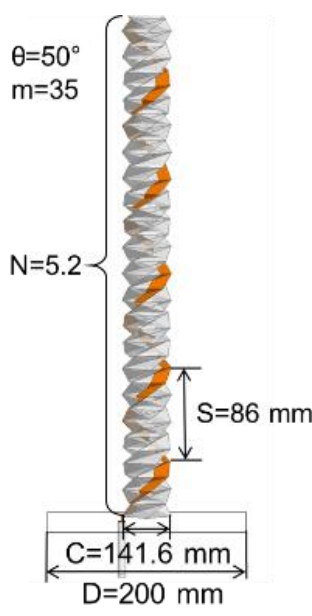

(a)

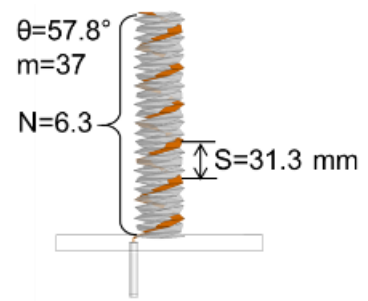

(b)

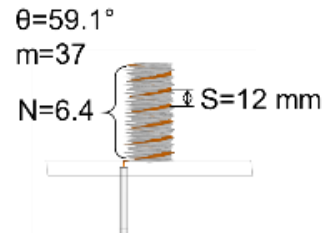

(c)

Figure 4.8. The origami monofilar to be compared with the origami multi-radii monofilar at: (a) state 1 (unfolded state), (b) state 2 (semi-folded state), and (c) state 3 (folded state).

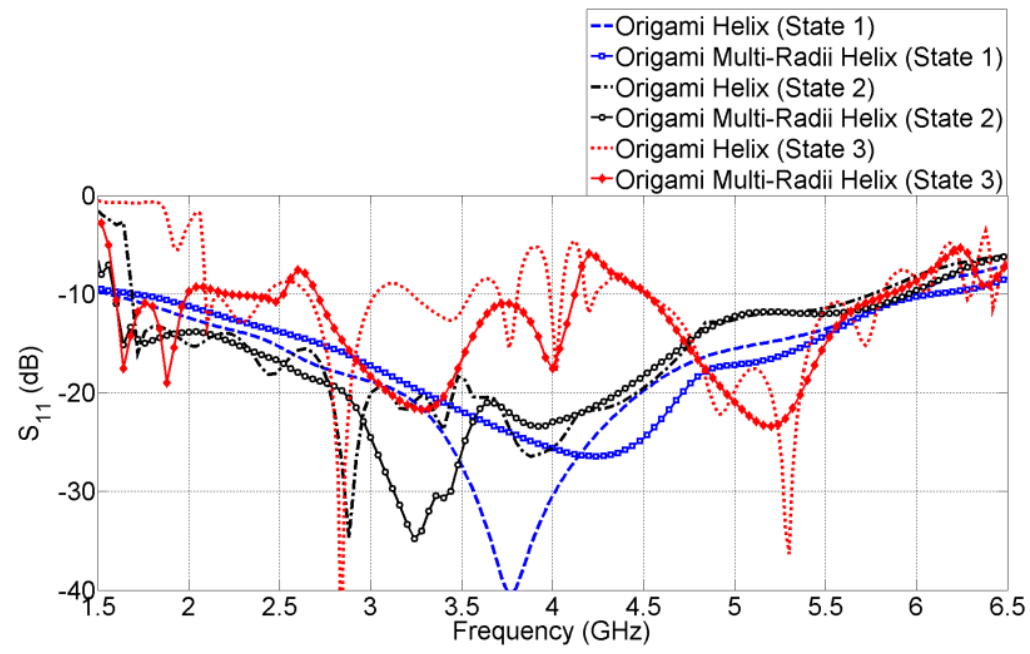

Figure 4.9. Comparison of simulated $S_{11}$ of origami single-radius and multi-radii helices at three states (blue lines: state 1; black lines: state 2; red lines: state 3). 


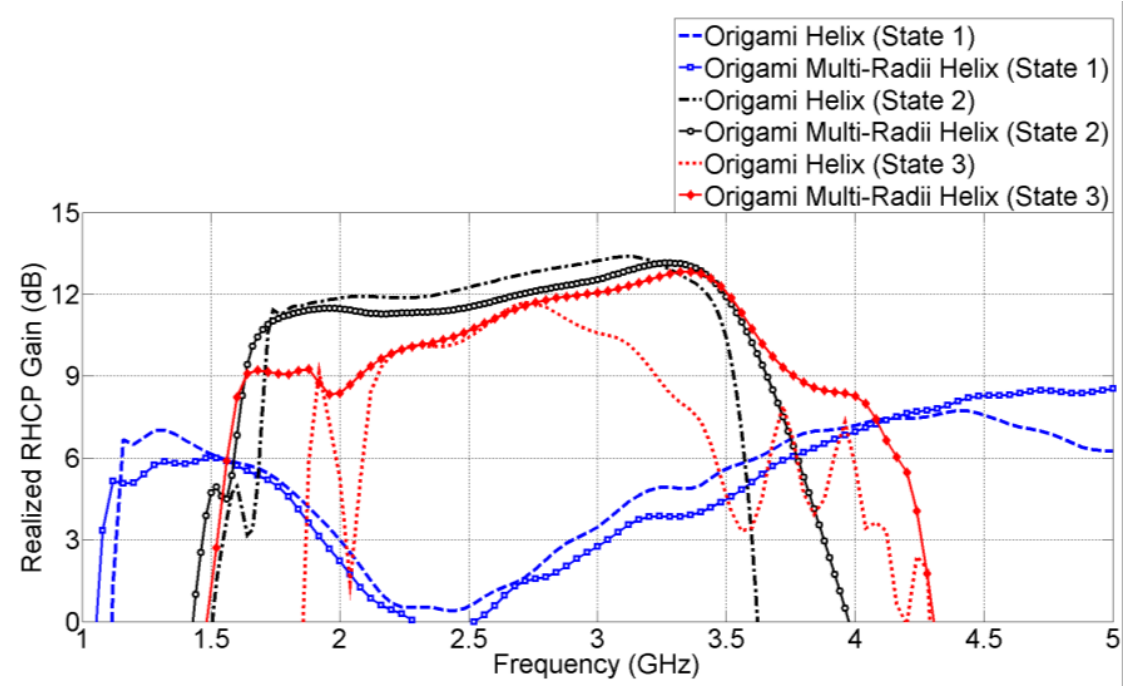

Figure 4.10. Comparison of simulated realized RHCP gain of origami single-radius and multi-radii helices at three states (blue lines: state 1; black lines: state 2; red lines: state 3).

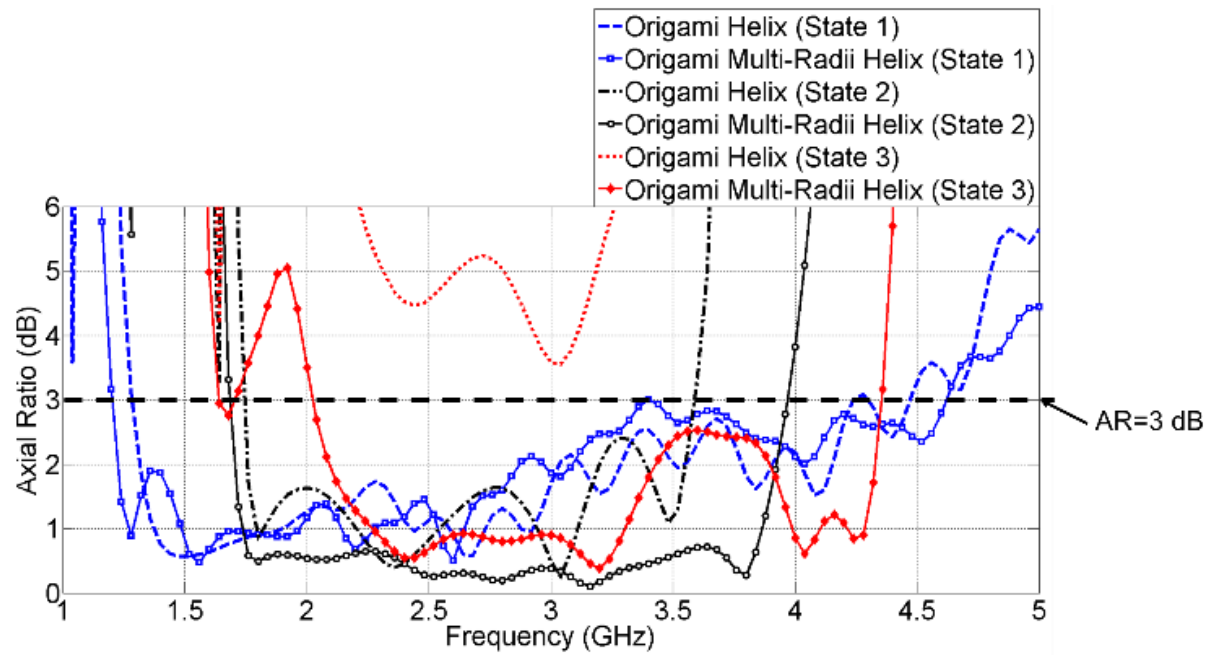

Figure 4.11. Comparison of simulated axial ratio of origami single-radius and multiradii helices at three states (blue lines: state 1; black lines: state 2; red lines: state 3).

The comparison of these results is summarized in Table 4.4. The following conclusions are drawn:

1) The standard origami helix, shown in Figure 4.8, can operate in only the first two states with $\mathrm{CP}$ performance covering the following frequency band: $1.3 \mathrm{GHz}-3.46$ GHz. However, the proposed origami multi-radii helix can operate at three states with $\mathrm{CP}$ performance covering the following bands: $1.22 \mathrm{GHz}-3.54 \mathrm{GHz}$ and $3.64 \mathrm{GHz}-4.04 \mathrm{GHz}$. 
2) The origami multi-radii helix has a smaller maximum AR at states 2 and 3, as shown in Figure 4.11.

3) At states 2 and 3, the origami multi-radii helix has lower sidelobe level than that of the standard origami helix. Also, at state 3 the origami multi-radii helix has a maximum RHCP gain that is larger by $2.8 \mathrm{~dB}$ than the one of the standard origami helix.

Table 4.4. Performance Comparison of Origami Multi-Radii Monofilar with Origami

Monofilar.

\begin{tabular}{|c|c|c|c|c|c|c|}
\hline \multicolumn{2}{|c|}{$\begin{array}{c}\text { State of Origami } \\
\text { Antennas }\end{array}$} & $\begin{array}{c}S_{11} \mathrm{BW} \\
\left(S_{11}^{<-10 ~ d B)}\right)\end{array}$ & $\begin{array}{c}\text { CP BW } \\
(\mathbf{A R}<-3 \mathrm{~dB})\end{array}$ & $\begin{array}{c}\text { Realized RHCP } \\
\text { Gain BW } \\
\text { within -2 dB } \\
\text { Variation from } \\
\text { the Maximum } \\
\end{array}$ & $\begin{array}{c}\text { Max. } \\
\text { Realized } \\
\text { RHCP } \\
\text { Gain }\end{array}$ & $\begin{array}{c}\text { AR Range } \\
\text { within 2- } \\
\text { dB RHCP } \\
\text { Gain BW }\end{array}$ \\
\hline \multirow[b]{2}{*}{1} & $\begin{array}{c}\text { Origami } \\
\text { Monofilar }\end{array}$ & $\begin{array}{l}1.56 \mathrm{GHz}- \\
5.96 \mathrm{GHz} \\
(\Delta f=117 \%)\end{array}$ & $\begin{array}{c}1.32 \mathrm{GHz}^{-} \\
4.2 \mathrm{GHz} \\
(\Delta f=104 \%)\end{array}$ & $\begin{array}{c}1.3 \mathrm{GHz}- \\
1.78 \mathrm{GHz} \\
(\Delta f=31.2 \%)\end{array}$ & $7 \mathrm{~dB}$ & $0.6 \mathrm{~dB}-3 \mathrm{~dB}$ \\
\hline & $\begin{array}{c}\text { Origami } \\
\text { Multi-radii } \\
\text { Monofilar }\end{array}$ & $\begin{array}{l}1.7 \mathrm{GHz}- \\
6.1 \mathrm{GHz} \\
(\Delta f=113 \%)\end{array}$ & $\begin{array}{l}1.22 \mathrm{GHz}- \\
3.4 \mathrm{GHz} \\
(\Delta f=94 \%)\end{array}$ & $\begin{array}{c}1.22 \mathrm{GHz}- \\
1.84 \mathrm{GHz} \\
(\Delta f=42.1 \%)\end{array}$ & $6.1 \mathrm{~dB}$ & $0.5 \mathrm{~dB}-3 \mathrm{~dB}$ \\
\hline \multirow{2}{*}{2} & $\begin{array}{c}\text { Origami } \\
\text { Monofilar }\end{array}$ & $\begin{array}{c}1.7 \mathrm{GHz}-5.76 \\
\mathrm{GHz} \\
(\Delta f=109 \%)\end{array}$ & $\begin{array}{c}1.75 \mathrm{GHz}- \\
3.59 \mathrm{GHz} \\
(\Delta f=68.9 \%)\end{array}$ & $\begin{array}{c}1.78 \mathrm{GHz}- \\
3.46 \mathrm{GHz} \\
(\Delta f=64.1 \%)\end{array}$ & $13.4 \mathrm{~dB}$ & $\begin{array}{l}0.3 \mathrm{~dB}- \\
2.4 \mathrm{~dB}\end{array}$ \\
\hline & $\begin{array}{c}\text { Origami } \\
\text { Multi-radii } \\
\text { Monofilar } \\
\end{array}$ & $\begin{array}{c}1.6 \mathrm{GHz}- \\
5.96 \mathrm{GHz} \\
(\Delta f=116 \%) \\
\end{array}$ & $\begin{array}{c}1.69 \mathrm{GHz}- \\
3.94 \mathrm{GHz} \\
(\Delta f=79.9 \%)\end{array}$ & $\begin{array}{c}1.78 \mathrm{GHz}- \\
3.54 \mathrm{GHz} \\
(\Delta f=66.2 \%)\end{array}$ & $13 \mathrm{~dB}$ & $\begin{array}{l}0.1 \mathrm{~dB}- \\
0.6 \mathrm{~dB}\end{array}$ \\
\hline \multirow{2}{*}{3} & $\begin{array}{c}\text { Origami } \\
\text { Monofilar }\end{array}$ & $\begin{array}{c}2.66 \mathrm{GHz}- \\
3.02 \mathrm{GHz} \\
(\Delta f=12.7 \%)\end{array}$ & N/A & $\begin{array}{c}3.9 \mathrm{GHz}-4 \mathrm{GHz} \\
(\Delta f=2.5 \%)\end{array}$ & $7.3 \mathrm{~dB}$ & $9 \mathrm{~dB}-10 \mathrm{~dB}$ \\
\hline & $\begin{array}{c}\text { Origami } \\
\text { Multi-radii } \\
\text { Monofilar }\end{array}$ & $\begin{array}{l}2.18 \mathrm{GHz}- \\
4.1 \mathrm{GHz} \\
(\Delta f=116 \%)\end{array}$ & $\begin{array}{c}1.6 \mathrm{GHz}- \\
4.4 \mathrm{GHz} \\
(\Delta f=93.3 \%)\end{array}$ & $\begin{array}{c}3.64 \mathrm{GHz}- \\
4.04 \mathrm{GHz} \\
(4 f=10.4 \%)\end{array}$ & $10.1 \mathrm{~dB}$ & $\begin{array}{l}0.6 \mathrm{~dB}- \\
2.5 \mathrm{~dB}\end{array}$ \\
\hline
\end{tabular}




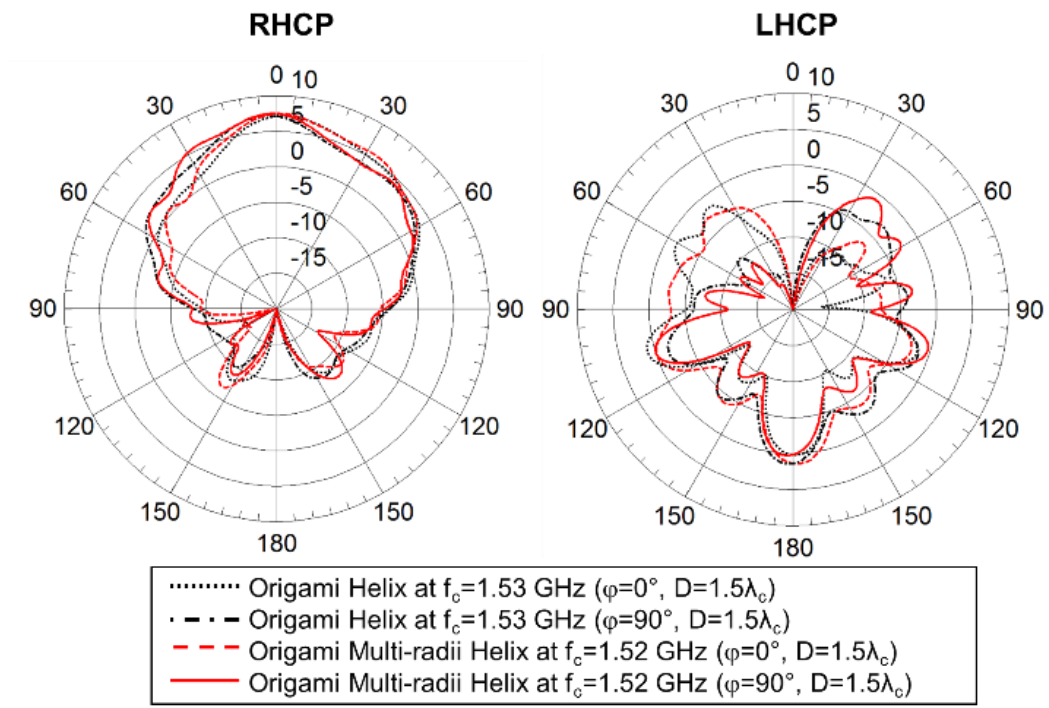

(a) State 1 at $f_{c}$
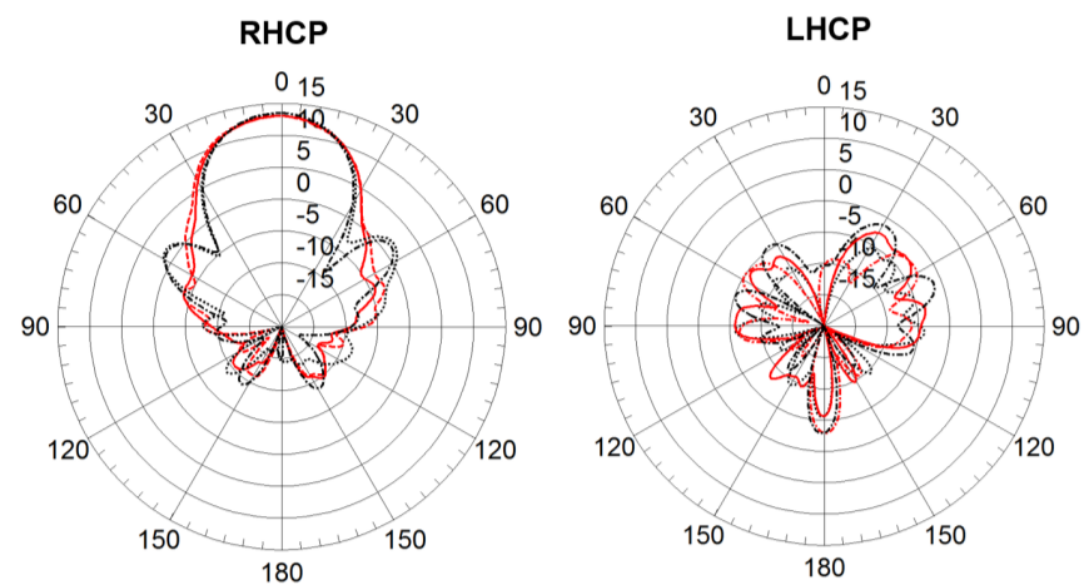

…… Origami Helix at $\mathrm{f}_{\mathrm{c}}=2.62 \mathrm{GHz}\left(\varphi=0^{\circ}, \mathrm{D}=1.5 \lambda_{\mathrm{c}}\right)$
--- Origami Helix at $\mathrm{f}_{\mathrm{c}}=2.62 \mathrm{GHz}\left(\varphi=90^{\circ}, \mathrm{D}=1.5 \lambda_{\mathrm{c}}\right)$
--- Origami Multi-radii Helix at $\mathrm{f}_{\mathrm{c}}=2.65 \mathrm{GHz}\left(\varphi=0^{\circ}, \mathrm{D}=1.5 \lambda_{\mathrm{c}}\right)$
- Origami Multi-radii Helix at $\mathrm{f}_{\mathrm{c}}=2.65 \mathrm{GHz}\left(\varphi=90^{\circ}, \mathrm{D}=1.5 \lambda_{\mathrm{c}}\right)$

(b) State 2 at $f_{c}$ 


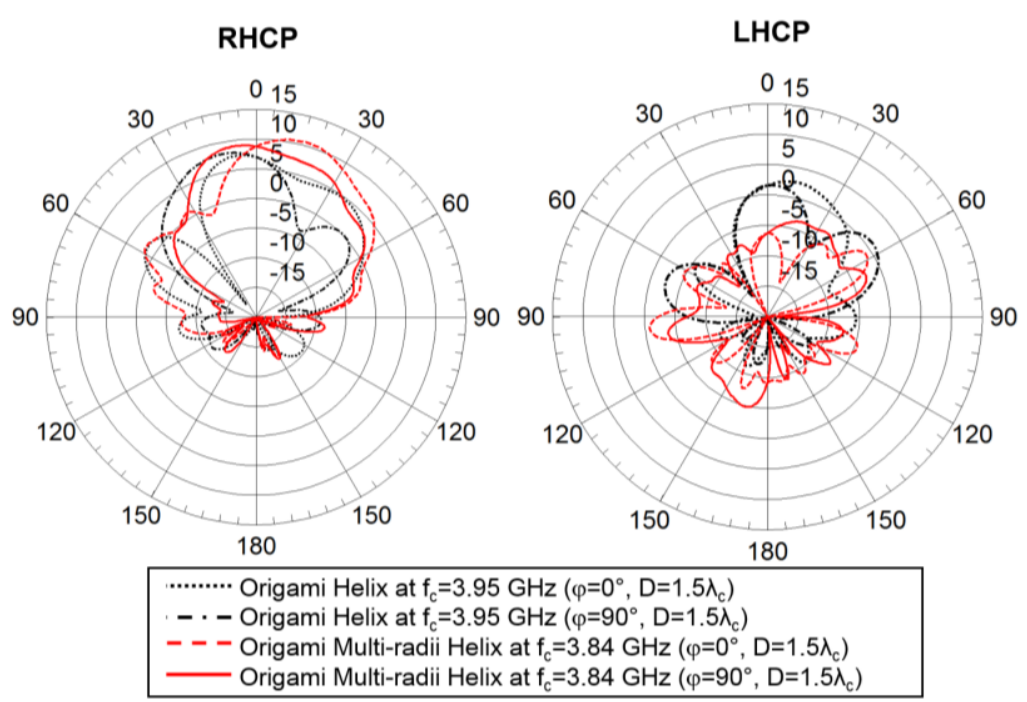

(c) State 3 at $f_{c}$

Figure 4.12. Comparison of simulated elevational radiation patterns of the origami single-radius and multi-radii helices at the center frequencies $f_{c}$ in their 2-dB realized gain bandwidths at: (a) state 1; (b) state 2; and (c) state 3.

\subsection{Parametric Analysis of the Origami Multi-radii Helical Antenna}

The process to design the origami multi-radii monofilar has been elucidated in section 4.2, and the details in determining its parameters at state 2 will be shown here. Determining its parameters at other states follows similar process and will be omitted. First, the dimension of the bottom helix, $a$, is determined using Eqn. (4.10) as $35.4 \mathrm{~mm}$ to make the antenna operate at approximately $1.48 \mathrm{GHz}-2.82 \mathrm{GHz}$. Then, the other parameters are determined as it will be described below.

\subsubsection{Determining Parameter a1 of the Top Helix}

The circumference of the top helix needs to be determined such that the AR and RHCP gain of the multi-radii antenna improve at state 2. The successive parameter $a_{l}$ in Table 4.2 can be optimized by varying the dominant parameter $f_{\text {scale }}$ which is the ratio of the radial dimension of the top helix to the one of the bottom helix (i.e., $f_{\text {scale }}=a_{1} / a$ ) in 
Table 4.1. Also, the ratio $_{1}$ is picked using Eqn. (4.2) so that the pitch size of the top helix, $S_{1}$, remains constant for different values of $f_{\text {scale. }}$ The geometric parameters of this antenna that remain constant during this optimization are shown in Table 4.5.

Table 4.5. Constant Parameters of the Antenna with Varying $f_{\text {scale. }}$

\begin{tabular}{|c|c|c|c|c|c|c|c|}
\hline $\boldsymbol{a}$ & $\boldsymbol{m}, \boldsymbol{m}_{\boldsymbol{I}}$ & $\boldsymbol{n}$ & ratio & $\boldsymbol{\theta}_{\boldsymbol{\theta}} \boldsymbol{\theta}_{\boldsymbol{I}}$ & $\boldsymbol{N}, \boldsymbol{N}_{\boldsymbol{I}}$ & $\boldsymbol{S}$ & $\boldsymbol{S}_{\boldsymbol{I}}$ \\
\hline $35.4 \mathrm{~mm}$ & 18 & 4 & 0.7 & $57.8^{\circ}$ & 3.08 & $31.3 \mathrm{~mm}$ & $40 \mathrm{~mm}$ \\
\hline
\end{tabular}

The simulated performance of the antenna for different values of $f_{\text {scale }}$ is summarized in Table 4.6, where it can be seen that as $f_{\text {scale }}$ increases, the 2-dB RHCP gain bandwidth decreases. The geometries of the considered antennas are shown in Figure 4.13. When $f_{\text {scale }}$ becomes larger than 1 , the operating frequency band of the antenna shifts to lower frequencies. Also, the maximum gain and best $\mathrm{AR}$ values are achieved when $f_{\text {scale }}=0.8$. Therefore, $f_{\text {scale }}$ is selected as 0.8 for optimum RHCP gain and AR without decreasing significantly the 2-dB RHCP bandwidth.

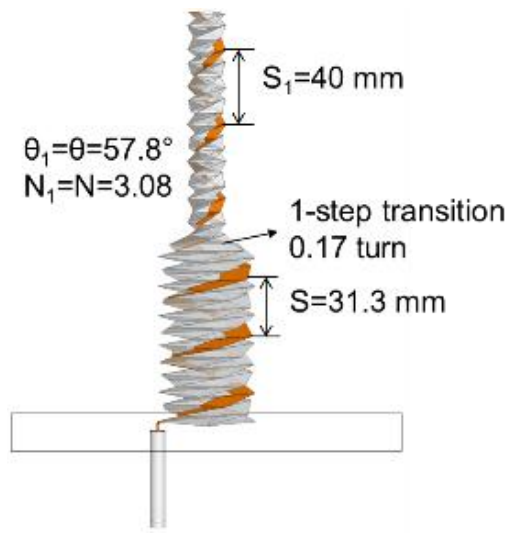

(a) $f_{\text {scale }}=0.4$

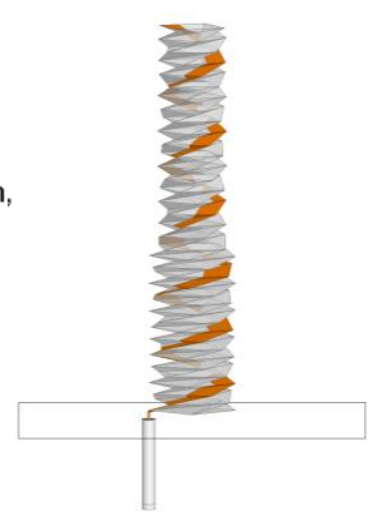

(b) $f_{\text {scale }}=0.8$

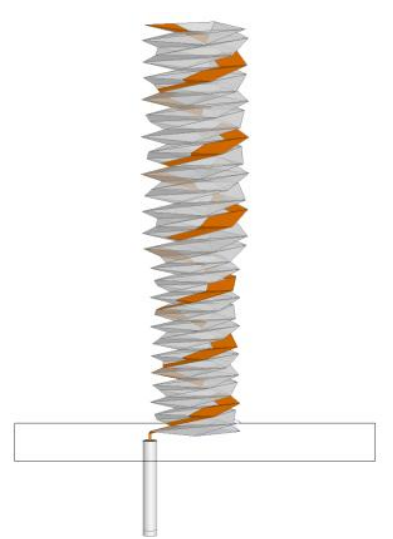

(c) $f_{\text {scale }}=1.2$

Figure 4.13. Models of multi-radii monofilar with variable $f_{\text {scale }}$. 
Table 4.6. Simulated Antenna Performances vs $f_{\text {scale }}$ and $a_{l}$.

\begin{tabular}{|c|c|c|c|c|}
\hline$f_{\text {scale }}$ & $a_{l}$ & $\begin{array}{c}\text { Bandwidth with }-2 \mathrm{~dB} \text { RHCP } \\
\text { Gain Variation from the } \\
\text { Maximum }\end{array}$ & $\begin{array}{c}\text { Max. RHCP } \\
\text { Gain }\end{array}$ & AR Range \\
\hline 0.4 & $14.2 \mathrm{~mm}$ & $\begin{array}{c}1.94 \mathrm{GHz}-3.52 \mathrm{GHz} \\
(\Delta f=57.9 \%)\end{array}$ & $11.4 \mathrm{~dB}$ & $0.4 \mathrm{~dB}-2.9 \mathrm{~dB}$ \\
\hline 0.8 & $28.3 \mathrm{~mm}$ & $\begin{array}{c}2 \mathrm{GHz}-3.52 \mathrm{GHz} \\
(\Delta f=55.1 \%)\end{array}$ & $13.2 \mathrm{~dB}$ & $0 \mathrm{~dB}-2.1 \mathrm{~dB}$ \\
\hline 1.2 & $42.4 \mathrm{~mm}$ & $\begin{array}{c}1.64 \mathrm{GHz}-2.72 \mathrm{GHz} \\
(\Delta f=49.5 \%)\end{array}$ & $13 \mathrm{~dB}$ & $0.1 \mathrm{~dB}-2.9 \mathrm{~dB}$ \\
\hline
\end{tabular}

\subsubsection{Determining the Number of Turns of the Large Helix}

The number of turns of the large helix, $N$, is optimized for best 2-dB RHCP gain BW. To vary $N$, we vary the number of steps of the large helix, $m$, while maintaining constant $\theta$ and $n$, as shown in Eqn. (4.3). When $m$ changes from 6 to 30, the number of turns of the large helix changes from 1.03 to 5.13, respectively. The antenna performance for different values of $m_{1}$ (and corresponding $N$ ) is shown in Table 4.8. The parameters that remain constant are listed in Table 4.7. It can be concluded from Table 4.8 that when $m=18$, the optimum 2-dB RHCP gain bandwidth is achieved.

Table 4.7. Constant Parameters of the Antenna with Varying $m$.

\begin{tabular}{|c|c|c|c|c|c|c|c|c|}
\hline $\boldsymbol{a}$ & $\boldsymbol{m}_{\boldsymbol{I}}$ & $\boldsymbol{n}$ & ratio, ratio $_{\boldsymbol{I}}$ & $\boldsymbol{f}_{\text {scale }}$ & $\boldsymbol{\theta}, \boldsymbol{\theta}_{\boldsymbol{I}}$ & $\boldsymbol{N}_{\boldsymbol{I}}$ & $\boldsymbol{S}$ & $\boldsymbol{S}_{\boldsymbol{I}}$ \\
\hline $35.4 \mathrm{~mm}$ & 18 & 4 & 0.7 & 0.8 & $57.8^{\circ}$ & 3.08 & $31.3 \mathrm{~mm}$ & $25 \mathrm{~mm}$ \\
\hline
\end{tabular}

Table 4.8. Simulated Antenna Performances vs $m$.

\begin{tabular}{|c|c|c|c|c|}
\hline$m$ & $N$ & $\begin{array}{c}\text { Bandwidth with }-2 \mathrm{~dB} \text { RHCP } \\
\text { Gain Variation from the } \\
\text { Maximum }\end{array}$ & Max. RHCP Gain & AR Range \\
\hline 6 & 1.03 & $\begin{array}{c}2.2 \mathrm{GHz}-3.08 \mathrm{GHz} \\
(\Delta f=33.3 \%)\end{array}$ & $11 \mathrm{~dB}$ & $0.1 \mathrm{~dB}-2.9 \mathrm{~dB}$ \\
\hline 18 & 3.08 & $\begin{array}{c}1.94 \mathrm{GHz}-3.46 \mathrm{GHz} \\
(\Delta f=56.3 \%)\end{array}$ & $12.7 \mathrm{~dB}$ & $0.4 \mathrm{~dB}-3 \mathrm{~dB}$ \\
\hline 30 & 5.13 & $\begin{array}{c}1.92 \mathrm{GHz}-3.34 \mathrm{GHz} \\
(\Delta f=54 \%)\end{array}$ & $13.7 \mathrm{~dB}$ & $0.3 \mathrm{~dB}-2.4 \mathrm{~dB}$ \\
\hline
\end{tabular}

\subsubsection{Determining the Number of Turns of the Small Helix}

Similarly, the number of turns of the small helix, $N_{l}$, is optimized for best 2-dB 
RHCP gain BW. To vary $N_{l}$, we vary the number of steps of the small helix, $m_{l}$, while maintaining constant $\theta_{1}$ and $n$, as shown in Eqn. (4.4). When $m_{l}$ is changed from 0 to 30, the number of turns of the small helix is changed from 0 to 5.13. The antenna performance for different values of $m_{l}$ (and corresponding $N$ ) is shown in Table 4.10. The parameters that remain constant are listed in Table 4.9. We select $m_{l}=18$ to as compromise for optimal 2-dB RHCP gain bandwidth and maximum RHCP gain.

Table 4.9. Constant Parameters of the Antenna with Varying $m_{l}$.

\begin{tabular}{|c|c|c|c|c|c|c|c|c|}
\hline $\boldsymbol{a}$ & $\boldsymbol{m}$ & $\boldsymbol{n}$ & ratio, ratio $\boldsymbol{1}$ & $\boldsymbol{f}_{\text {scale }}$ & $\boldsymbol{\theta}, \boldsymbol{\theta}_{\boldsymbol{1}}$ & $\boldsymbol{N}$ & $\boldsymbol{S}$ & $\boldsymbol{S}_{\boldsymbol{I}}$ \\
\hline $35.4 \mathrm{~mm}$ & 18 & 4 & 0.7 & 0.8 & $57.8^{\circ}$ & 3.08 & $31.3 \mathrm{~mm}$ & $25 \mathrm{~mm}$ \\
\hline
\end{tabular}

Table 4.10. Simulated Antenna Performances vs $m_{1}$.

\begin{tabular}{|c|c|c|c|c|}
\hline$m_{l}$ & $N_{l}$ & $\begin{array}{c}\text { Bandwidth with }-2 \mathrm{~dB} \text { RHCP Gain } \\
\text { Variation from the Maximum }\end{array}$ & Max. RHCP Gain & AR Range \\
\hline 0 & 0 & $\begin{array}{c}1.94 \mathrm{GHz}-3.26 \mathrm{GHz} \\
(\Delta f=50.8 \%)\end{array}$ & $11.1 \mathrm{~dB}$ & $0.7 \mathrm{~dB}-2.7 \mathrm{~dB}$ \\
\hline 6 & 1.03 & $\begin{array}{c}1.94 \mathrm{GHz}-3.5 \mathrm{GHz} \\
(\Delta f=57.4 \%)\end{array}$ & $11.6 \mathrm{~dB}$ & $0.3 \mathrm{~dB}-3 \mathrm{~dB}$ \\
\hline 18 & 3.08 & $\begin{array}{c}1.94 \mathrm{GHz}-3.46 \mathrm{GHz}-3 \mathrm{~dB} \\
(\Delta f=56.3 \%)\end{array}$ \\
\hline 30 & 5.13 & $\begin{array}{c}2.04 \mathrm{GHz}-3.42 \mathrm{GHz} \\
(\Delta f=50.5 \%)\end{array}$ & $13.5 \mathrm{~dB}$ & $0.5 \mathrm{~dB}-1.9 \mathrm{~dB}$ \\
\hline
\end{tabular}

\subsubsection{Spacing between Adjacent Turns of Bottom Helix}

The spacing between adjacent turns of the bottom helix, $S$, determines the frequency-band reconfigurability of the multi-radii antenna as shown in Table 4.12. According to Eqn. (4.1), $S$ is only related to the ratio of unit lengths in Figure 4.1, when all other parameters of the antenna constant (these are listed in Table 4.11). Therefore, we vary the ratio and the geometries of the considered antennas are shown in Figure 4.14.

Table 4.11. Constant Parameters of the Antenna with Varying ratio.

\begin{tabular}{|c|c|c|c|c|c|c|c|}
\hline $\boldsymbol{a}$ & $\boldsymbol{m}, \boldsymbol{m}_{\boldsymbol{I}}$ & $\boldsymbol{n}$ & ratio $_{\boldsymbol{I}}$ & $\boldsymbol{f}_{\text {scale }}$ & $\boldsymbol{\theta}, \boldsymbol{\theta}_{\boldsymbol{I}}$ & $\boldsymbol{N}_{,} \boldsymbol{N}_{\boldsymbol{I}}$ & $\boldsymbol{S}_{\boldsymbol{I}}$ \\
\hline $35.4 \mathrm{~mm}$ & 18 & 4 & 0.72 & 0.8 & $57.8^{\circ}$ & 3.08 & $40 \mathrm{~mm}$ \\
\hline
\end{tabular}




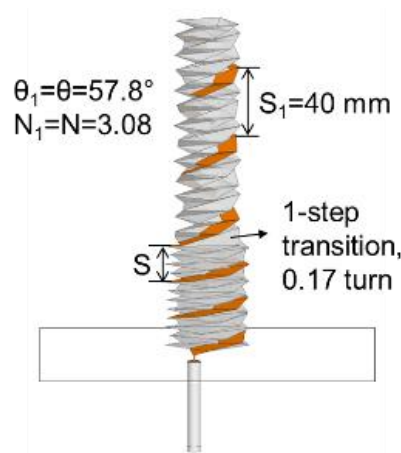

(a) $S=20 \mathrm{~mm}$

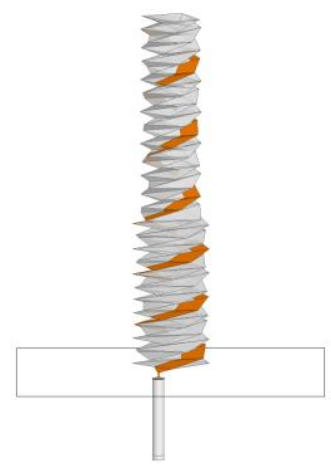

(b) $S=31.3 \mathrm{~mm}$

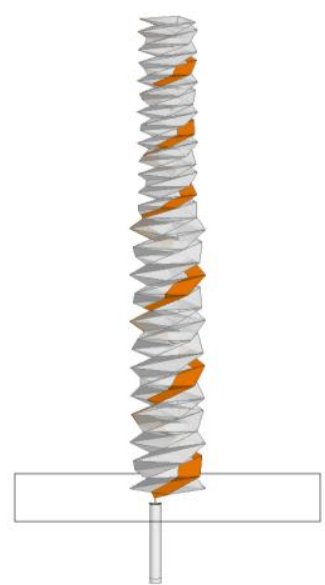

(c) $S=60 \mathrm{~mm}$

Figure 4.14. Models of multi-radii helix with variable $S$.

The simulated performance of the antenna versus $S$ is summarized in Table 4.12 and shows that as $S$ increases, the operating frequency band of the multi-radii helix shifts to lower frequencies, and the 2-dB gain bandwidth will first increase and then decrease. Therefore, the optimal $S$ to achieve the widest 2-dB RHCP gain bandwidth is $31.3 \mathrm{~mm}$ which corresponds to a ratio of 0.7 .

Table 4.12. $\quad$ Simulated Antenna Performances vs $S$.

\begin{tabular}{|c|c|c|c|c|}
\hline ratio & $S$ & $\begin{array}{c}\text { Bandwidth with }-2 \mathrm{~dB} \text { RHCP } \\
\text { Gain Variation from the } \\
\text { Maximum }\end{array}$ & $\begin{array}{c}\text { Max. RHCP } \\
\text { Gain }\end{array}$ & AR Range \\
\hline 0.69 & $20 \mathrm{~mm}$ & $\begin{array}{c}2.48 \mathrm{GHz}-3.66 \mathrm{GHz} \\
(\Delta f=38.4 \%)\end{array}$ & $13.9 \mathrm{~dB}$ & $0.2 \mathrm{~dB}-1.9 \mathrm{~dB}$ \\
\hline 0.7 & $31.3 \mathrm{~mm}$ & $\begin{array}{c}2 \mathrm{GHz}-3.52 \mathrm{GHz} \\
(\Delta f=55.1 \%)\end{array}$ & $13.2 \mathrm{~dB}$ & $0 \mathrm{~dB}-2.1 \mathrm{~dB}$ \\
\hline 0.74 & $60 \mathrm{~mm}$ & $\begin{array}{c}1.76 \mathrm{GHz}-2.12 \mathrm{GHz} \\
(\Delta f=18.6 \%)\end{array}$ & $9.8 \mathrm{~dB}$ & $0.7 \mathrm{~dB}-2.6 \mathrm{~dB}$ \\
\hline
\end{tabular}

\subsubsection{Spacing between Adjacent Turns of Top Monofilar-S1}

Similarly, from Eqn. (4.2), we can optimize $S_{l}$ by keeping all other parameters constant except for ratiol. Also, the antenna models for different values of $S_{1}$ are shown in Figure 4.15. The parameters that remain constant are listed in Table 4.13. 
Table 4.13. Constant Parameters of the Antenna with Varying ratio.

\begin{tabular}{|c|c|c|c|c|c|c|c|}
\hline $\boldsymbol{a}$ & $\boldsymbol{m}, \boldsymbol{m}_{\boldsymbol{I}}$ & $\boldsymbol{n}$ & ratio & $\boldsymbol{f}_{\text {scale }}$ & $\boldsymbol{\theta}, \boldsymbol{\theta}_{\boldsymbol{I}}$ & $\boldsymbol{N}, \boldsymbol{N}_{\boldsymbol{I}}$ & $\boldsymbol{S}$ \\
\hline $35.4 \mathrm{~mm}$ & 18 & 4 & 0.7 & 0.8 & $57.8^{\circ}$ & 3.08 & $31.3 \mathrm{~mm}$ \\
\hline
\end{tabular}

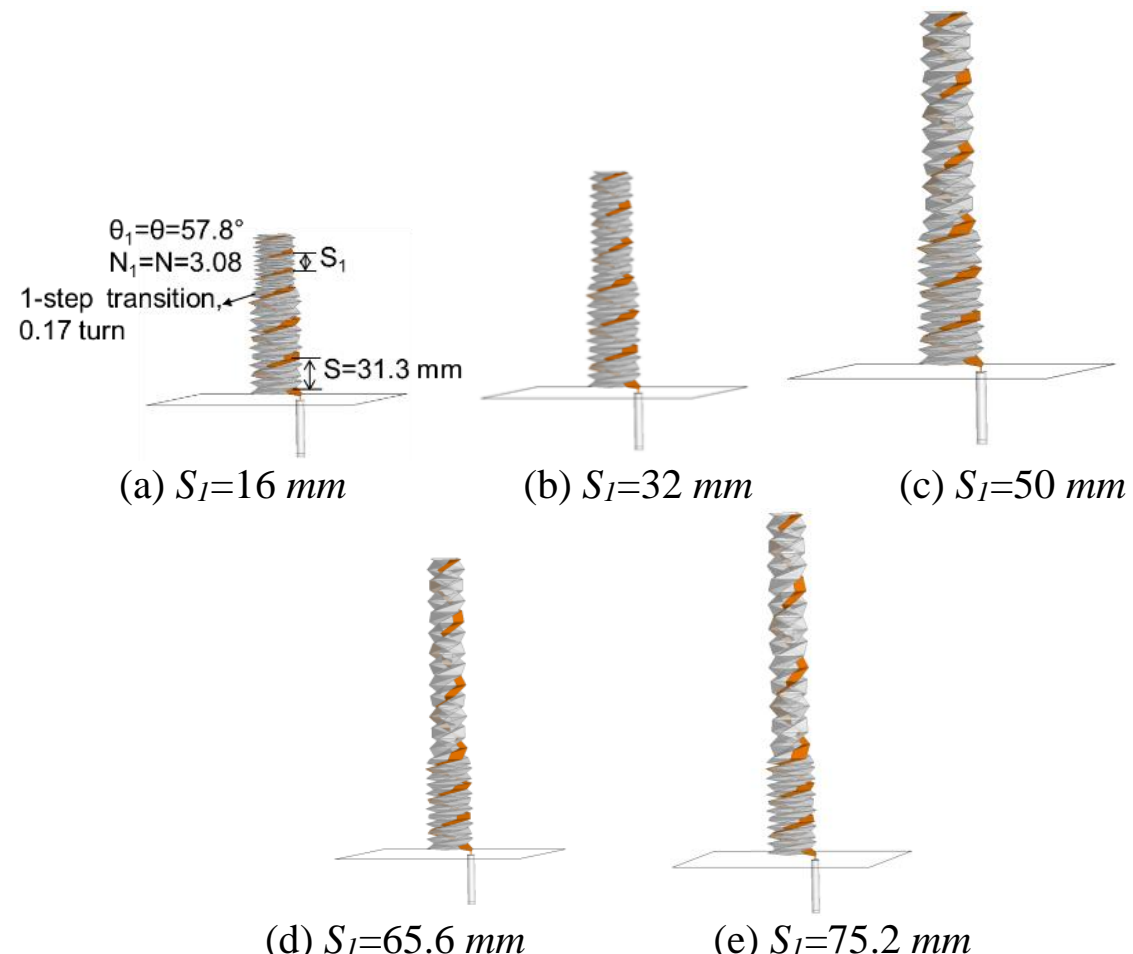

Figure 4.15. Models of multi-radii helix with variable $S_{1}$.

Table 4.14 shows that there is the optimal $S_{1}$ of $65.6 \mathrm{~mm}$ achieves the widest 2-dB RHCP gain bandwidth $(\Delta f=68.7 \%)$ without significantly impacting the maximum gain.

Table 4.14. Simulated Antenna Performances vs $S_{l}$.

\begin{tabular}{|c|c|c|c|c|}
\hline ratio $_{1}$ & $S_{l}$ & $\begin{array}{c}\text { Bandwidth with }-2 \mathrm{~dB} \text { RHCP } \\
\text { Gain Variation from the } \\
\text { Maximum }\end{array}$ & $\begin{array}{c}\text { Max. RHCP } \\
\text { Gain }\end{array}$ & AR Range \\
\hline 0.69 & $16 \mathrm{~mm}$ & $\begin{array}{c}2.4 \mathrm{GHz}-3.1 \mathrm{GHz} \\
(\Delta f=25.5 \%)\end{array}$ & $12.5 \mathrm{~dB}$ & $0.6 \mathrm{~dB}-3 \mathrm{~dB}$ \\
\hline 0.71 & $32 \mathrm{~mm}$ & $\begin{array}{c}1.96 \mathrm{GHz}-3.48 \mathrm{GHz} \\
(\Delta f=55.9 \%)\end{array}$ & $13.2 \mathrm{~dB}$ & $0.5 \mathrm{~dB}-2.9 \mathrm{~dB}$ \\
\hline 0.75 & $50 \mathrm{~mm}$ & $\begin{array}{c}1.96 \mathrm{GHz}-3.44 \mathrm{GHz} \\
(\Delta f=54.8 \%)\end{array}$ & $13.2 \mathrm{~dB}$ & $0.1 \mathrm{~dB}-1.2 \mathrm{~dB}$ \\
\hline 0.79 & $65.6 \mathrm{~mm}$ & $\begin{array}{c}1.72 \mathrm{GHz}-3.52 \mathrm{GHz} \\
(\Delta f=68.7 \%)\end{array}$ & $12.5 \mathrm{~dB}$ & $0.1 \mathrm{~dB}-1.4 \mathrm{~dB}$ \\
\hline 0.82 & $75.2 \mathrm{~mm}$ & $\begin{array}{c}1.74 \mathrm{GHz}-3.48 \mathrm{GHz} \\
(\Delta f=66.7 \%)\end{array}$ & $12.6 \mathrm{~dB}$ & $0.2 \mathrm{~dB}-1 \mathrm{~dB}$ \\
\hline
\end{tabular}




\subsection{Fabrication of Antenna and Actuation Mechanism}

\subsubsection{Fabrication of the Origami Multi-Radii Helix}

The origami base of the designed origami multi-radii helix in Figure 4.2 is fabricated using 2-mil thick Kapton, which is a material that is used in space applications. An axial force applied on the top step of the antenna is needed to deploy and stow the antenna. As the antenna collapses it also rotates. The rotated angle between the two states is: $m \cdot \Delta \theta+\left(1+m_{1}\right) \cdot \Delta \theta_{l}$. The 2-mil thick Kapton is more suitable than a thicker substrate, since it requires less force to change the antenna height and maintains the shape of the folded planes without deformation. Also, this antenna can completely collapse and it can be stowed in a compact volume given by [29],

$$
\text { Volume }_{\text {compact }}=\frac{\left(m+m_{1}+1\right) t n^{2} a^{2}}{\pi}
$$

where $t$ is the thickness of flexible substrate, the footprint of the origami base is $n^{2} a^{2} /(4 \pi)$, and the height of the compacted origami base is $4\left(m+m_{1}+1\right) t$. The folding pattern in Figure 4.1 is perforated with Silhouette Cameo on the Kapton substrate for accurate and well memorized folding creases. A 3-mil copper trace is glued on the 2-mil planar FPC Kapton substrate as shown in Figure 4.1 and then the 3-D antenna is folded up, as shown in Figure 4.16. The ground plane is built using a sheet of single-sided 1-mm thick FR4 board with one layer of copper on the back of it, and no other copper sheet is put on top of the ground. Also, the volume saving for this antenna is $96.6 \%$ and can be expressed below:

$$
\frac{\text { Volume }_{\text {unfolded }}-\text { Volume }_{\text {compact }}}{\text { Volume }_{\text {unfolded }}}=1-\frac{4\left(m+m_{1}+1\right) t}{S \cdot N+S_{1} \cdot\left(N_{0}+N_{1}\right)}
$$




\subsubsection{Fabrication of the Actuating Mechanism}

An actuation mechanism is proposed for this antenna as shown in Figure 4.17 that can reconfigure the antenna height without the need of a rotational mechanism. This actuation mechanism is placed along the axis of the helical antenna. Two freely-rotational $1 \mathrm{~mm}$-thick square slabs are positioned at the top end of two concentric tubes, as shown in Figure 4.17 (a). The larger square Slab is fixed to the 4 sides of the top end of the bottom origami cylinder base, and the smaller square $\operatorname{Slab}_{1}$ is fixed to the 4 sides of the top end of the top origami cylinder base. The bottom ends of the two concentric tubes $T$ and $T_{1}$ are movable. After installing the antenna on its ground plane, $T$ is used to adjust the height of the bottom helix $H$, then $T_{1}$ is used to adjust the height of the top helix $\left(H_{1}-H\right)$. The concentric tubes are $0.15-\mathrm{mm}$ thin polypropylene, so its dielectric property does not affect the antenna performance. Also, the polypropylene tubes are bendable to accommodate antenna measurement in the anechoic chamber. Other parts are made of PLA and are 3-D printed with Makerbot. Since these PLA parts are electrically small $(<0.045 \lambda)$, they also have little impact on the antenna performance. The main dimensions of the actuating mechanism are listed in Table 4.15.

Table 4.15. Dimensions of Actuation Mechanism.

\begin{tabular}{|c|c|c|c|c|c|}
\hline $\boldsymbol{H}$ & $\boldsymbol{H 1}$ & $\boldsymbol{a}$ & $\boldsymbol{a 1}$ & $\boldsymbol{r}$ & $\boldsymbol{r} \boldsymbol{1}$ \\
\hline $232 \mathrm{~mm}$ & $552 \mathrm{~mm}$ & $35.3 \mathrm{~mm}$ & $28 \mathrm{~mm}$ & $4.5 \mathrm{~mm}$ & $2.6 \mathrm{~mm}$ \\
\hline
\end{tabular}




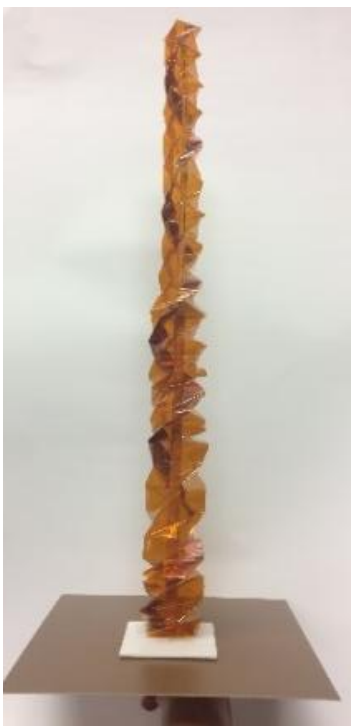

(a) State 1

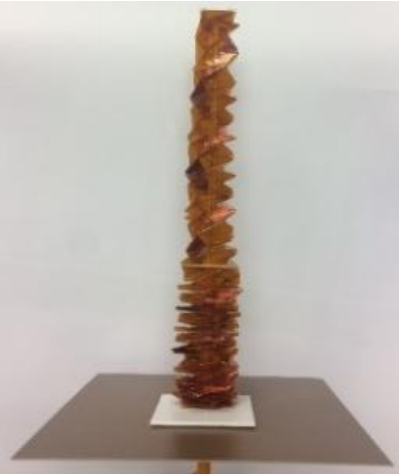

(b) State 2

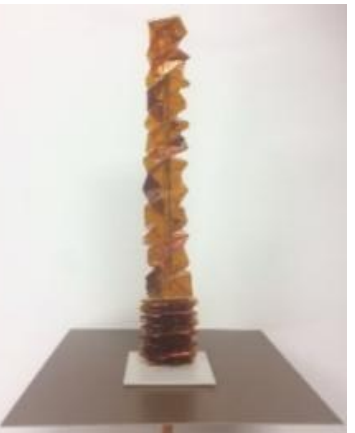

(c) State 3

Figure 4.16. Prototype of origami multi-radii helix at 3 reconfigurable states.

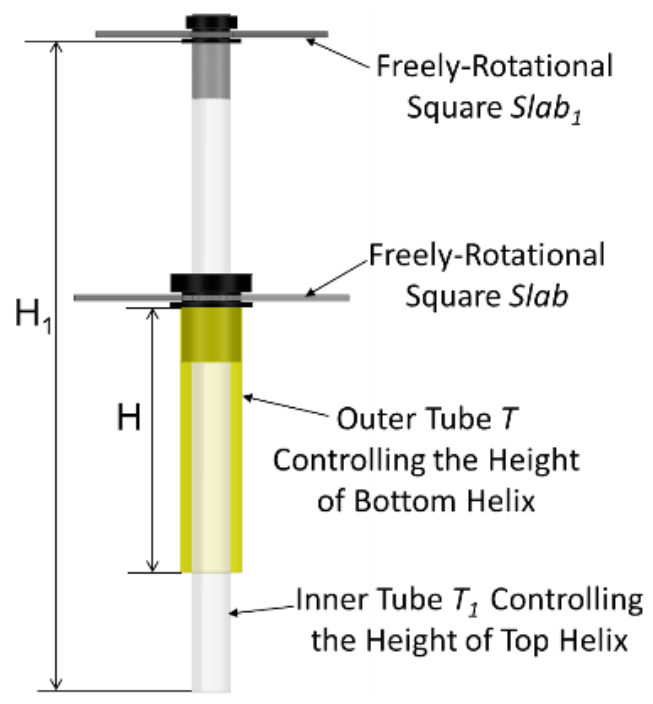

(a) Side view

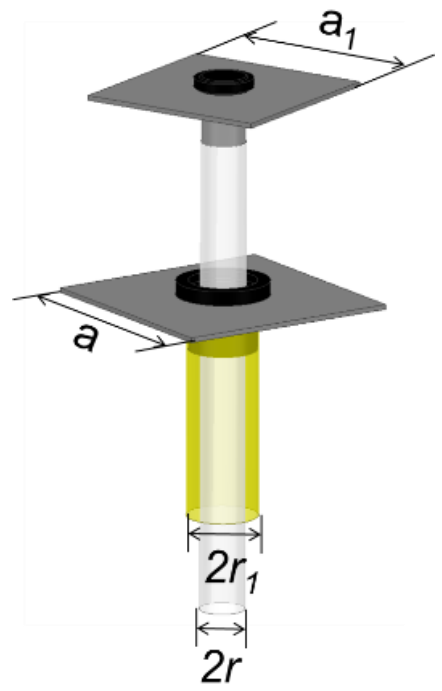

(b) Perspective view

Figure 4.17. Actuation mechanism of the origami multi-radii helix.

\subsection{Simulated and Measured Results}

The wideband frequency reconfigurability of our origami multi-radii helix is validated with simulated and measured results, as shown in Figure 4.18-Figure 4.21 and Table 4.16. In Figure 4.19, the 3-D pattern at the operating frequency with maximum 
RHCP gain of each state is shown, and the CP bandwidth where AR is less than $3 \mathrm{~dB}$ is shaded. Also, the radiation patterns at these typical operating frequencies are shown in Figure 4.21. The measurements were performed using a StarLab Anechoic Chamber.

The measured results validate that the designed origami multi-radii helix can change its height to reconfigure its operation between at 3 states while maintaining RHCP. The three bands are: $1.42 \mathrm{GHz}-2.01 \mathrm{GHz}$ at state $1,1.78 \mathrm{GHz}-3.64 \mathrm{GHz}$ at state 2 and 3.72 GHz-4.06 GHz at state 3, which can satisfy applications of GPS, satellite radio, WiMax and satellite communications.

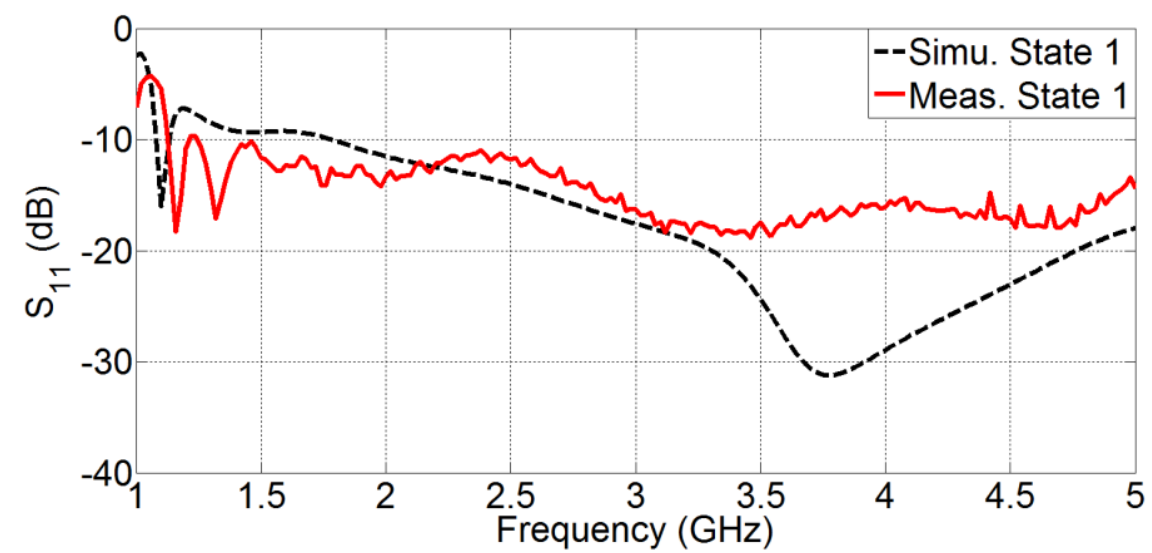

(a)

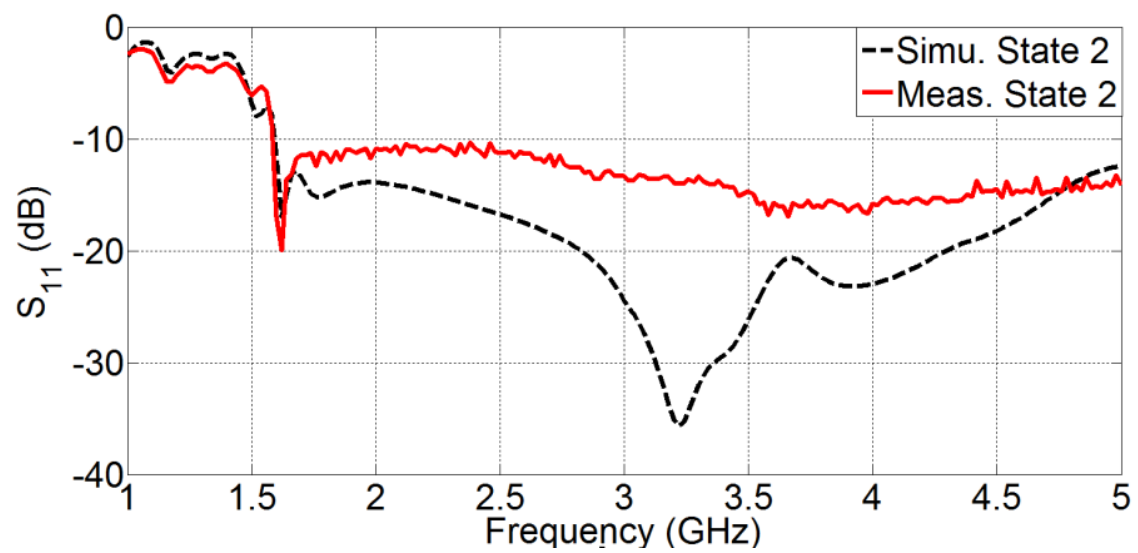

(b) 


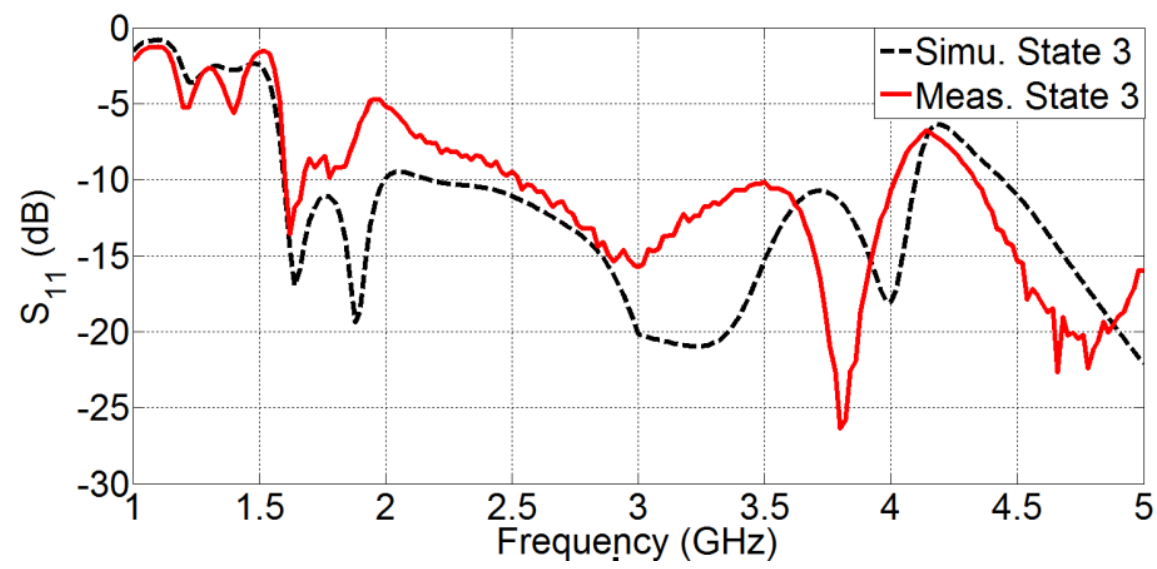

(c)

Figure 4.18. Simulated and measured $S_{11}$ results of the origami multi-radii helix at: (a) state 1 , (b) state 2 and (c) state 3.

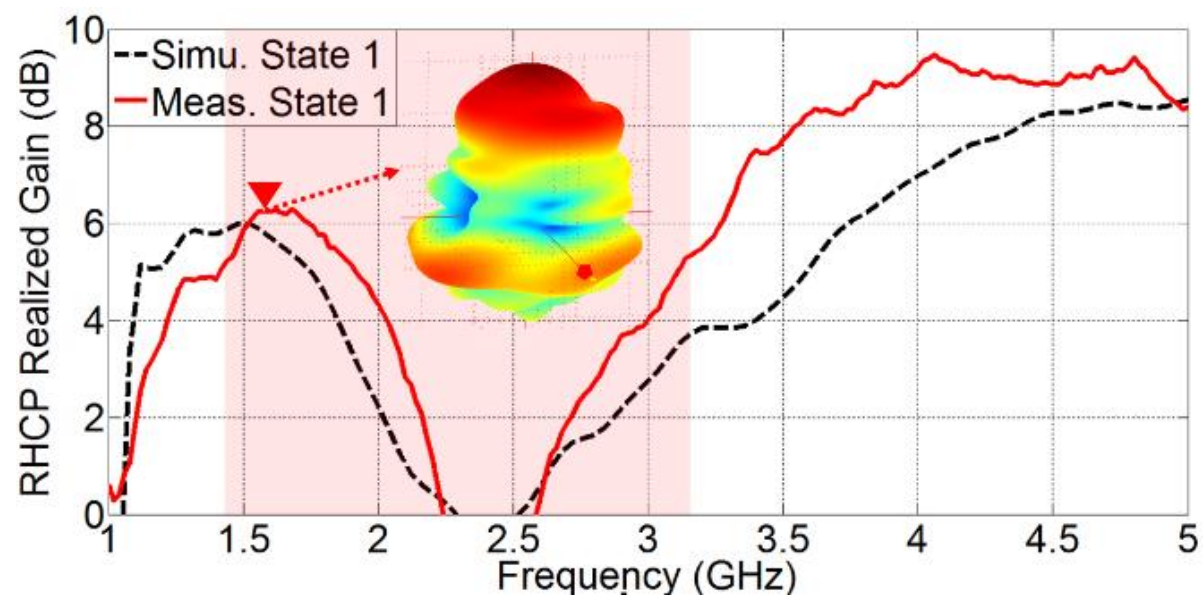

(a)

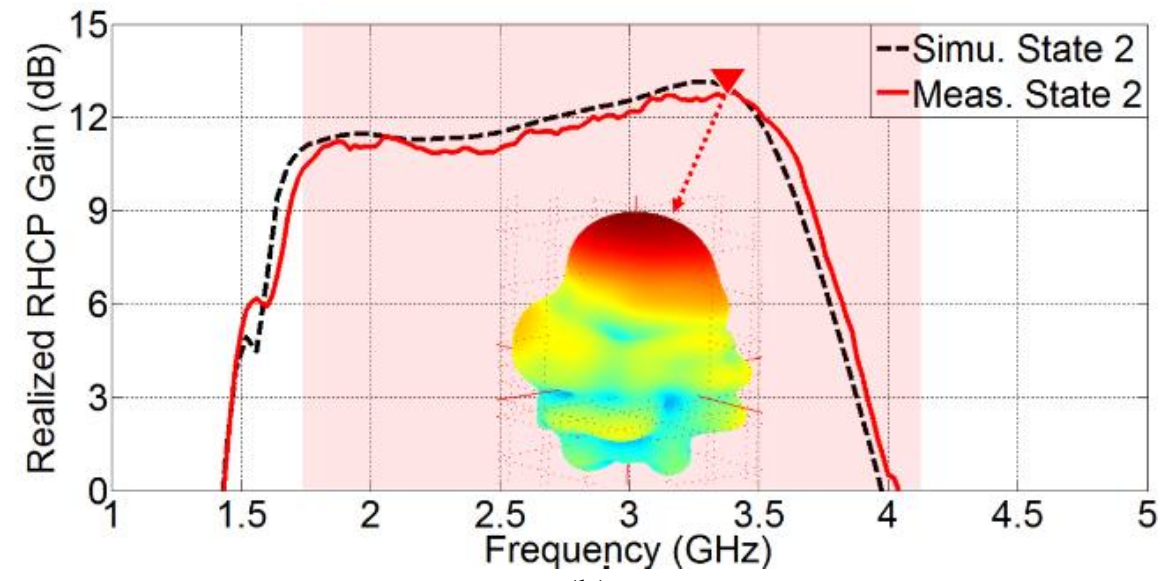

(b) 


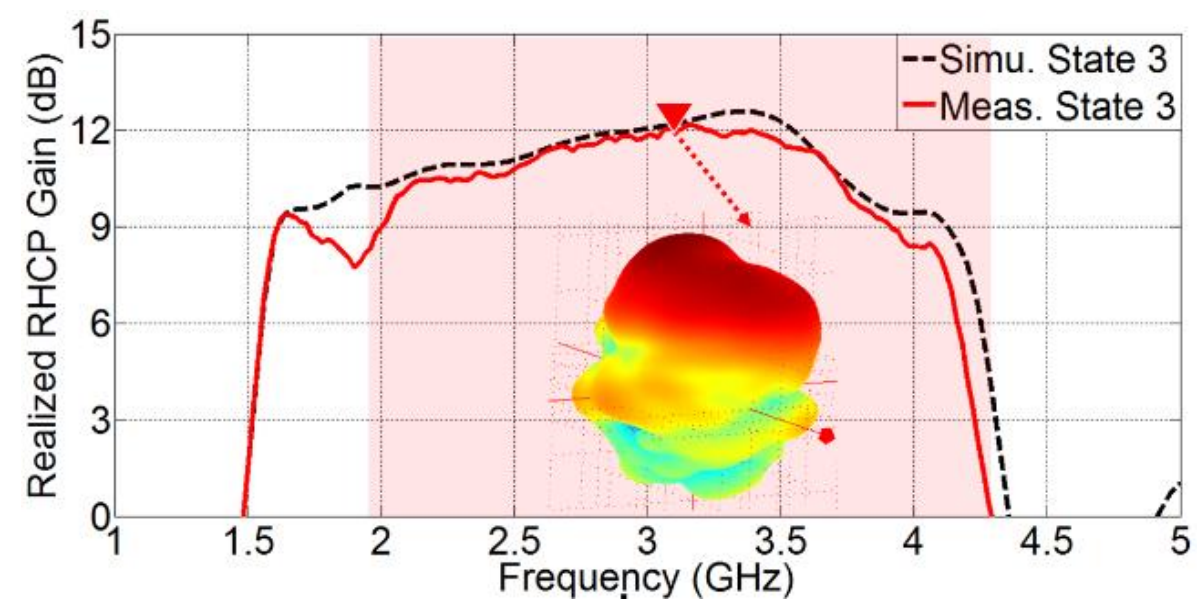

(c)

Figure 4.19. Simulated and measured realized RHCP gain of the origami multi-radii helix at: (a) state 1, (b) state 2 and (c) state 3 .

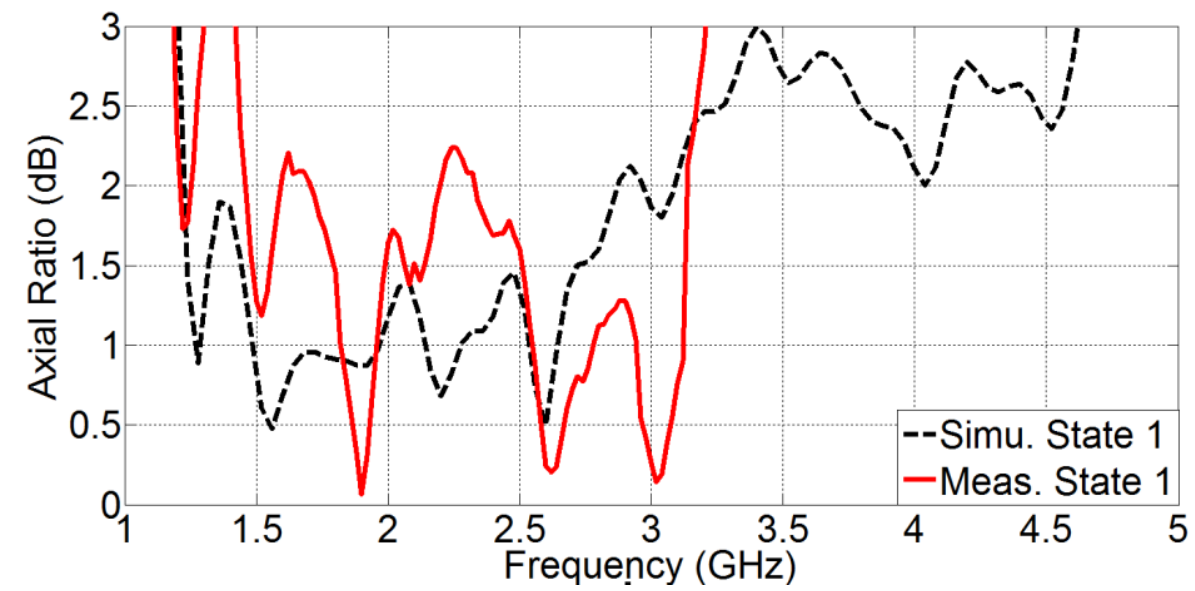

(a)

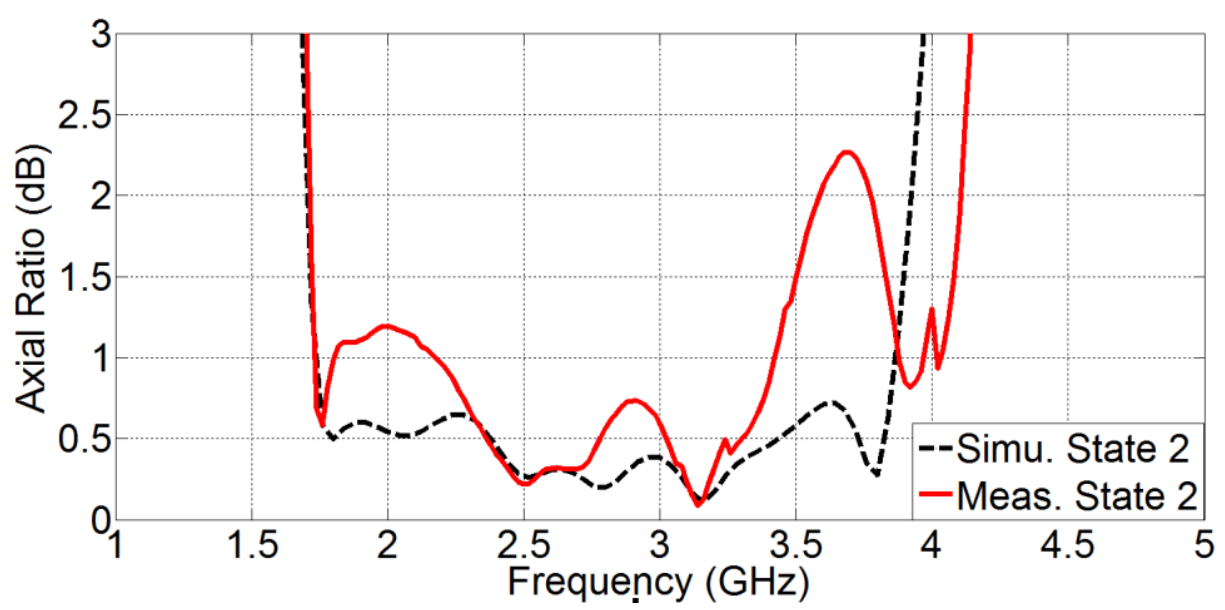

(b) 


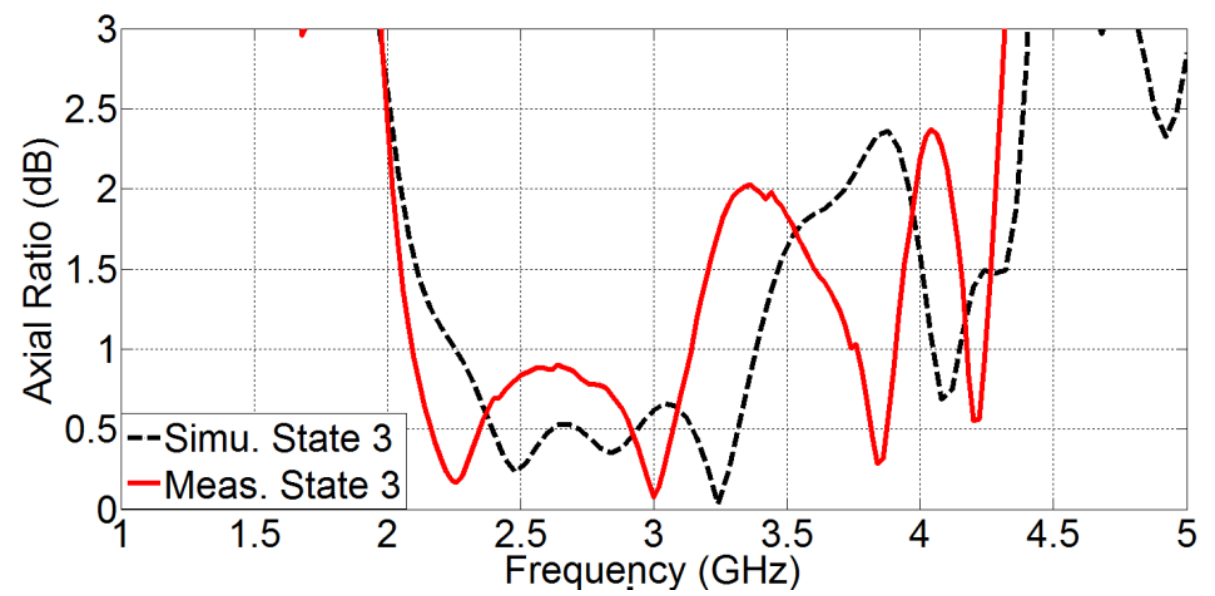

(c)

Figure 4.20. Simulated and measured axial ratio of the origami multi-radii helix at: (a) state 1, (b) state 2 and (c) state 3.
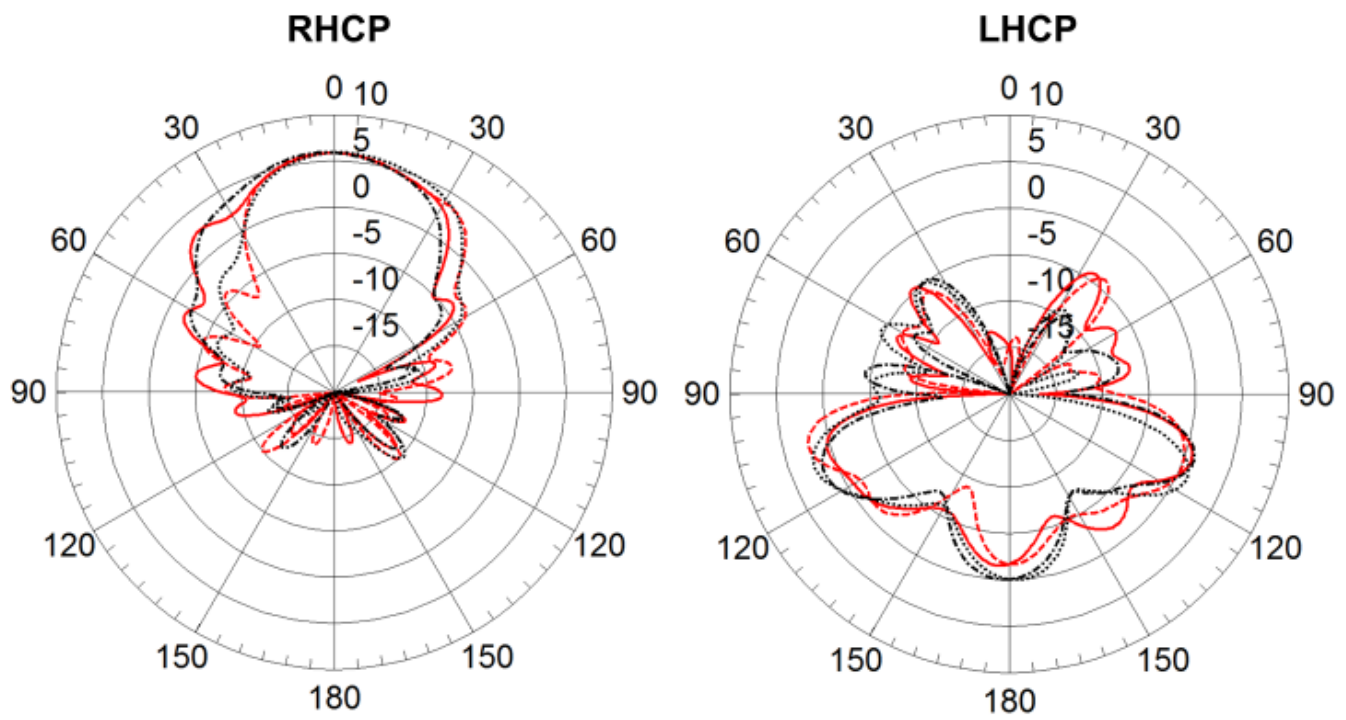

$$
\begin{aligned}
& \cdots-- \text { Simu. State } 1 \text { at } 1.56 \mathrm{GHz}\left(\varphi=0^{\circ}\right) \\
& \ldots . \cdots \text { Simu. State } 1 \text { at } 1.56 \mathrm{GHz}\left(\varphi=90^{\circ}\right) \\
& --- \text { Meas. State } 1 \text { at } 1.56 \mathrm{GHz}\left(\varphi=0^{\circ}\right) \\
& -- \text { Meas. State } 1 \text { at } 1.56 \mathrm{GHz}\left(\varphi=90^{\circ}\right)
\end{aligned}
$$

(a) 

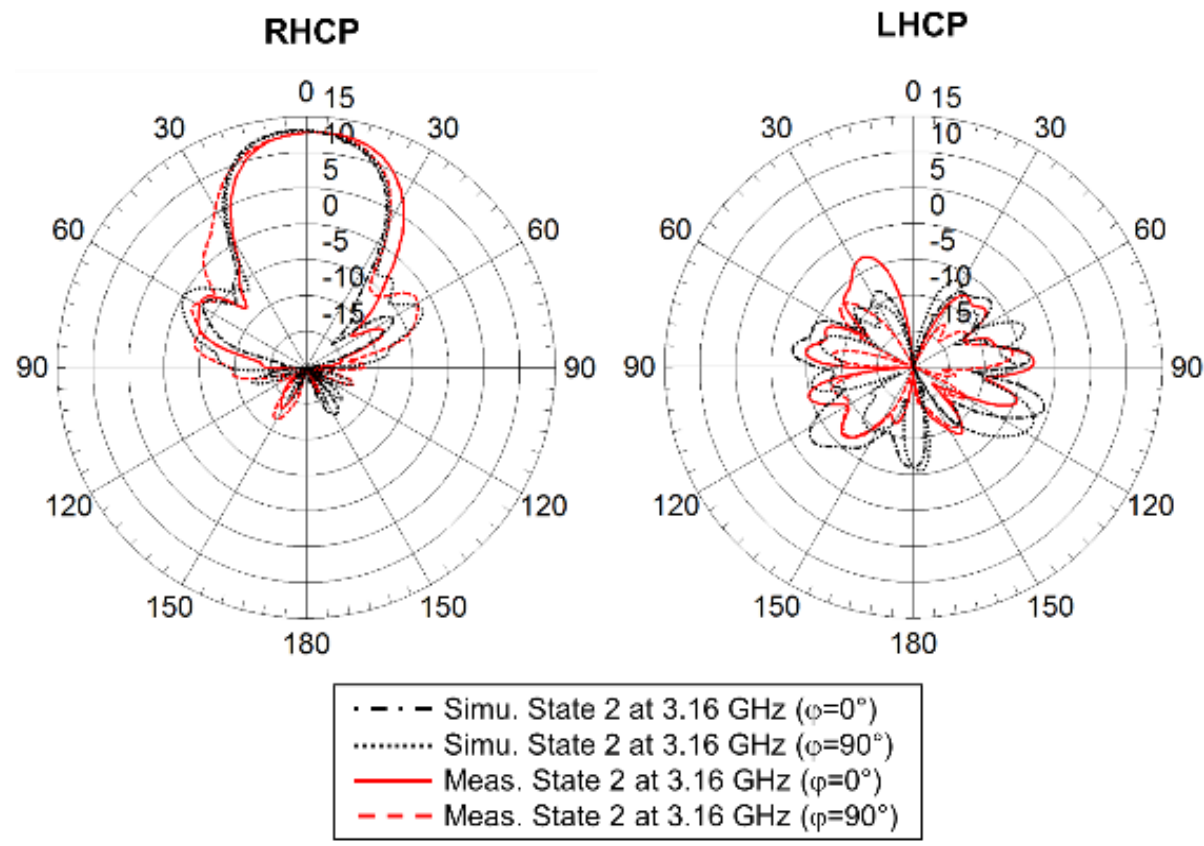

(b)

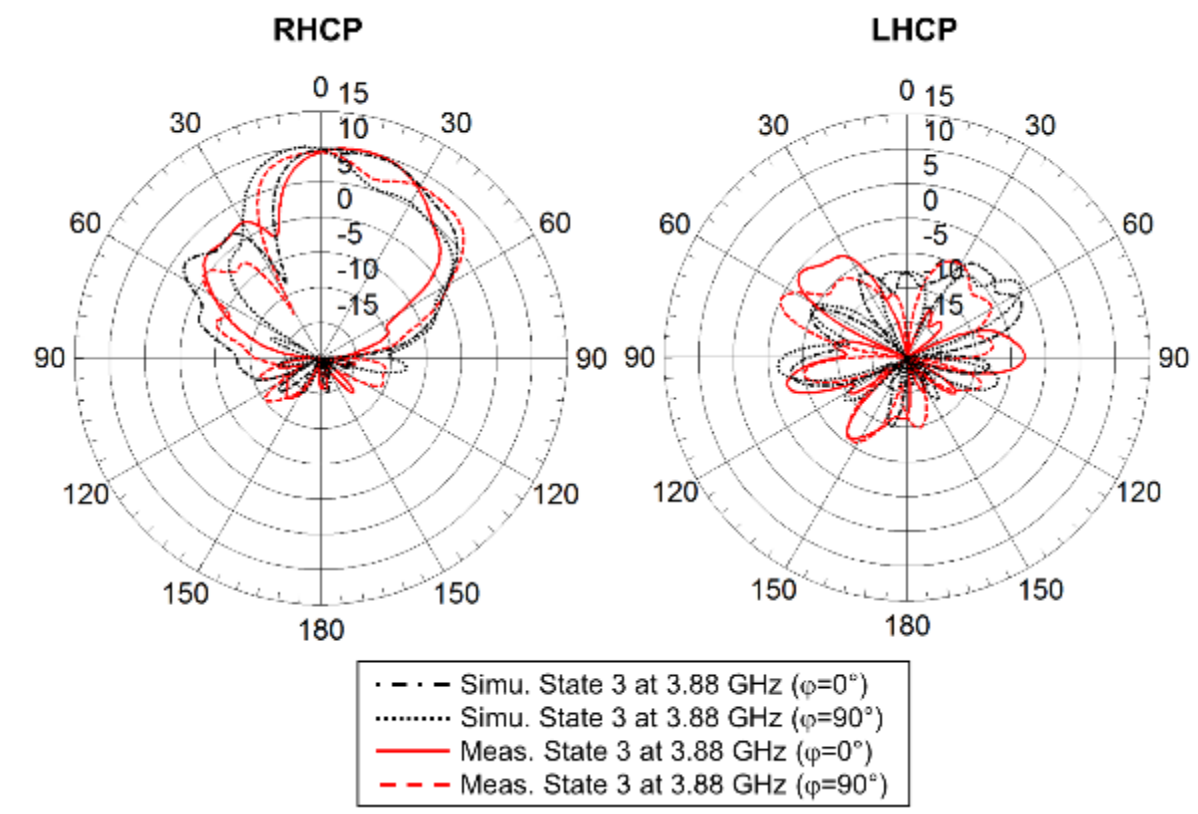

(c)

Figure 4.21. Simulated and measured elevational radiation patterns of the origami multi-radii helix at: (a) state 1 at $1.56 \mathrm{GHz}$, (b) state 2 at $3.16 \mathrm{GHz}$, and (c) state 3 at $3.88 \mathrm{GHz}$. 
Table 4.16. Simulated and Measured Results of the Origami Multi-Radii Helix at 3 States.

\begin{tabular}{|c|c|c|c|c|c|}
\hline \multicolumn{2}{|c|}{$\begin{array}{c}\text { State of } \\
\text { Origami } \\
\text { Antennas }\end{array}$} & $\begin{array}{c}\text { CP BW } \\
(\text { AR<-3 dB })\end{array}$ & $\begin{array}{c}\text { Realized RHCP } \\
\text { Gain BW within -2 } \\
\text { dB Variation from } \\
\text { the Maximum }\end{array}$ & $\begin{array}{c}\text { Max. } \\
\text { Realized } \\
\text { RHCP Gain }\end{array}$ & $\begin{array}{c}\text { AR Range within } \\
\text { 2-dB RHCP } \\
\text { Gain BW }\end{array}$ \\
\hline \multirow{2}{*}{$\mathbf{1}$} & Simu. & $\begin{array}{c}1.22 \mathrm{GHz}-3.4 \mathrm{GHz} \\
(\Delta f=94 \%)\end{array}$ & $\begin{array}{c}1.22 \mathrm{GHz}-1.84 \mathrm{GHz} \\
(\Delta f=42.1 \%)\end{array}$ & $6.1 \mathrm{~dB}$ & $0.5 \mathrm{~dB}-3 \mathrm{~dB}$ \\
\cline { 2 - 6 } & Meas. & $\begin{array}{c}1.42 \mathrm{GHz}-3.2 \mathrm{GHz} \\
(\Delta f=77.1 \%)\end{array}$ & $\begin{array}{c}1.42 \mathrm{GHz}-2.01 \mathrm{GHz} \\
(\Delta f=34.4 \%)\end{array}$ & $6.3 \mathrm{~dB}$ & $0.1 \mathrm{~dB}-3 \mathrm{~dB}$ \\
\hline \multirow{2}{*}{$\mathbf{2}$} & Simu. & $\begin{array}{c}1.69 \mathrm{GHz}-3.94 \mathrm{GHz} \\
(\Delta f=79.9 \%)\end{array}$ & $\begin{array}{c}1.78 \mathrm{GHz}-3.54 \mathrm{GHz} \\
(\Delta f=66.2 \%)\end{array}$ & $13 \mathrm{~dB}$ & $0.1 \mathrm{~dB}-0.6 \mathrm{~dB}$ \\
\cline { 2 - 6 } & Meas. & $\begin{array}{c}1.7 \mathrm{GHz}-4.14 \mathrm{GHz} \\
(\Delta f=83.6 \%)\end{array}$ & $\begin{array}{c}1.78 \mathrm{GHz}-3.64 \mathrm{GHz} \\
(\Delta f=68.6 \%)\end{array}$ & $12.7 \mathrm{~dB}$ & $0.1 \mathrm{~dB}-2.2 \mathrm{~dB}$ \\
\hline \multirow{2}{*}{3} & Simu. & $\begin{array}{c}1.6 \mathrm{GHz}-4.4 \mathrm{GHz} \\
(\Delta f=93.3 \%)\end{array}$ & $\begin{array}{c}3.64 \mathrm{GHz}-4.04 \mathrm{GHz} \\
(\Delta f=10.4 \%)\end{array}$ & $10.1 \mathrm{~dB}$ & $0.6 \mathrm{~dB}-2.5 \mathrm{~dB}$ \\
\cline { 2 - 6 } & Meas. & $\begin{array}{c}1.98 \mathrm{GHz}-4.3 \mathrm{GHz} \\
(\Delta f=73.9 \%)\end{array}$ & $\begin{array}{c}3.72 \mathrm{GHz}-4.06 \mathrm{GHz} \\
(\Delta f=8.7 \%)\end{array}$ & $10.5 \mathrm{~dB}$ & $0.3 \mathrm{~dB}-2.4 \mathrm{~dB}$ \\
\hline
\end{tabular}

\subsection{Conclusions}

This chapter has a design of origami multi-radii antenna that can be stowed efficiently. The volume saving of this antenna is up to $96.6 \%$ from its unfolded state. Also, this antenna can dynamically change its height to reconfigure its performance and operate in different bands while maintaining circular polarization for applications, such as, GPS, satellite radio, WiMax and satellite communications. The concentric tubes of its actuating mechanism can be made telescopic in the future to further improve the stowability of the whole system. The performance of this antenna was validated through simulations and measurements. The design process for this antenna along with its optimization were also provided. In addition, this antenna outperforms the standard single and multi-radii helical antennas as it exhibits larger bandwidths. Finally, our antenna outperforms the singleradius origami helix as it exhibits improved $\mathrm{CP}$ performance at all of three states of operation. 


\section{CHAPTER 5}

\section{REFLECTOR RECONFIGURABLE ORIGAMI QUADRIFILAR AND MONOFILAR HELICAL ANTENNA FOR SATELLITE COMMUNICATIONS}

\subsection{Origami QHA with Reflector}

This section presents a design of a circularly polarized origami Quadrifilar Helical Antenna (QHA) with a reconfigurable reflector that can operate at 3 states in $\mathrm{K}$, Ka, and EHF bands. The K, Ka, and EHF bands employ millimeter wavelengths and can support high bandwidth transmissions using small receiving antennas [41]. The proposed reflector and QHA are able to reconfigure themselves at three different states using origami folding. A 10:1 scale model of the proposed origami QHA is manufactured and measured in order to validate our design.

\subsubsection{Design of Origami QHA}

The QHA is designed to operate in axial mode. Empirically, the optimum circumference and pitch size for a circularly polarized helical antenna in axial mode should be $0.75 \lambda_{0}<C<1.33 \lambda_{0}$, and $S=0.25 \lambda_{0}$, where $\lambda_{0}$ is the wavelength at its operating frequency, $C$ is the circumference of the helix and $S$ is the spacing between each turn [13]. Therefore, a helical antenna with fixed total length can achieve a frequency reconfigurability by changing its pitch, $S$. Here, an origami QHA is proposed in order to achieve frequency reconfigurability for $\mathrm{K}, \mathrm{Ka}$ and $\mathrm{EHF}$ bands.

The origami pattern used to fold the cylinder base of the QHA is shown in Figure 5.1. The number of sides, $n$, is picked to be equal to 4 in order to enable symmetric placement of the four helical arms of the QHA around the origami cylinder. 


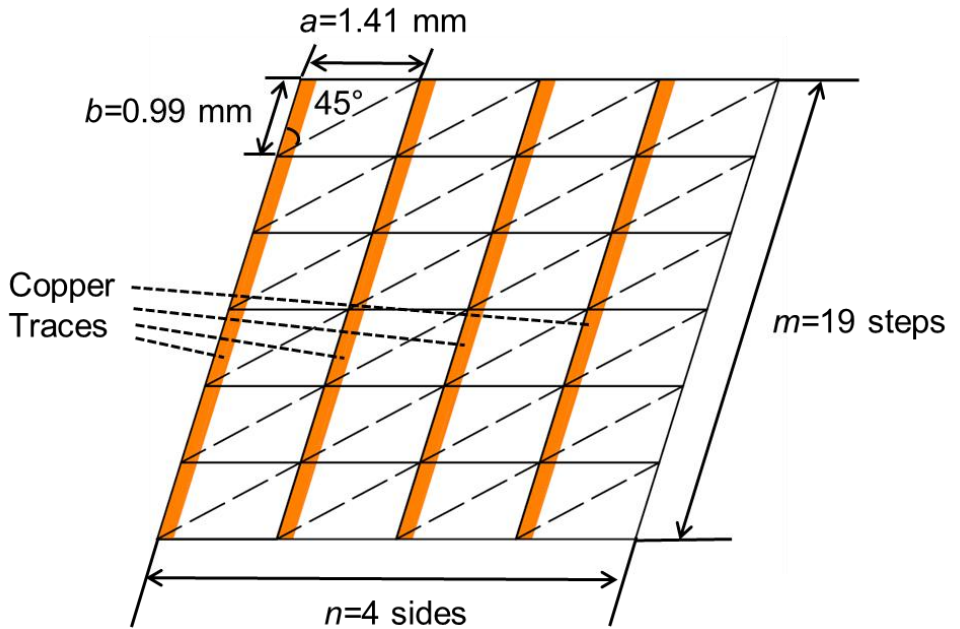

Figure 5.1. Origami folding pattern of the QHA cylinder base.

The 3-D QHA model is shown in Figure 5.2. The QHA is fed using a progressive $90^{\circ}$ phase difference from port to port counter-clockwisely (as shown in Figure 5.2) in order to achieve a right-hand circular polarization. The total height, $H$, of the QHA can be adjusted to change its operating frequency from $20.7 \mathrm{GHz}$ to $30 \mathrm{GHz}$ and $44.5 \mathrm{GHz}$ in $\mathrm{K}$, Ka and EHF bands, respectively. It should be noted that when $H$ is decreased, the number of turns $N$ is increased, as expressed below:

$$
N=\frac{\sqrt{m^{2} b^{2}-H^{2}}}{n a}
$$

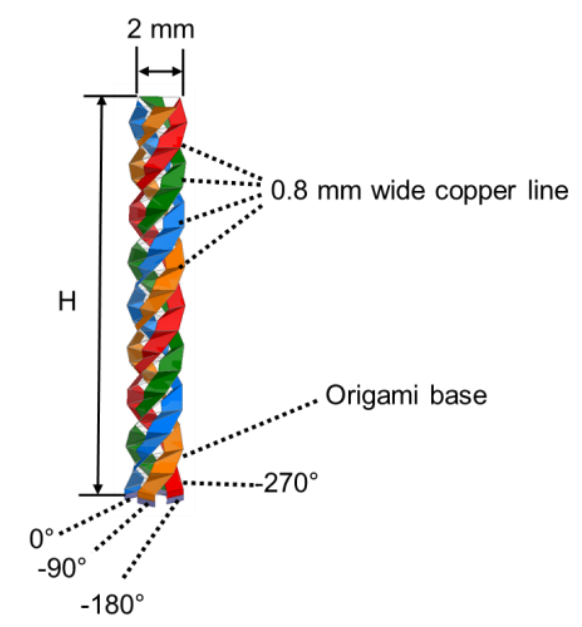

Figure 5.2. Origami quadrifilar helical antenna model. 


\subsubsection{Design of the Origami Reflector}

The impact of various reflectors on the performance of helical antennas has been previously studied [47]. The truncated-cone ground provides the highest gain for helical antennas compared to square, cylindrical-cup, and conical grounds [47].

Based on the truncated-cone ground, a novel foldable truncated-heptahedron reflector is proposed in this paper, which can reconfigure to cover the three operating bands of the proposed QHA. The geometries of the three reconfigurable states of the reflector QHA are shown in Figure 5.3 along with the corresponding folding patterns of the reflector, where red dashed lines represent valleys, blue dash-dot lines are hills and green solid lines are outlines.

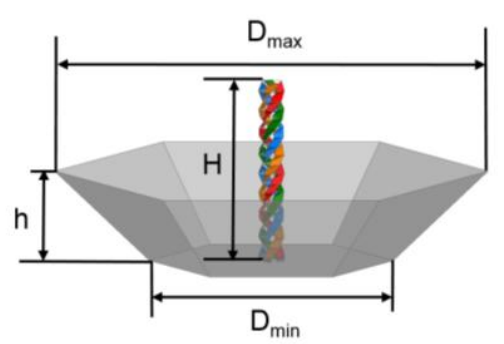

$D_{\max }=33.5 \mathrm{~mm}(2.31 \lambda)$

$D_{\min }=18.85 \mathrm{~mm}(1.3 \lambda)$ $\mathrm{h}=7 \mathrm{~mm}(0.48 \lambda)$ $\mathrm{H}=13.6 \mathrm{~mm}$

(a) State 1 at $20.7 \mathrm{GHz}$.
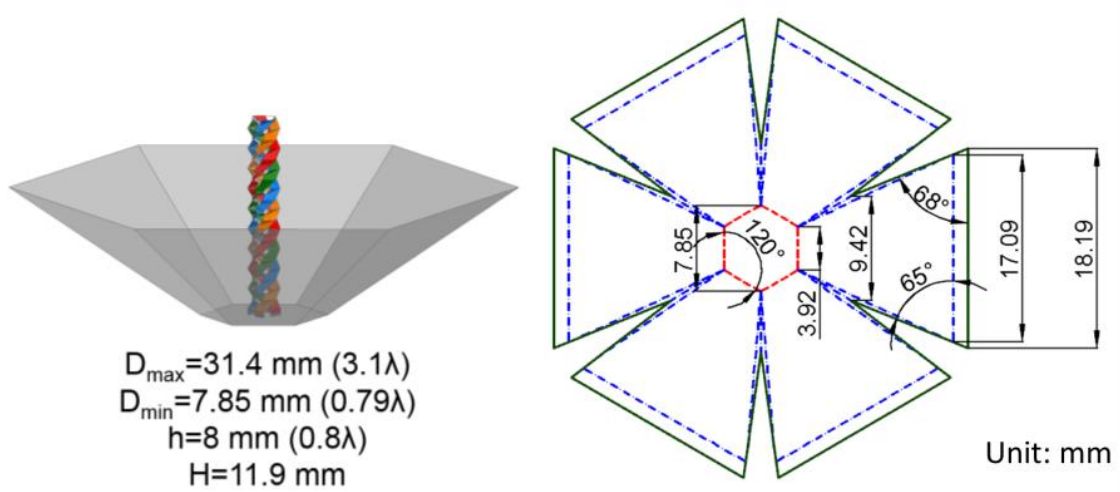

(b) State 2 at $30 \mathrm{GHz}$. 

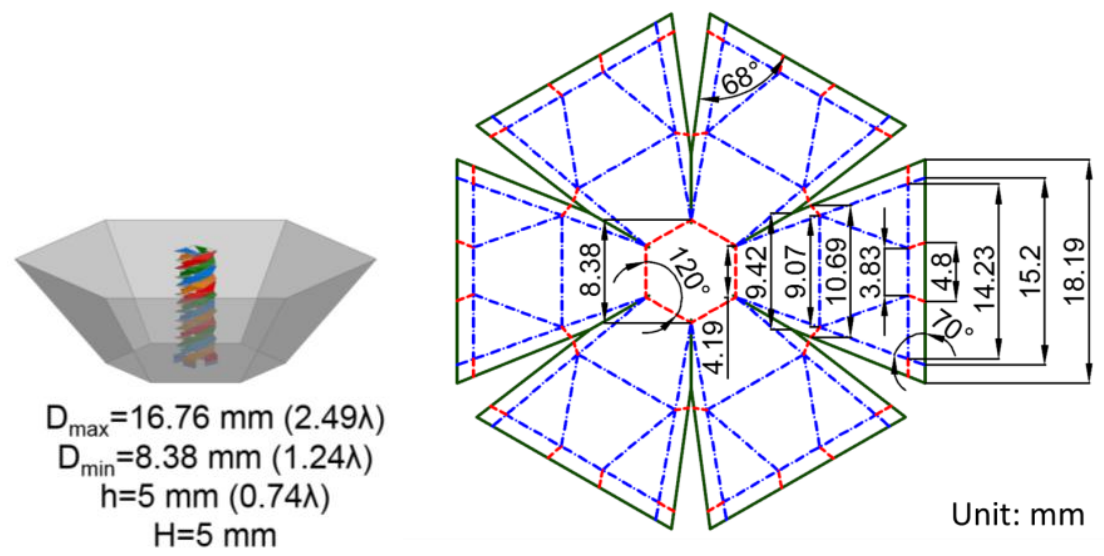

(c) State 3 at $44.5 \mathrm{GHz}$.

Figure 5.3. The three states of the reconfigurable origami QHA with the foldable reflector and the folding patterns of the reflector.

\subsubsection{Simulation Results}

This reflector QHA antenna was modeled and analyzed in ANSYS HFSS. The simulated $\mathrm{S}_{11}$, realized RHCP gain, and axial ratio are shown in Figure 5.4-Figure 5.6. Figure 5.4 shows that the designed reconfigurable origami QHA with the reflector has a return loss greater than $15 \mathrm{~dB}$ in all three states. Also, the three states of the designed antenna are circularly polarized and they have a realized RHCP gain higher than $15 \mathrm{~dB}$ at their operating frequencies, as shown in Figure 5.4-Figure 5.6.

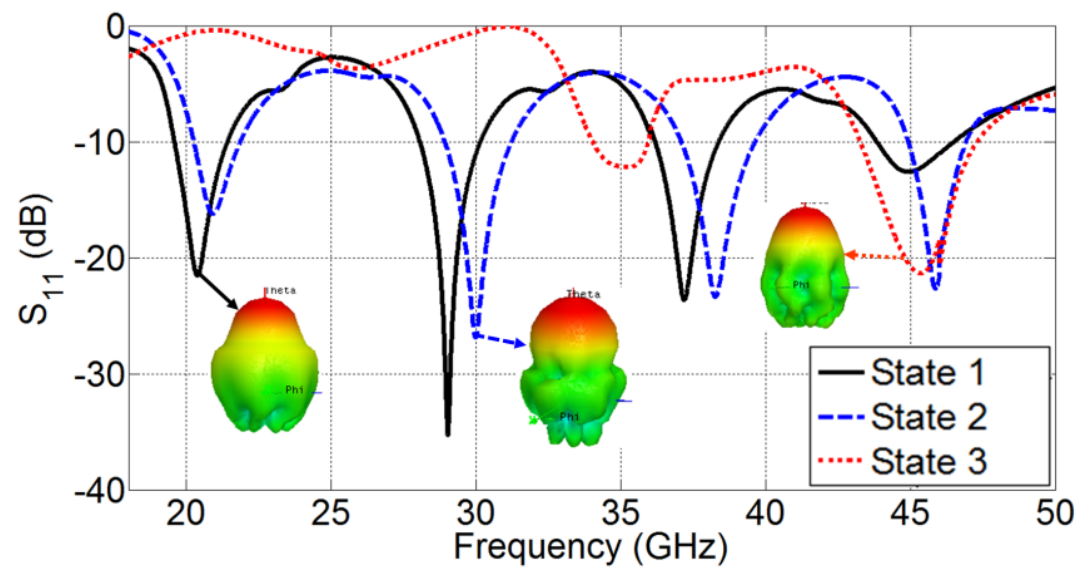

Figure 5.4. Simulated $S_{11}$ of the reconfigurable origami QHA with the reflector at three states. 


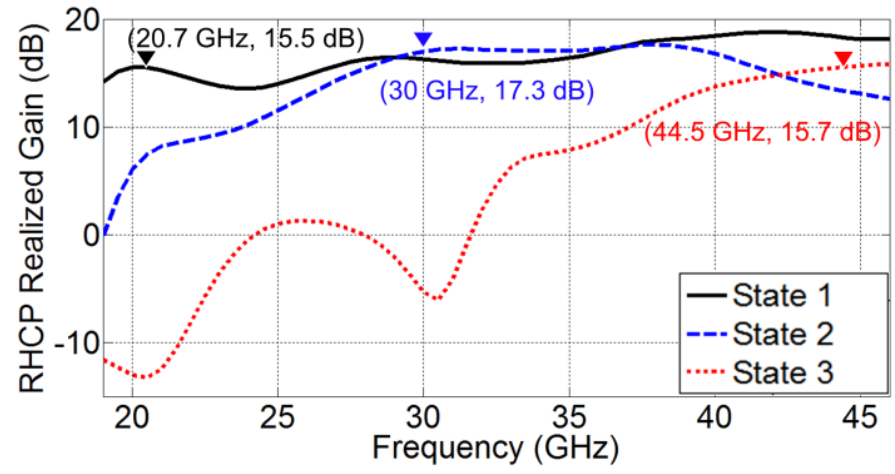

Figure 5.5. Simulated realized RHCP gain of the reconfigurable origami QHA with the reflector at three states.

Figure 5.7 shows that the reflector QHA exhibits the best performance in terms of gain and pattern at the operating frequency of each state compared to the other two states. It should be pointed out that Figure 5.5 shows that the first state (corresponding to K-band operation, $H=13.6 \mathrm{~mm}$ ) exhibits approximately the same gain as the second state (corresponding to Ka-band operation, $H=11.9 \mathrm{~mm}$ ) at the Ka band and a higher gain than the gain of the third state (corresponding to EHF-band operation, $H=5 \mathrm{~mm}$ ) at the EHF band. However, the radiation patterns of the first state (see Figure 5.7), exhibit large side lobes at Ka band $(8.9 \mathrm{~dB})$ and EHF band $(5.2 \mathrm{~dB})$ and therefore, the first state cannot be used in the Ka and EHF bands.

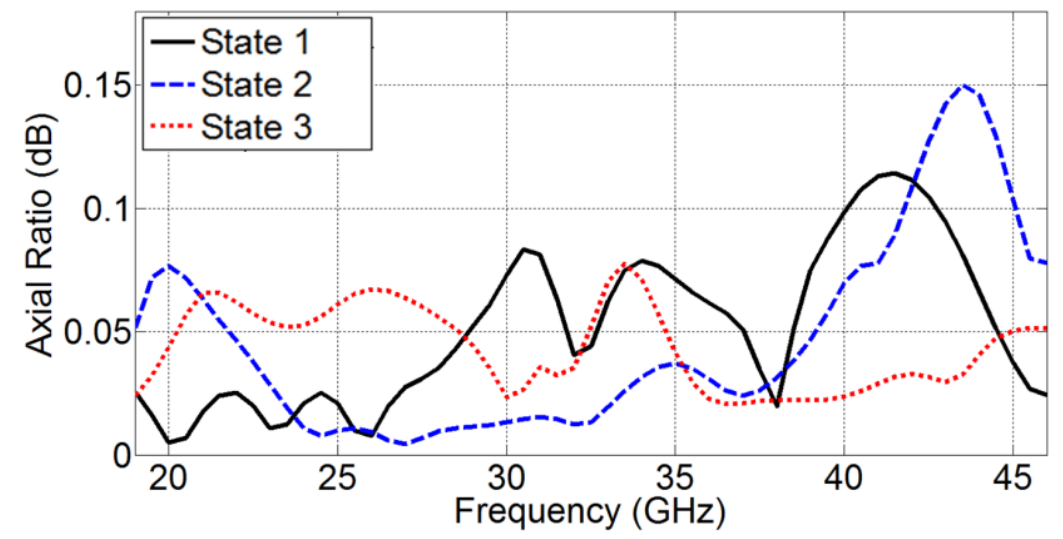

Figure 5.6. Simulated axial ratio of the reconfigurable origami QHA with the reflector at three states. 


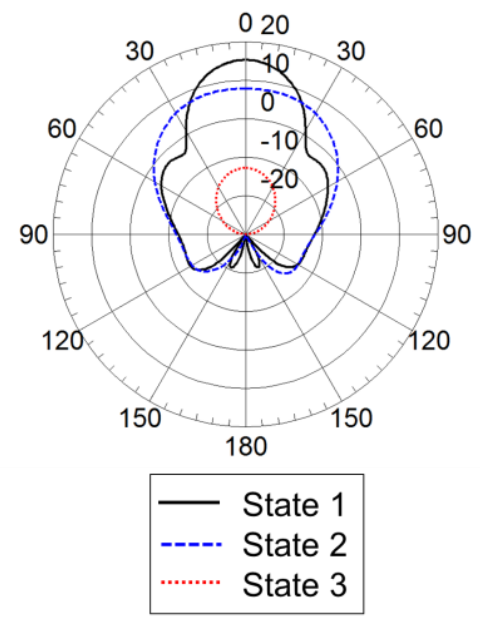

(a) $20.7 \mathrm{GHz}$.

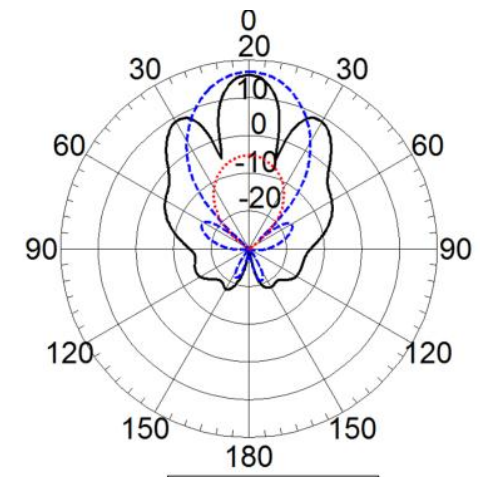

- State 1

----- State 2

........ State 3

(b) $30 \mathrm{GHz}$.

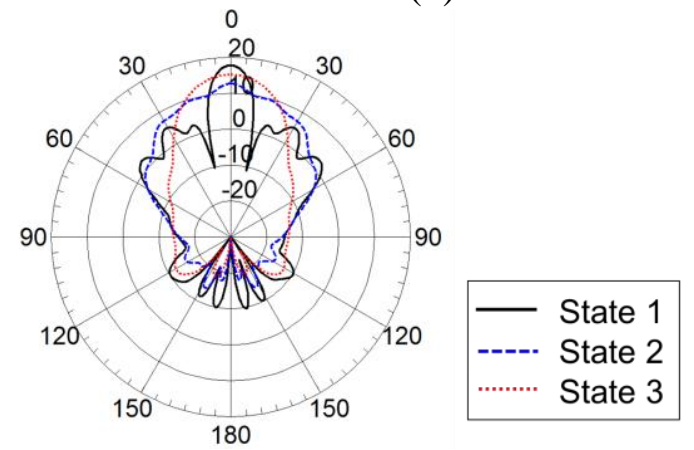

(c) $44.5 \mathrm{GHz}$.

Figure 5.7. RHCP patterns at three states of the reconfigurable origami reflector QHA at designated operating frequencies.

To prove that 3 configurations of the reflector are necessary to optimize the QHA performances at the 3 operating frequencies, simulated RHCP patterns of the QHA at 3 reconfigurable states of height resonating at the designated operating frequencies with one common reflector state are shown in Figure 5.8 for 3 common reflector states. It can be seen from Figure 5.8 that although the QHA performance can be optimized at one of operating frequencies with the common reflector, the radiation patterns at the other 2 reconfigurable frequencies can't be as good due to larger side lobes or lower gains. Therefore, 3 states of the reflector were optimized for each operating frequency, as introduced earlier in $\S 5.1 .2$. 


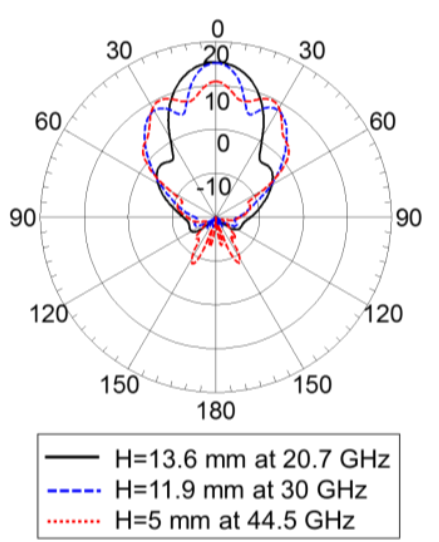

(a) Reflector at state 1

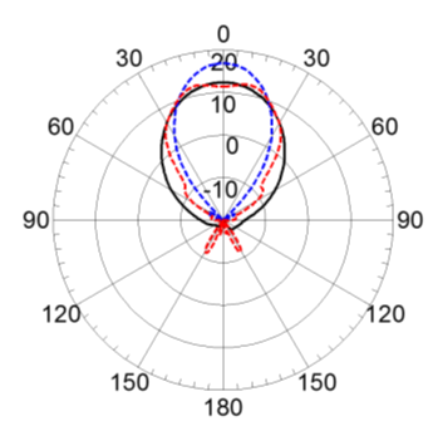

$\mathrm{H}=13.6 \mathrm{~mm}$ at $20.7 \mathrm{GHz}$ -... $\mathrm{H}=11.9 \mathrm{~mm}$ at $30 \mathrm{GHz}$ ....... $\mathrm{H}=5 \mathrm{~mm}$ at $44.5 \mathrm{GHz}$

(b) Reflector at state 2

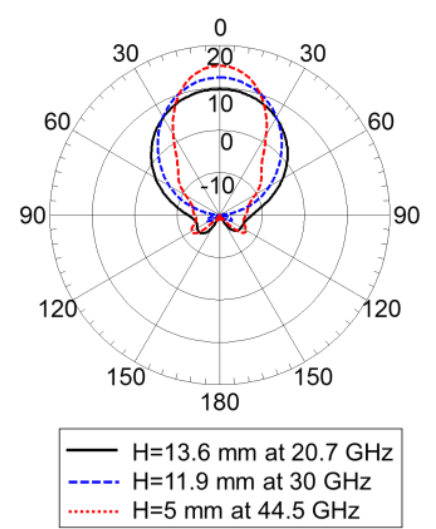

(c) Reflector at state 3

Figure 5.8. RHCP patterns of reconfigurable QHA resonating at 3 designated operating frequencies with one common reflector state.

\subsubsection{0:1 Scale Model of Origami QHA}

The size of the proposed origami QHA is too small; therefore, it is difficult to build its prototype by hand, and new manufacturing techniques need to be explored. Therefore, we decided to build a 10:1 scale model of the proposed origami QHA in order to validate its performance. The 10:1 scale QHA will operate at the operating frequencies of $2.07 \mathrm{GHz}$, $3 \mathrm{GHz}$ and $4.45 \mathrm{GHz}$. Since the SMA connector feed slightly decreases the resonant frequencies of the antenna, the initial 10:1 scale dimensions of the origami pattern and QHA model are slightly adjusted ( $a$ increased by $1.2 \mathrm{~mm}, b$ increased by $0.8 \mathrm{~mm}, \mathrm{~m}$ decreased by 2) in order to compensate this effect of the SMA connector feed and tune the QHA at the scaled frequencies, as shown in Figure 5.9. Also, the dimensions of the 10:1 scale reflector were slightly adjusted through simulations to provide optimal performance for each state of the slightly adjusted 10:1 scale QHA, as shown in Figure 5.10. 


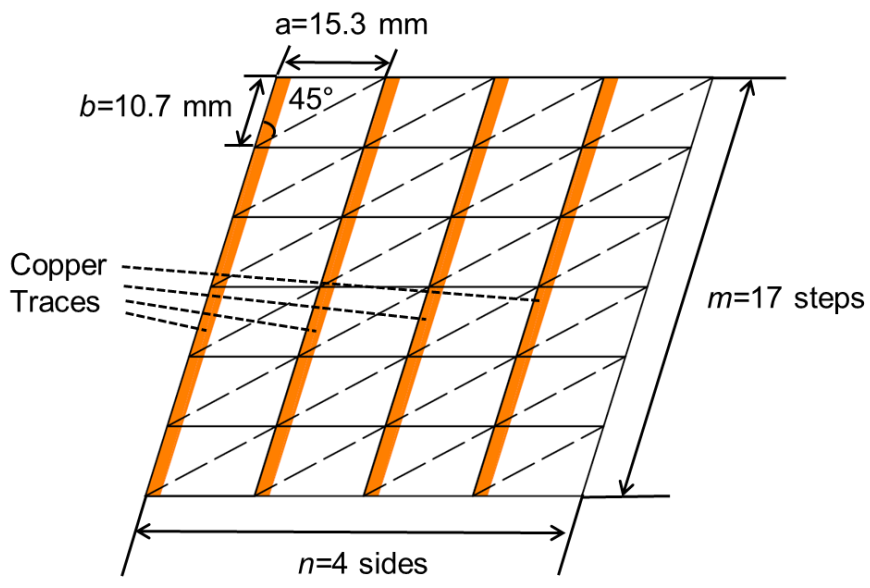

(a)

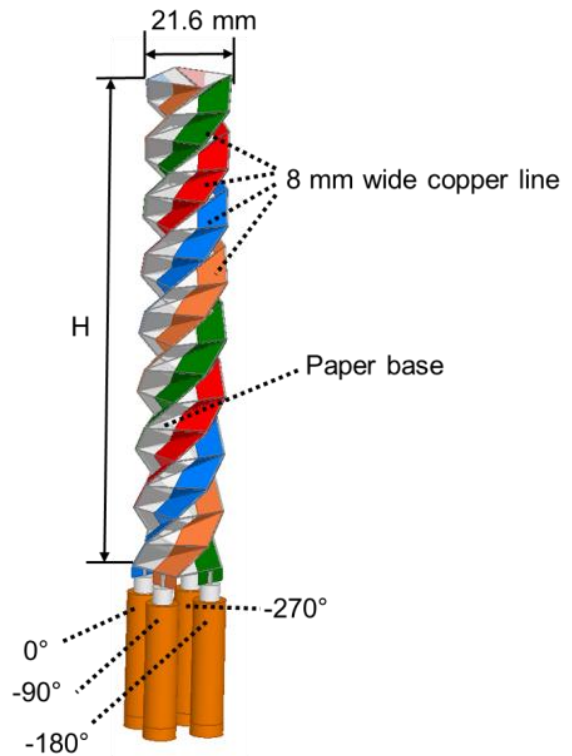

(b)

Figure 5.9. Geometry of the 10:1 scale model of the origami QHA. (a) origami folding pattern, and (b) 3D model.

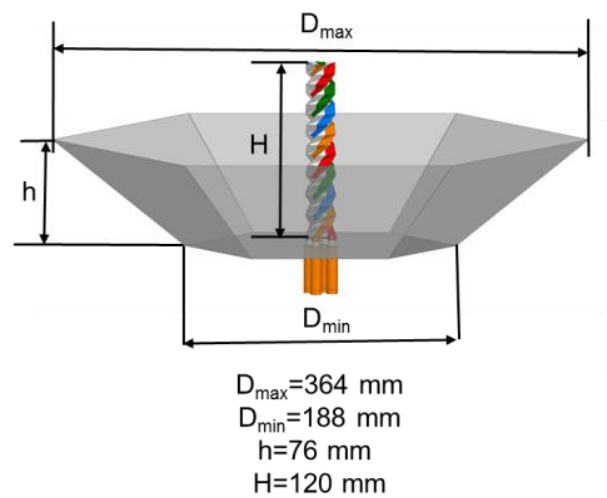

(a)

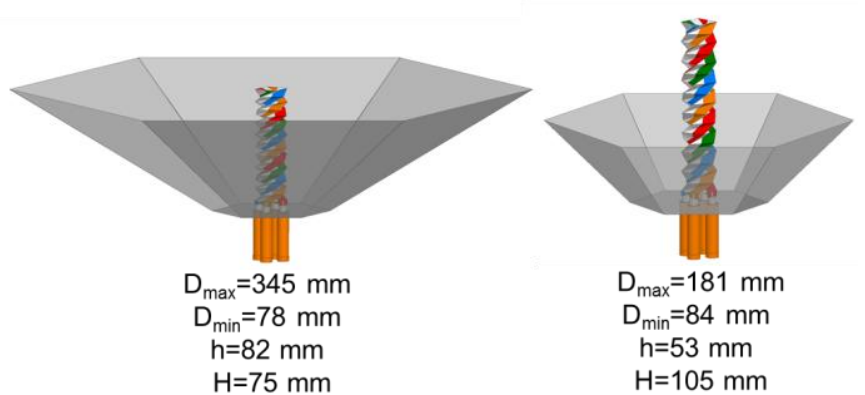

(c)

Figure 5.10. Geometry of 10:1 scale model of the origami QHA with its reflector at three states: (a) state 1 ( $\mathrm{H}=120 \mathrm{~mm})$; (b) state $2(\mathrm{H}=75 \mathrm{~mm})$; (c) state $3(\mathrm{H}=105 \mathrm{~mm})$.

The prototype of the 10:1 scale reflector of the QHA was manufactured and its three states are shown in Figure 5.11. The 10:1 scale QHA was constructed by attaching copper tape (arms of the QHA) on sketching paper and folding the paper base into an origami cylinder, as shown in Figure 5.9(a). The 10:1 scale reflector was constructed by gluing copper foil on a single piece of sketching paper. This reflector can be reconfigured into 
three different states following the folding pattern shown in Figure 5.3. The QHA prototype can be reconfigured by applying a force at the top of the origami helix to adjust its height from state 1 to state 3 . Also the reflector prototype was reconfigured manually in measurements.

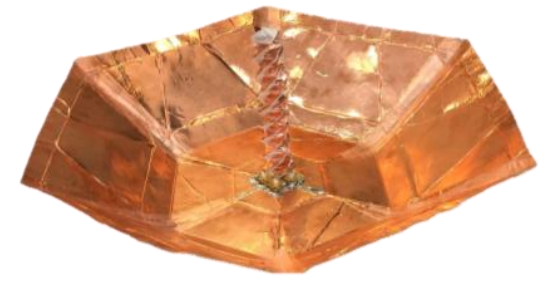

(a) State $1(\mathrm{H}=120 \mathrm{~mm})$
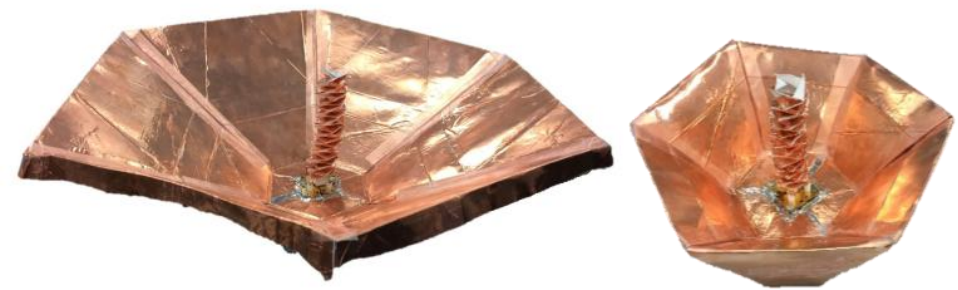

(b) State $2(\mathrm{H}=75 \mathrm{~mm})$

(c) State $3(\mathrm{H}=105 \mathrm{~mm})$

Figure 5.11. Geometry of 10:1 scale model of the origami QHA with its reflector.

The S-parameters were measured using an E5071C Agilent network analyzer. Figure 5.12 compares the simulated and measured $S_{11}$ for the 3 states. The feeding network is constructed using one $180^{\circ}$ hybrid coupler and two $90^{\circ}$ hybrid couplers. The radiation pattern and gain measurements were performed using a Diamond Engineering antenna measurement system.

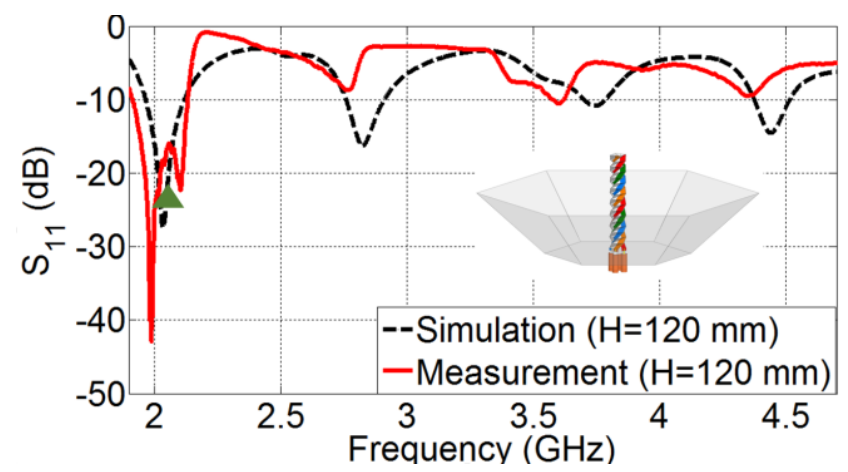

(a) State 1 (operating frequency, $f_{0}=2.07 \mathrm{GHz}$ ) 


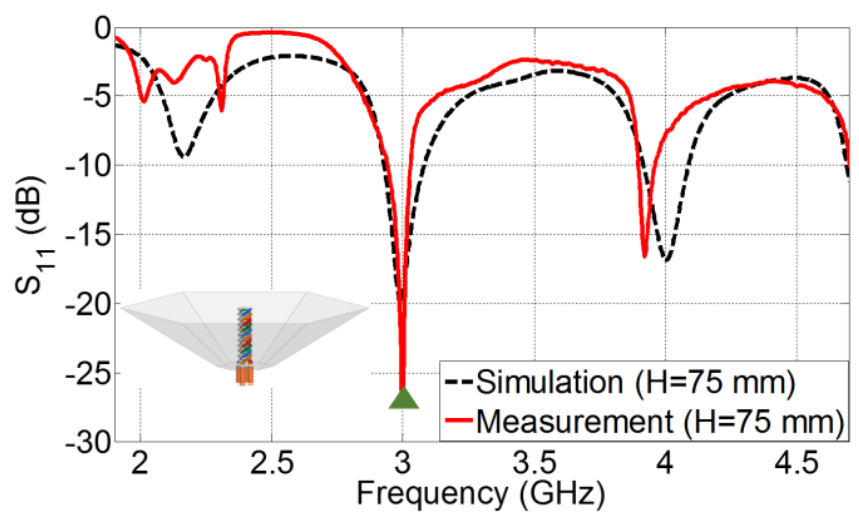

(b) State 2 (operating frequency, $f_{0}=3 \mathrm{GHz}$ )

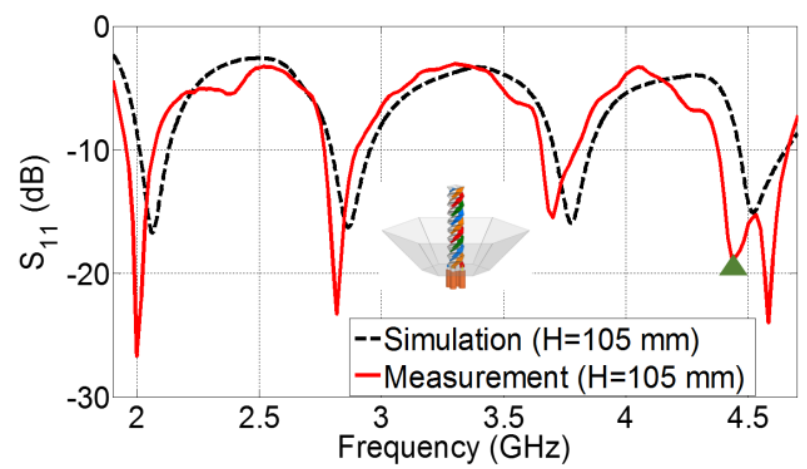

(c) State 3 (operating frequency, $f_{0}=4.45 \mathrm{GHz}$ )

Figure 5.12. Comparison of simulated and measured $S_{11}$ at the three states.

The simulated and measured radiation patterns of the 3 states are compared in Figure 5.13. Also, the simulated and measured realized RHCP gains and axial ratios are listed in Table 5.1 at 2.07 GHz, $3 \mathrm{GHz}$ and $4.45 \mathrm{GHz}$. Figure 5.13 shows that the reflector origami QHA operates in axial mode at the 3 states, and Table 5.1 shows that this antenna is right-hand circularly polarized with measured gains over $12 \mathrm{~dB}$. Compared to the proposed design in section II, this 10:1 scale model has successfully enlarged its operating wavelength by 10 times to operate at $2.07 \mathrm{GHz}, 3 \mathrm{GHz}$ and $4.45 \mathrm{GHz}$, as shown in Table 5.1. 


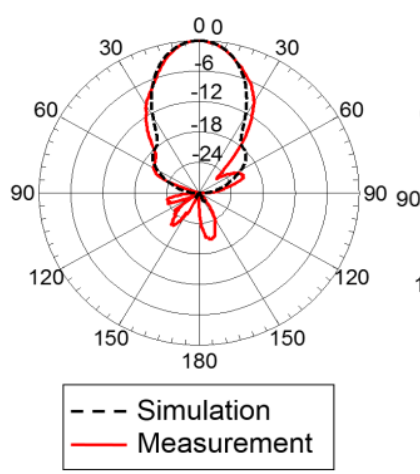

(a)

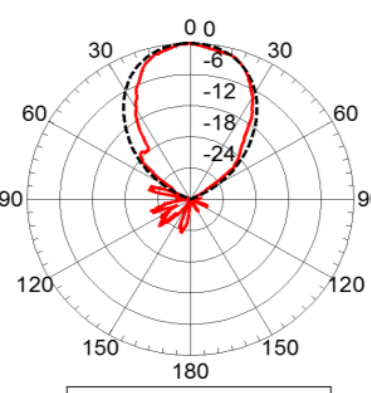

- - - Simulation - Measurement

(b)

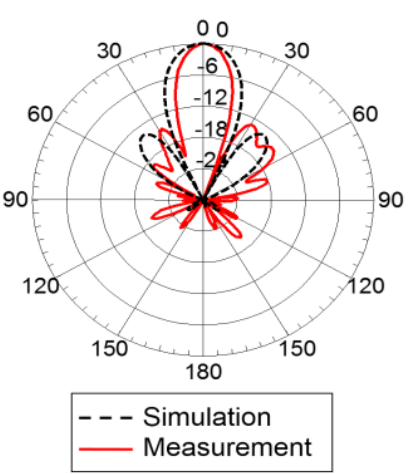

(c)

Figure 5.13. Simulated and measured normalized radiation patterns at the three states: (a) state 1 at $2.07 \mathrm{GHz}$, (b) state 2 at $3 \mathrm{GHz}$, and (c) state 3 at $4.45 \mathrm{GHz}$.

Table 5.1 Simulated and Measured Results at Designated Frequencies of the 10:1

Scale Antenna.

\begin{tabular}{|c|c|c|c|}
\hline Reconfigurable State & $\begin{array}{c}\text { State 1 } \\
(H=120 \mathrm{~mm})\end{array}$ & $\begin{array}{c}\text { State 2 } \\
(H=75 \mathrm{~mm})\end{array}$ & $\begin{array}{c}\text { State 3 } \\
(H=105 \mathrm{~mm})\end{array}$ \\
\hline Center Operating Frequency (GHz) & 2.07 & 3.00 & 4.45 \\
\hline Simulated Realized RHCP Gain (dB) & 13.87 & 12.50 & 15.41 \\
\hline Measured Realized RHCP Gain (dB) & 13.20 & 12.13 & 14.86 \\
\hline Simulated AR (dB) & 0.04 & 0.11 & 0.03 \\
\hline Measured AR (dB) & 0.66 & 0.09 & 0.55 \\
\hline
\end{tabular}

\subsubsection{Conclusion}

Section 5.1 presents a design of an origami RHCP QHA with a foldable reflector that can reconfigure itself to operate in three different bands, namely $\mathrm{K}, \mathrm{Ka}$ and EHF. Simulated and measured results of a 10:1 scale model of this antenna validated the reconfigurable performance of this antenna at the three bands. Our future work will focus on robust manufacturing of this reconfigurable origami QHA for the K, Ka and EHF bands. 


\subsection{Tri-band Reconfigurable Origami Helical Array}

\subsubsection{Geometry of Single Helical Antenna Element}

According to antenna theory, to achieve the optimum $\mathrm{CP}$ performance in a helical antenna, the length of one turn of the helix should be approximately equal to one wavelength [37]. However, this condition could not be satisfied at all the reconfiguration states of an origami monofilar. Therefore, a smaller helical section is added for each element to achieve CP. The folding pattern of single element is shown in Figure 5.14 (a), and the folded origami monofilar is shown in Figure 5.14 (b). The values of the geometrical parameters of this helical antenna are listed in Table 5.2. Thus, the diameters of the monofilar are: $d_{l}=27.2 \mathrm{~mm}$ and $d=34 \mathrm{~mm}$. The height of one turn in the two helical sections (pitch and pitch $)_{1}$, and the number of turns of the two helical sections $\left(N\right.$ and $\left.N_{l}\right)$ can be varied by changing their folding angles [29] in order to achieve frequency reconfiguration and $\mathrm{CP}$ at the three states (see $\S 5.2 .3$ ).

Table 5.2 Geometrical Parameters of Single Helical Element.

\begin{tabular}{|c|c|c|c|c|c|c|}
\hline $\boldsymbol{m}$ & $\boldsymbol{m}_{\boldsymbol{1}}$ & $\boldsymbol{n}$ & $\boldsymbol{a}$ & $\boldsymbol{w}$ & $\boldsymbol{f}_{\text {scale }}$ & ratio \\
\hline 15 & 6 & 4 & $24 \mathrm{~mm}$ & $16 \mathrm{~mm}$ & 0.8 & 0.85 \\
\hline
\end{tabular}

\subsubsection{Geometry of Single Reflector Element}

The single reflector element is shown in Figure 5.14, and its geometrical parameters are listed in Table 5.3. The geometry of the reflector can be solely determined by its angle to the ground $\alpha$ and the side length of bottom hexagon $a_{\min }$. We chose a common reflector for all three operational states with $a_{\min }=50 \mathrm{~mm}$ and $\alpha=40^{\circ}$ for compromised maximum gains at the 3 states. 


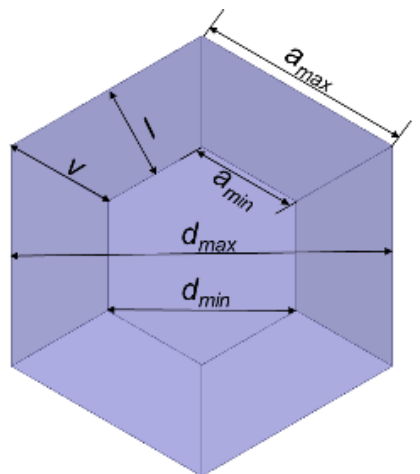

(a)

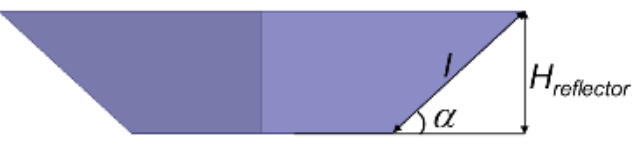

(b)

Figure 5.14. Geometry of single reflector element: (a) top view; and (b) side view.

Table 5.3 Geometrical parameters of Single Reflector Element.

\begin{tabular}{|c|c|c|c|c|c|c|c|}
\hline $\boldsymbol{\alpha}$ & $\boldsymbol{a}_{\min }$ & $\boldsymbol{a}_{\max }$ & $\boldsymbol{d}_{\min }$ & $\boldsymbol{d}_{\max }$ & $\boldsymbol{l}$ & $\boldsymbol{v}$ & $\boldsymbol{H}_{\text {reflector }}$ \\
\hline $40^{\circ}$ & $50 \mathrm{~mm}$ & $101 \mathrm{~mm}$ & $86.6 \mathrm{~mm}$ & $175 \mathrm{~mm}$ & $57.7 \mathrm{~mm}$ & $63.1 \mathrm{~mm}$ & $37 \mathrm{~mm}$ \\
\hline
\end{tabular}

\subsubsection{Geometry of 7-element Array}

The 3 states of the 7-element multi-radii origami helical array are shown in Figure 5.15 with the distance between elements being set to gap $=5 \mathrm{~mm}$. The geometrical parameters and number of turns at each state are listed in Table 5.4.

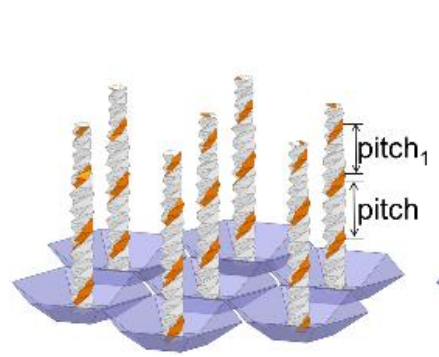

(a)

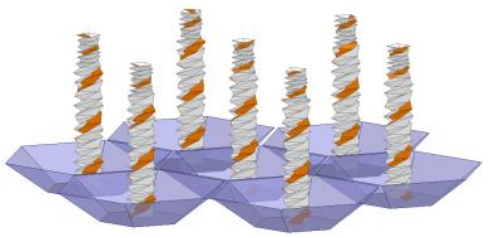

(b)

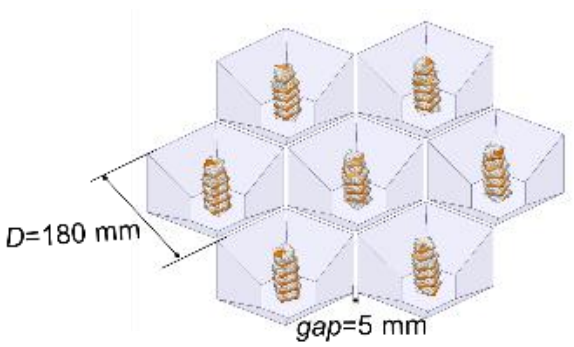

(c)

Figure 5.15. Antenna array model at: (a) state 1, (b) state 2 and (c) state 3.

Table 5.4 Geometrical parameters at Each State.

\begin{tabular}{|c|c|c|c|}
\hline & State $1\left(f_{c}=2.07 \mathrm{GHz}\right)$ & State $2\left(f_{c}=3 \mathrm{GHz}\right)$ & State $3\left(f_{c}=4.45 \mathrm{GHz}\right)$ \\
\hline pitch & $80 \mathrm{~mm}$ & $50 \mathrm{~mm}$ & $15 \mathrm{~mm}$ \\
\hline pitch & $65 \mathrm{~mm}$ & $25 \mathrm{~mm}$ & $10 \mathrm{~mm}$ \\
\hline$N$ & 2.45 & 2.83 & 3.15 \\
\hline$N_{l}$ & 1.14 & 1.41 & 1.48 \\
\hline
\end{tabular}




\subsubsection{Fabrication of Prototype}

The helical antenna elements are fabricated with 3-mil thick copper tape glued on 6.5-mil thick sketching paper, and the reflector elements are fabricated with 4-mil thick copper foil glued on 13-mil thick cardboard, as shown in Figure 5.16.

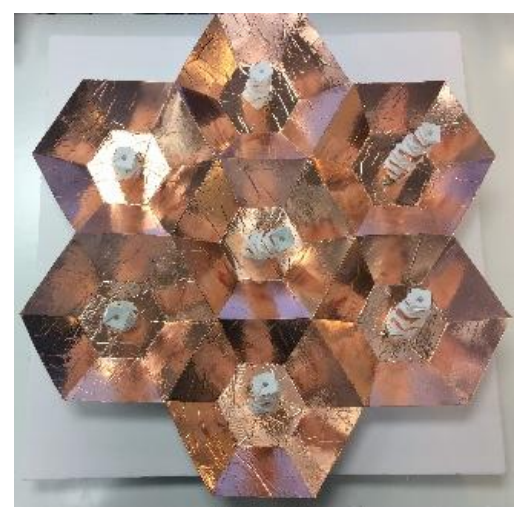

Figure 5.16. Fabricated prototype of the 7-element origami helical array.

\subsubsection{Simulated and Measured Results}

The performance of the proposed helical array is verified by the simulated and measured results as shown in Table 5.5 and Figure 5.17.

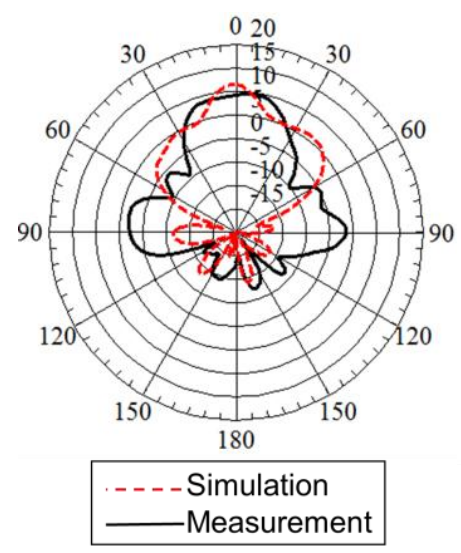

(a)

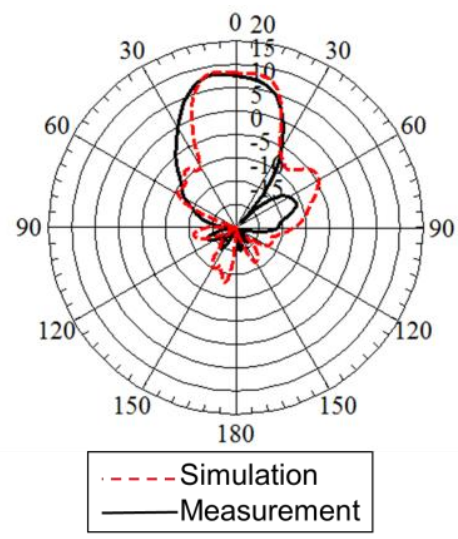

(b)

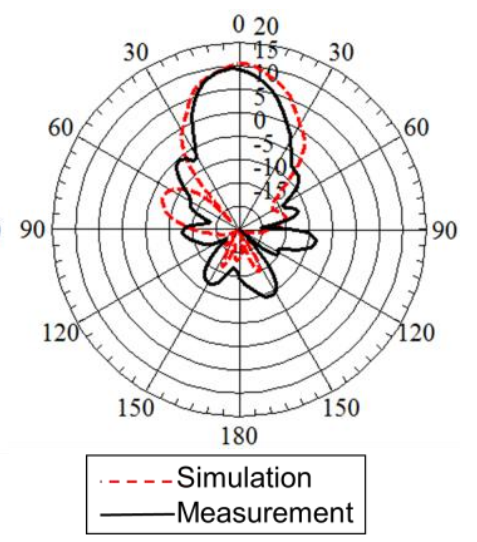

(c)

Figure 5.17. Simulated and measured radiation patterns of the helical array at (a) state 1 at $2.07 \mathrm{GHz}$, (b) state 2 at $3 \mathrm{GHz}$ and (c) state 3 at $4.45 \mathrm{GHz}$. 
Table 5.5 Simulated and Measured Results of the Array.

\begin{tabular}{|c|c|c|c|c|c|c|}
\hline \multirow{2}{*}{} & \multicolumn{2}{|c|}{$\begin{array}{c}\text { State 1 } \\
\left(f_{c}=2.07 \mathrm{GHz}\right)\end{array}$} & \multicolumn{2}{c|}{$\begin{array}{c}\text { State } 2 \\
\left(f_{c}=3 \mathrm{GHz}\right)\end{array}$} & \multicolumn{2}{c|}{$\begin{array}{c}\text { State } 3 \\
\left(f_{c}=4.45 \mathrm{GHz}\right)\end{array}$} \\
\cline { 2 - 7 } & Meas. & Simu. & Meas. & Simu. & Meas. & Simu. \\
\hline$S_{11}(\mathrm{~dB})$ & $<-14$ & $<-2.1$ & $<-10$ & $<-9.3$ & $<-12$ & $<-45$ \\
\hline Polarization & RHCP & RHCP & RHCP & RHCP & RHCP & RHCP \\
\hline Gain $_{\text {total }}(\mathrm{dB})$ & 9.7 & 11.6 & 13 & 13.3 & 14.7 & 15.7 \\
\hline Zenithal AR $(\mathrm{dB})$ & 1.35 & 0.76 & 1.17 & 0.85 & 0.64 & 0.69 \\
\hline
\end{tabular}




\section{CHAPTER 6}

\section{OTHER ORIGAMI ANTENNA STRUCTURES}

\subsection{Mode Reconfigurable Bistable Spiral Antenna Based on Kresling Origami}

Conical spiral antennas with two or four arms are often used due to their symmetry and zenithal directional radiation patterns [48]. Based on Kresling origami, a conical spiral antenna is developed that does not need mechanical support after is deployed because of the buckling of a thin cylindrical or conical shell under torsional loading [32]. Also, this antenna can be very compact without any hinges and can be easily fabricated from a planar origami pattern to a 3-D conical spiral antenna, providing a low-cost and potentially disposable design. Also, here we demonstrate a general analytical method for designing bistable conical or cylindrical Kresling origami and show the performance a modereconfigurable spiral antenna based on a Kresling origami pattern.

\subsubsection{Kresling Conical or Cylindrical Origami}

The geometry of a 6-side Kresling origami and the top view and perspective view of one if its steps is shown in Figure 6.1. We define $b=$ ratio $\cdot a$, and the scaling factor between adjacent steps so that $a^{\prime}=f_{\text {scale }} \cdot a$. We have concluded in [29] that

$$
h=\sqrt{b^{2}-\frac{a^{2} \cdot \sin ^{2}\left(\frac{\theta}{2}\right)}{\sin ^{2}\left(\frac{180^{\circ}}{n}\right)}}
$$

Similarly, for an ordinary origami pattern with scaling factor $f_{\text {scale }}$ for each step, we have: 


$$
h=a \cdot f_{\text {scale }} \sqrt{\text { ratio }^{2}-\frac{\sin ^{2}\left(\frac{\theta}{2}\right)}{\sin ^{2}(\alpha)}}
$$

where $\alpha=\pi / n$ is the internal angle of the polygon at the cross section of the origami step in Figure 6.1. In a rectangular coordinate system, the lower point A with diagonal length $c$ of the first step in Figure 6.1 has coordinates $\left(\frac{a}{2 \sin (\alpha / 2)}, 0,0\right)$. Then, the upper point B can be has coordinates $\left(\frac{a \cdot f_{\text {scale }} \cos (\alpha+\theta)}{2 \sin (\alpha / 2)}, \frac{a \cdot f_{\text {scale }} \sin (\alpha+\theta)}{2 \sin (\alpha / 2)}, h\right)$.

Therefore, we can calculate the length of $c$ and express it with its ratio to the length of $a$. Based on the method stated above and using the strain energy [32], we are able to find an origami pattern with a suitable $f_{\text {scale }}=0.83$, and ratio $=1.6$ that provides a bistable structure and buckles when $\theta=34^{\circ}$ and $\theta=106.25^{\circ}$.

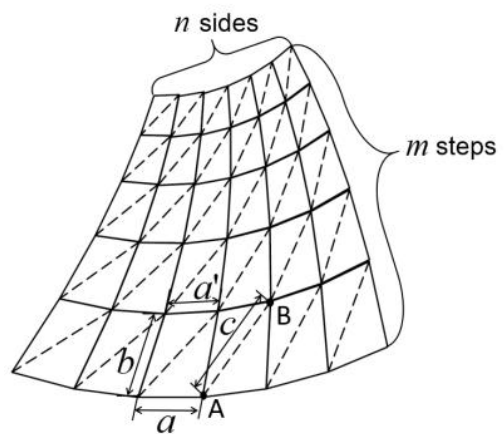

(a)

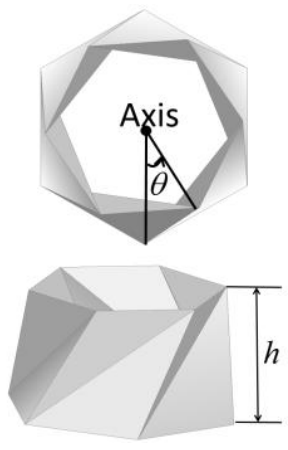

(b)

Figure 6.1 (a) Kresling origami pattern, (b) Top view and perspective view of one step of the pattern. 


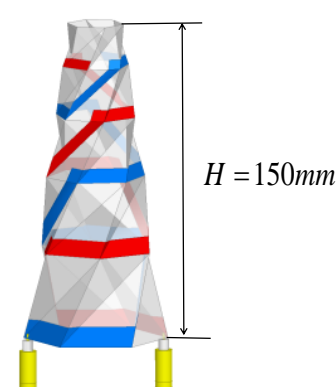

(a) Conical spiral

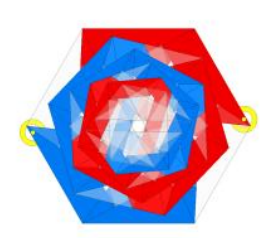

(b) Planar spiral

Figure 6.2 Model of the conical and planar spiral antenna.

\subsubsection{Simulated Results}

The simulated model is shown in Figure 6.2. The two SMA ports are fed out of phase $\left(0^{\circ}\right.$ and $\left.180^{\circ}\right)$, and the ground plane is omitted so as not to interfere with the bidirectional radiation pattern of the planar spiral antenna when it is collapsed. Ideally, the height of this planar state can be as small as $1.8 \mathrm{~mm}$ in simulation.

The simulated realized gain is shown in Figure 6.3. At the unfolded state, the conical spiral antenna is circularly polarized from $2.5 \mathrm{GHz}$ to $3.2 \mathrm{GHz}$. The radiation patterns of the two states at $2.7 \mathrm{GHz}$ are shown in Figure 6.4.

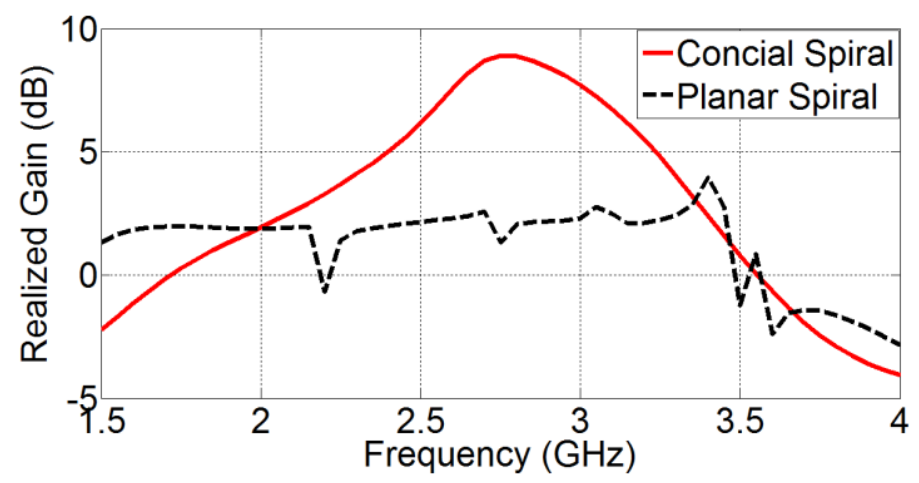

Figure 6.3 Simulated realized gain at the two states. 


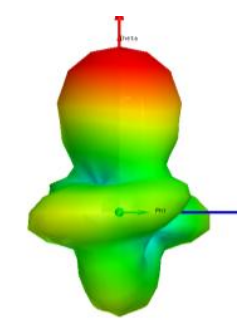

(a)

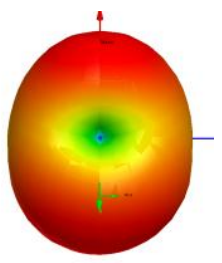

(b)

Figure 6.4 Radiation patterns at 2.7 GHz: (a) conical spiral; (b) planar spiral.

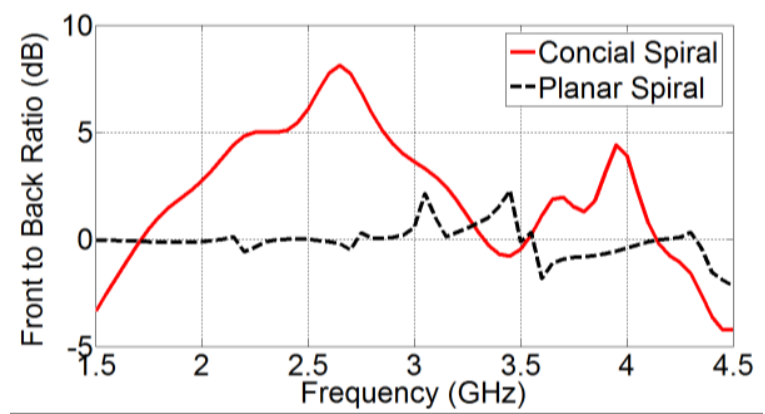

Figure 6.5 Front to back ratio at the two states.

\subsection{A Frequency Tunable Origami Spherical Helical Antenna}

Spherically folded helical antennas are suitable for developing electrically small antennas, and they have radiation patterns similar with an electric dipole or a magnetic dipole [49]. However, such antennas have high $Q$-factors. Therefore, their maximum bandwidths are limited since $\Delta f=\frac{f_{0}}{Q}$. Research has been carried out on how to decrease the $Q$-factor of electrically small antennas and increase their bandwidth [49]. A novel spherical antenna structure and novel prototyping method have been proposed in [50]. It has been found that by adjusting the number of arms $M$, number of turns $N$ and the dimension of the sphere, the impedance of a spherical antenna can be tuned with less reactance [51]. Specifically, increasing $M$ alone increases the antenna's capacitance, increasing $N$ alone increases its inductance, while the more closely the antenna is winded 
the more self-capacitive it gets.

Origami antennas have been are very compact, flexible, low-cost and light weight. Origami helical antennas have been proposed and been validated with frequency and mode reconfigurability while being able to be very compact and suitable for satellites or applications that require portability [52]-[55].

This paper presents an origami spherical helical antenna that has a frequency tunability from $1.77 \mathrm{GHz}$ to $2.32 \mathrm{GHz}$ with the ease of being fabricated from planar to 3D.

\subsubsection{Origami Pattern}

The proposed origami pattern is shown in Figure 6.6. The pattern comprises of 4 sides for each step, and there are total 4 steps. One folded step is shown in Figure 6.6 (b). The folding angle $\theta$ shows the axial displacement between adjacent steps. The larger $\theta$ is, the more the origami sphere is twisted, and the smaller it becomes. The conductive traces are shown in orange, and valley folding creases are represented by dashed lines. To fabricate the 3-D two arm spherical antenna, each side needs to be connected with its adjacent sides.

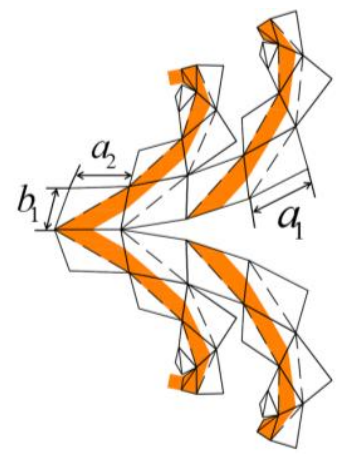

(a)

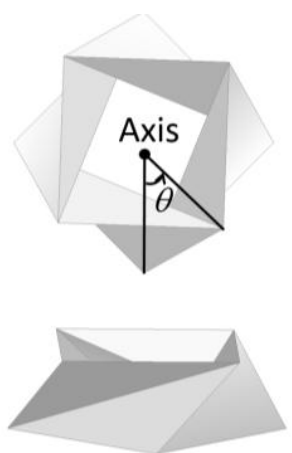

(b)

Figure 6.6 (a) The 4-step origami pattern of spherical helical antenna; and (b) one folded step.

The parallel and vertical sides in the 1 st step are called $a_{1}$ and $b_{1}$, and we have 
$b_{1}=\operatorname{ratio} \cdot a_{1}$. For the 2 nd step, $a_{2}=f_{\text {scale }} \cdot a_{1}$, and so on. A different scaling factor is chosen for each step to mimic an origami sphere. The parameters are: $a_{1}=21.2 \mathrm{~mm}$, ratio $=0.7$, $f_{\text {scale } 1}=0.9, f_{\text {scale } 2}=0.75, f_{\text {scale } 3}=0.6, f_{\text {scale } 4}=0.5$.

\subsubsection{Simulated Model and Results}

The four states of folded 3-D spherical antenna are shown in Figure 6.7. A two-arm spherical helix works better than one-arm and four-arm helices, because it has less reactance. Also, the reactance of a two-arm spherical helix has a larger range of tunability as $h$ changes. When the antenna collapses from state 1 to state 4 , the number of turns of each arm changes from about 1 to 1.5 while the total wire length stays the same. The antenna is fed at the center of one arm with all other parts connected together.

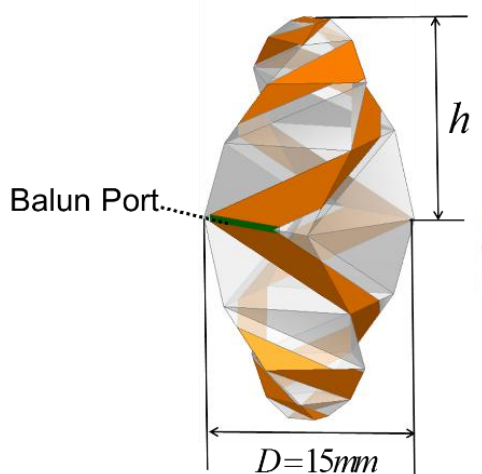

(a)

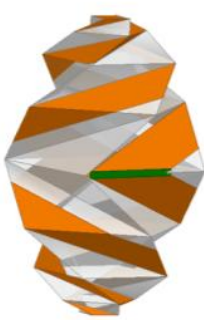

(b)

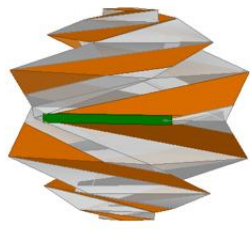

(c)

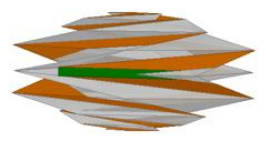

(d)

Figure 6.7 The 4 states of the spherical antenna: (a) state1 $(\mathrm{h}=8.69 \mathrm{~mm})$; (b) state 2 $(\mathrm{h}=21.8 \mathrm{~mm})$; $(\mathrm{c})$ state $3(\mathrm{~h}=11.6 \mathrm{~mm})$; and $(\mathrm{d})$ state $4(\mathrm{~h}=6.5 \mathrm{~mm})$.

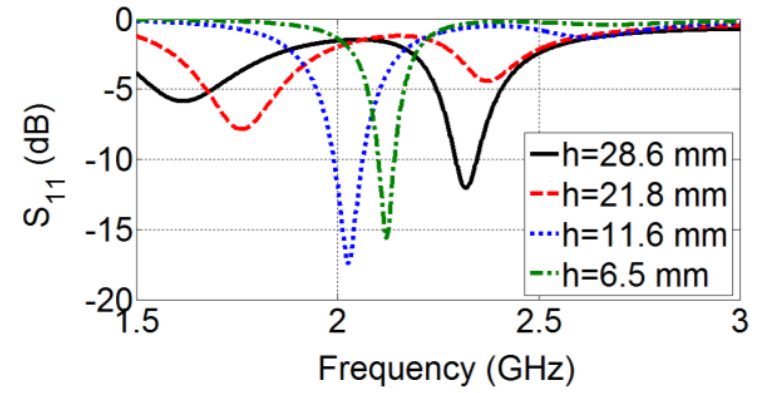

Figure 6.8 The simulated $S_{11}$ at the 4 states of height. 
The $S_{11}$ of the 4 states are shown in Figure 6.8, and the radiation patterns of the four states at their operating frequencies are shown in Figure 6.9. The maximum realized gain at operating frequencies of the 4 states of height are: $2.9 \mathrm{~dB}$ at $2.32 \mathrm{GHz}$ at state $1,1.4 \mathrm{~dB}$ at $1.77 \mathrm{GHz}$ at state $2,2.9 \mathrm{~dB}$ at $2.07 \mathrm{GHz}$ at state 3 and $3 \mathrm{~dB}$ at $2.12 \mathrm{GHz}$ at state 4 . The radiation pattern at state 1 is in the vertical plane, because the mutual coupling between the turns is small and therefore, the antenna operates like a loop antenna.

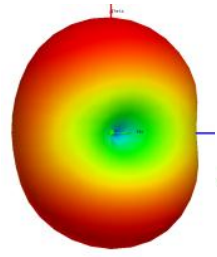

(a)

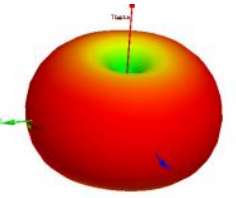

(b)

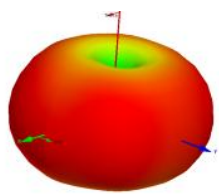

(c)

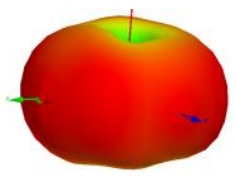

(d)

Figure 6.9 Simulated radiation patterns of the 4 states at their resonant frequencies: (a) $h=28.6 \mathrm{~mm}$ at $2.32 \mathrm{GHz}$; (b) $h=21.8 \mathrm{~mm}$ at $1.77 \mathrm{GHz}$; (c) $h=11.6 \mathrm{~mm}$ at $2.07 \mathrm{GHz}$; (d) $h=6.5 \mathrm{~mm}$ at $2.12 \mathrm{GHz}$.

\subsubsection{Conclusion}

A frequency reconfigurable normal mode spherical antenna is proposed and it has a potential to be applied in radio or TV communications. Also, the fabricating process is simple as to put conductive layer along the creases and then fold it up. Therefore, a lowcost and lightweight design is provided. 


\section{CHAPTER 7}

\section{CONCLUSION AND FUTURE WORK}

\subsection{Conclusions}

This dissertation presented research of origami antennas for novel reconfigurable communication systems. Reconfigurable monofilar, bifilar and quadrifilar antennas based on origami cylinders were proposed and validated. Novel fabrications of practical designs were presented with detailed geometrical analysis. In addition, multi-radii origami antennas were proposed, analyzed, fabricated and validated and they exhibit very good circular polarization performance and wide bandwidths at the 3 reconfigurable states. Also, an actuation mechanism was developed for this antenna.

A low-cost and lightweight reconfigurable origami antenna with a reflector and an array of this antenna were proposed to improve antenna gain at multiple states. Also, a Kresling conical spiral antenna and a spherical helical antenna were designed with mode reconfigurabilities and validated by simulated results.

These origami structures can easily reconfigure their heights to operate in various resonant frequencies or different radiation modes, and they can achieve large volume savings when they are stowed. Also, our origami antennas can be applied in novel communication and sensing applications requiring lightweight and multi-functional systems and real-time reconfigurability.

\subsection{Future Work}

Novel fabrication processes and new materials need to be studied for developing robust origami antennas that can maintain their mechanical functionality through a large 
number of deployment/stowage cycles. Also, inflatable reconfigurable origami antennas can be developed to make new actuation systems.

In addition, other types of antennas, such as, Vivaldi antennas and patch arrays, can be embodied on reconfigurable origami structures for stowability and multi-functionality. 


\section{REFERENCES}

[1] Y. Akira, “Atarashii Origami Geijutsu,” Tokyo: Origami Geijutsusha, 1954.

[2] P. Engel, “Origami from Angelfish to Zen,” Dover Publications, 1994.

[3] S. D. Guest and S. Pellegrino, "The Folding of Triangulated Cylinder, Part I, Geometric Considerations," J. of Appl., vol. 61, pp. 773-777, 1994.

[4] B. A. Cipra, "In the Fold; Origami Meets Mathematics," SIAM News, vol. 34, 2002.

[5] T. Nojima, "Origami Modeling of Functional Structures based on Organic Patterns", Kyoto University.

[6] Erik D. DemaineJoseph O'Rourke, "Geometric Folding Algorithms: Linkages, Origami, Polyhedra," Cambridge University Press New York, NY, USA, 2007.

[7] J. P. Gardner, et, “The James Webb Space Telescope," Space Sci. Reviews, vol. 123, pp. 485-606, May 2006.

[8] K. Kuribayashi, K. Tsuchiya, Z. You, D. Tomus, M. Umemoto, T. Ito and M. Sasaki, "Self-deployable Origami Stent Grafts as a Biomedical Application of Nirich TiNi Shape Memory Alloy Foil”, Mater. Sci. Eng., vol. 419, pp. 131-137, 2006.

[9] R. Hoffmann, A. K. Pickett, D. Ulrich, E. Haug, D. Lasry and J. Clinkemailllie, "A Finite Element Approach to Occupant Simulation: the PAM-CRASH Airbag Model", Automotive frontal impacts, pp. 79-87, 1989.

[10] Mark Schenk, Andrew D. Viquerat, Keith A. Seffen and Simon D. Guest, "Review of Infatable Booms for Deployable Space Structures: Packing and Rigidization," Journal of Spacecraft and Rockets, vol. 51, no. 3, pp. 762-778, 2014.

[11] K. Kuribayashi, H. Onoe and S. Takeuchi, "Cell Origami: Self-Folding of ThreeDimensional Cell-Laden Microstructures Driven by Cell Traction Force," PLOS One, vol. 7, no. 12, Dec. 2006.

[12] S. Felton, M. Tolley, E. Demaine, D. Rus and R. Wood, "A Method for Building Self-Folding Machines," Sci., vol. 345, pp. 644-646, 2014.

[13] C. A. Balanis, "Antenna Theory Analysis and Design," 3rd ed. Hoboken, NJ, USA: Wiley, 2005.

[14] R. H. Patnam, "Broadband CPW-Fed Planar Koch Fractal Loop Antenna," IEEE Antennas Wireless Propag. Lett., vol. 7, pp. 429-431, 2008 
[15] G. J. Hayes, Y. Liu, J. Genzer, G. Lazzi and M. D. Dickey, "Self-Folding Origami Microstrip Antennas," IEEE Antennas Wireless Propag. Lett., vol. 62, no. 10, pp. 5416-5419, 2014.

[16] Selding, P. "Boeing Finishes Deployment of Stuck SkyTerra 1 Antenna," Space News, Dec. 2012.

[17] R. C. Gupta, S. K. Sagi, K. P. Raja, N. K. Sharma and R. Jyoti, "Shaped PrimeFocus Reflector Antenna for Satellite Communication," IEEE Antennas Wireless Propag. Lett., vol. 16, pp. 1945-1946, 2017.

[18] T. K. Sreeja, A. Arun and J. Jaya Kumari, "An S-band Micro-Strip Patch Array Antenna for Nano-Satellite Applications," ICGT Internat. Conf., pp. 325-328, Trivandrum, India, Dec. 2012.

[19] S. K. Podilchak, A. P. Murdoch and Y. M.M. Antar, "Compact, Microstrip-Based Folded-Shorted Patches: PCB Antennas for Use on Microsatellites," IEEE Antennas and Propag. Magazine, vol. 59, no. 2, pp. 88-95, 2017.

[20] G. M. Olson, S. Pellegrino, J. Costantine and J. Banik, "Structure Architectures for a Deployable Wideband UHF Antenna," 53 $3^{\text {rd }}$ AIAA/ASME/ASCE/AHS structure, structural dynamics mater. conf., Hawaii, 2012.

[21] N. Robinson, “The Origami Bible,” North Light Books, 2004.

[22] R. J. Lang, "The Complete Book of Origami: Step-by Step Instructions in Over 1000 Diagrams/37 Original Models," Courier Dover Publications, 1988.

[23] Z. Abel, J. Cantarella, E. D. Demaine, D. Eppstein, Thomas C. Hull, Jason S. Ku, Robert J. Lang and Tomohiro Tachi, "Rigid Origami Vertices: Conditions and Forcing Sets," J. of Computational Geometry, vol. 7, no. 1 (2016): 171-184.

[24] Cheng Lv, "Theoretical and Finite Element Analysis of Origami and Kirigami Based Structures," Dissertation for the Doctor of Philosophy Degree, Arizona State University, August 2016.

[25] C. M. Kruesi, R. J. Vyas and M. M. Tentzeris, "Design and development of a novel 3-D cubic antenna for wireless sensor networks and RFID applications," IEEE Trans. Antennas Propag., vol. 57, no. 10, pp. 3293-3299, 2009.

[26] H. Hu and S. V. Georgakopoulos, "Wireless Powering Based on Strongly Coupled Magnetic Resonance with SRR Elements," IEEE Antennas Propagat. Soc. Internat. Symp., Chicago, IL, Jul. 2012.

[27] C. A. Balanis, "Travelling wave and broad band antennas," Antenna Theory Analysis and Design, 3rd ed., chap 10, (New Jersey: Hoboken, 2005): 566-572. 
[28] A. R. Djordjević, A. G. Zajić, M. M. Ilić, and G. L. Stüber, "Optimization of Helical Antennas," IEEE Antennas and Propagation Magazine, vol. 48, no. 6 (2006): 107-116.

[29] X. Liu, S. Yao, B. S. Cook, M. M. Tentzeris, and S. V. Georgakopoulos, "An origami reconfigurable axial-mode bifilar helical antenna," IEEE Trans. on Ant. and Propag., vol. 63, no. 12, pp. 5897-5903, Dec. 2015.

[30] J. Zhong, A. Kiourti, T. Sebastian,Y. Bayram and J. L. Volakis, "Conformal loadbearing spiral antenna on conductive textile threads," IEEE Ant. \& Wireless Propag. Lett., vol. 16, pp. 230-233, May, 2016.

[31] S. D. Guest and S. Pellegrino, "The Folding of Triangulated Cylinders, Part III: Experiments", Journal of Applied Mechanics. Vol. 63 (1), pp. 77-83, 1996.

[32] C. Jiangguo, D. Xiaowei, Z. Ya, F. Jian and T. Yongming, "Bistable Behavior of the Cylindrical Origami Structure with Kresling Pattern", Journal of Mechanical Design, vol. 137, no. 061406, pp. 1-8, June 2015.

[33] S. Yao, X. Liu and S. V. Georgakopoulos, "Morphing origami conical spiral antenna based on the Nojima wrap," IEEE Trans. on Ant. and Propag., vol. 65, no. 5, pp. 2222-2232, May. 2017.

[34] J. Costantine, Y. Tawk, I. Maqueda, M. Sakovsky, G. Olson, S. Pellegrino and C. G. Christodoulou, "UHF Deployable Helical Antennas for CubeSats," IEEE Trans. on Ant. and Propag., vol. 64, no. 9, pp. 3752-3759, Sept. 2016.

[35] S. I. H. Shah, M. M. Tentzeris and S. Lim, "Low-cost Circularly Polarized Origami Antenna," IEEE Ant. and Wireless Propag. Lett., vol. 16, pp. 2026-2029, Apr. 2017.

[36] J. L. Wong and H. E. King, "Broadband Quasi-taper Helical Antennas," IEEE Trans. on Ant. and Propag., vol. AP-27, no. 1, pp. 72-78, Jan. 1979.

[37] Antenna theory and design, 3rd ed., John Wiley \& Sons, Inc., Hoboken, MA, 2012, pp. 217-219.

[38] F. Falzon and P. Blanc, "Deployable reflector in the form of a reuleaux triangle for a space observation instrument," U.S. Patent 007839567B2, Nov. 23, 2010.

[39] D. Heitmann, "Round reflector for electromagnetic radiation," U.S. Patent 008277086B2, Oct. 2, 2012.

[40] L. Stiles, J. Garrett, Th. Murphey, H. Dumm, and J. Banik, "Development of deployable aperture concepts for CubeSats," in 51st AIAA/ASME/ASCE/AHS/ASC Structures, Structural Dynamics, and Materials Conf., Orlando, 2010, pp. 1-10. 
[41] Bruce R. Elbert, "Frequency spectrum allocations," in Introduction to Satellite Communication, 3rd ed., ch. 1, Artech House, Inc. Massachusetts: Norwood, 2008, pp. 22-38.

[42] X. Liu, S. Yao, and S. V. Georgakopoulos, "Reconfigurable spherical helical Electrically Small Antenna in UHF band," in Antennas and Propagation Society Int. Symposium (APSURSI), Memphis, 2014, pp. 368-369.

[43] S. Yao, X. Liu, S. V. Georgakopoulos, and M. M. Tentzeris, "A novel tunable origami accordion antenna," in Antennas and Propagation Society Int. Symposium (APSURSI), Memphis, 2014, pp. 370-371.

[44] X. Liu, S. Yao, S. V. Georgakopoulos, and M. M. Tentzeris, "Origami Quadrifilar Helix Antenna in UHF band," in Antennas and Propagation Society Int. Symposium (APSURSI), Memphis, 2014, pp. 372-373.

[45] S. Yao, X. Liu, S. V. Georgakopoulos, and M. M. Tentzeris, "A novel reconfigurable origami spring antenna," in Antennas and Propagation Society Int. Symposium (APSURSI), Memphis, 2014, pp. 374-375.

[46] X. Liu, S. Yao, S.V. Georgakopoulos, B. S. Cook, and M. M. Tentzeris, "Reconfigurable helical antenna based on an origami structure for wireless communication system," in 2014 IEEE MTT-S Int. Microwave Symposium (IMS), Tampa, 2014, pp. 1-4.

[47] A. R. Djordjevic, A. G. Zajic and M. M. Ilic, "Enhancing the gain of helical antennas by shaping the ground conductor," IEEE Antennas and Wireless Propagat. Letters, vol. 5, pp. 138-140, Dec. 2006.

[48] A. J. Ernest, Y. Tawk, J. Costantine, and C. G. Christodoulou, "A bottom fed deployable conical log spiral antenna design for cubeSat", IEEE Antennas Propagat., vol. 63, no. 1, pp. 41-47, January 2015.

[49] O. S. Kim, "Minimum electrically small antennas", IEEE Trans. on Ant. and Propag., vol. 60, no. 8, pp. 3551-3558, August 2012.

[50] O. S. Kim, "Rapid prototyping of electrically small spherical wire antennas", IEEE Trans. on Ant. and Propag., vol. 62, no. 7, pp. 3839-3842, July 2014.

[51] H. Huang, K. Nieman, Y. Hu and D. Akinwande, "Electrically small folded elliptical antenna for medical implanted applicaton," 2011 IEEE International Symposium on Antennas and Propagation (APSURSI), pp. 769-771, 2011.

[52] X. Liu, S. Yao, S. V. Georgakopoulos, "Frequency reconfigurable origami quadrifilar helical antenna with reconfigurable reflector." ", IEEE Antennas Propagat. Society Internat. Symp., pp 2217-2218, Jul. 19-24, 2015. 
[53] S. Yao, X. Liu and S. V. Georgakopoulos, "Study and design of Nojima origami conical spiral antenna," IEEE Antennas Propagat. Society Internat. Symp., pp 1431-1432, 2016.

[54] X. Liu, S. Yao and S. V. Georgakopoulos, "Reconfigurable origami equiangular conical spiral antenna", IEEE Antennas Propagat. Society Internat. Symp., pp 2263-2264, Jul. 19-24, 2015.

[55] X. Liu, S. Yao, P. Gonzalez and S. V. Georgakopoulos, "A novel ultra-wideband origami reconfigurable quasi-taper helical antenna", IEEE Antennas Propagat. Society Internat. Symp., pp 839-840, Jul. 19-24, 2015. 


\section{XUELI LIU}

2005-2009

2009-2012

2013-2018
B. S., Applied Physics

University of Electronic Science and Technology of China Chengdu, China

M. S., Electromagnetic Field and Microwave Technology University of Electronic Science and Technology of China Chengdu, China

$\mathrm{Ph}$. D. Candidate, Electrical Engineering

Florida International University

Miami, Florida

\section{PUBLICATIONS and PRESENTATIONS}

[1] S. V. Georgakopoulos, X. Liu and S. Yao, "Origami Antennas," In: Antenna Engineering Handbook 5th Edition, J. L. Volakis ed., McGraw-Hill Press, 2017.

[2] S. V. Georgakopoulos and X. Liu, "Origami-Folded Antennas and Methods for Making the Same," Serial No.: 15/405,729. (patent filed on Jan. 13, 2017)

[3] X. Liu, S. Yao, B. S. Cook, M. M. Tentzeris and S. V. Georgakopoulos, "An Origami Reconfigurable Axial-Mode Bifilar Helical Antenna," in IEEE Transactions on Antennas and Propagation, vol. 63, no. 12, pp. 5897-5903, Dec. 2015.

[4] S. Yao, X. Liu and Stavros V. Georgakopoulos, "Morphing Origami Conical Spiral Antenna Based on the Nojima Wrap," IEEE Transactions on Antennas and Propagation, vol. 65, no. 5, pp. 2222-2232, 2017.

[5] X. Liu, S. V. Georgakopoulos and S. Rao, "Reconfigurable Origami Quadrifilar Helical Antenna with Foldable Reflector for Satellite Communications," in IEEE Antennas and Propagation Magazine, 2016.

[6] J. S. Gibson, X. Liu, S. V. Georgakopoulos, J. J. Wie, T. H. Ware and T. J. White, "Reconfigurable Antennas Based on Self-Morphing Liquid Crystalline Elastomers," in IEEE Access, vol. 4, pp. 2340-2348, 2016.

[7] X. Liu, S. Yao, N. Russo, and Stavros V. Georgakopoulos, "Reconfigurable Helical Antenna Based on Origami Neoprene with High Radiation Efficiency," IEEE Antennas Propagat. Society Internat. Symp., Boston, USA, 2018. (accepted)

[8] X. Liu, S. Yao, N. Russo, and Stavros V. Georgakopoulos, "Tri-band Reconfigurable Origami Helical Array," IEEE Antennas Propagat. Society Internat. Symp., Boston, USA, 2018. (accepted)

[9] X. Liu, S. Yao and Stavros V. Georgakopoulos, "A Frequency Tunable Origami Spherical Helical Antenna," IEEE Antennas Propagat. Society Internat. Symp., San Diego, California, Jul. 9- Jul. 14, 2017.

[10] X. Liu, S. Yao and Stavros V. Georgakopoulos, "Mode Reconfigurable Bistable Spiral Antenna Based on Kresling Origami," IEEE Antennas Propagat. Society Internat. Symp., San Diego, California, Jul. 9- Jul. 14, 2017.

[11] X. Liu, S. Yao, J. Gibson and Stavros V. Georgakopoulos, "Frequency Reconfigurable QHA Based on Kapton Origami Helical Tube for GPS, Radio and WiMAX Applications," ASME 2017 IDETC/CIE, Cleveland, Ohio, Aug. 6- Aug. 9, 2017. 
[12] S. Yao, X. Liu and Stavros V. Georgakopoulos, "Segmented Helical Antenna with Reconfigurable Polarization," IEEE Antennas Propagat. Society Internat. Symp., San Diego, California, Jul. 9- Jul. 14, 2017.

[13] S. Yao, K. Bao, X. Liu and Stavros V. Georgakopoulos, "Tunable UHF Origami Spring Antenna with Actuation System," IEEE Antennas Propagat. Society Internat. Symp., San Diego, California, Jul. 9- Jul. 14, 2017.

[14] S. Yao, X. Liu and S. V. Georgakopoulos, "Study And Design of Nojima Origami Conical Spiral Antenna," IEEE Antennas Propagat. Society Internat. Symp., Fajardo, Puerto Rico, Jun. 26- Jul. $1,2016$.

[15] S. Yao, X. Liu, S. V. Georgakopoulos and R. Schamp, "Polarization Switchable Origami Helical Antenna," IEEE Antennas Propagat. Society Internat. Symp., Fajardo, Puerto Rico, Jun. 26- Jul. $1,2016$.

[16] X. Liu, S. Yao and Stavros V. Georgakopoulos, "A Novel Foldable Mode Reconfigurable Cubic Patch Antenna," IEEE Antennas Propagat. Society Internat. Symp., Fajardo, Puerto Rico, Jun. 26- Jul. 1, 2016.

[17] X. Liu, S. Yao, P. J. Gonzalez and S. V. Georgakopoulos, “A Novel Ultra-Wideband Origami Reconfigurable Quasi-Taper Helical Antenna," IEEE Antennas Propagat. Society Internat. Symp., Fajardo, Puerto Rico, Jun. 26- Jul. 1, 2016.

[18] X. Liu, S. Yao and S. V. Georgakopoulos, "Design of a Novel Origami Ultra-wideband Monofilar Antenna," 2016 USNC-URSI National Radio Science Meeting (NRSM), Boulder, CO, USA, Jan. 6-9, 2016. (Oral Presentation)

[19] S. Yao, X. Liu, and S. V. Georgakopoulos, "A Mode Reconfigurable Nojima Origami Antenna," IEEE Antennas Propagat. Society Internat. Symp., Vancouver, BC, CA, Jul. 19-25, 2015.

[20] X. Liu, S. Yao, and S. V. Georgakopoulos, "Frequency Reconfigurable Origami Quadrifilar Helical Antenna with Reconfigurable Reflector," IEEE Antennas Propagat. Society Internat. Symp., Vancouver, BC, CA, Jul. 19-25, 2015.

[21] X. Liu, S. Yao, and S. V. Georgakopoulos, "Reconfigurable Origami Equiangular Conical Spiral Antenna," IEEE Antennas Propagat. Society Internat. Symp., Vancouver, BC, CA, Jul. 19-25, 2015.

[22] S. Yao, X. Liu, J. Gibson, and S. V. Georgakopoulos, "Deployable Origami Yagi Loop Antenna," IEEE Antennas Propagat. Society Internat. Symp., Vancouver, BC, CA, Jul. 19-25, 2015.

[23] X. Liu and S. V. Georgakopoulos, "A Novel Mode and Frequency Reconfigurable Origami Quadrifilar Helical Antenna," 2015 IEEE 16th Annual IEEE Wireless and Microwave Technology Conference (WAMICON), Cocoa Beach, FL, April 13-15, 2015.

[24] S. Yao, X. Liu, S. V. Georgakopoulos and M. M. Tentzeris, "A Novel Reconfigurable Origami Spring Antenn," IEEE Antennas Propagat. Society Internat. Symp., Memphis, TN, Jul. 6-12, 2014.

[25] S. Yao, X. Liu, S. V. Georgakopoulos and M. M. Tentzeris, "A Novel Tunable Origami Accordion Antenna," IEEE Antennas Propagat. Society Internat. Symp., Memphis, TN, Jul. 612, 2014.

[26] X. Liu, S. Yao and S. V. Georgakopoulos, "Quadrifilar Helix Antenna in UHF Band," IEEE Antennas Propagat. Society Internat. Symp., Memphis, TN, Jul. 6-12, 2014.

[27] X. Liu, S. Yao and S. V. Georgakopoulos, "Reconfigurable Spherical Helical Electrically Small Antenna in UHF band," IEEE Antennas Propagat. Society Internat. Symp., Memphis, TN, Jul. 6-12, 2014.

[28] X. Liu, S. Yao, S. V. Georgakopoulos and M. M. Tentzeris, "Reconfigurable Helical Antenna Based on an Origami Structure for Wireless Communication System," IEEE MTT-S International Microwave Symposium (IMS), Tampa, FL, Jun. 1-6, 2014. 